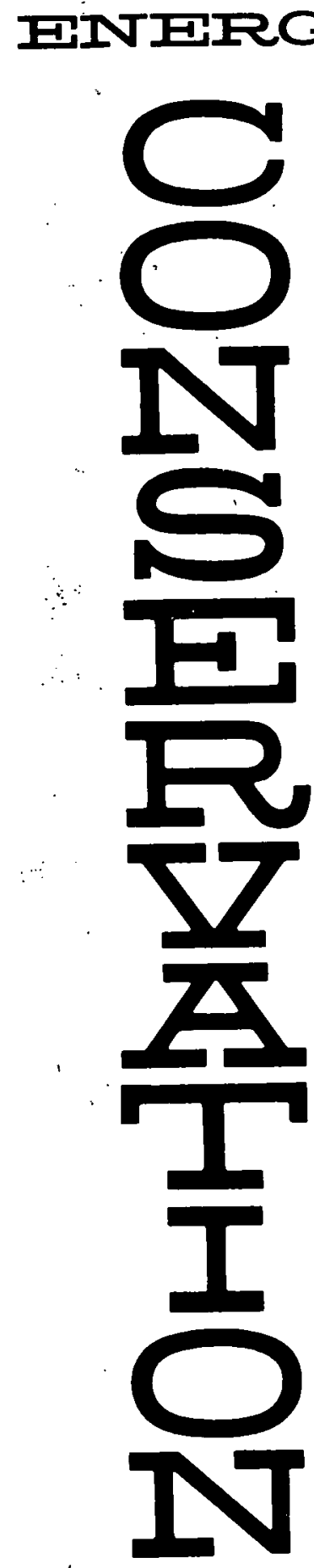

CONS/2109:

UC- $95 d$

\title{
Infrared Thermography Requirements Study for Energy Conservation
}

\author{
Worked Performed Under
}

Contract No. EX-76-C-01-2109

April, 1977

AERODYNE RESEARCH, INC., Bedford, Massachusetts Richard B. Headley

Robert J. Larsen

Gershon G. Goldberg

NAHB RESEARCH FOUNDATION, INC., Rockville,

Maryland

Robert J. Boyd

Prepared for the

Energy Research \& Development Administration Assistant Administrator for Conservation

Division of Buildings and Community Systems

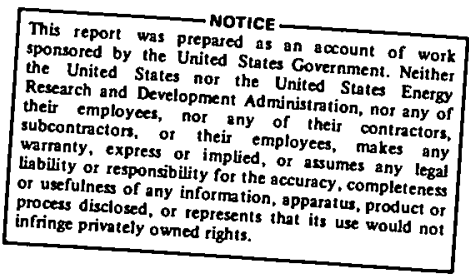




\section{DISCLAIMER}

This report was prepared as an account of work sponsored by an agency of the United States Government. Neither the United States Government nor any agency Thereof, nor any of their employees, makes any warranty, express or implied, or assumes any legal liability or responsibility for the accuracy, completeness, or usefulness of any information, apparatus, product, or process disclosed, or represents that its use would not infringe privately owned rights. Reference herein to any specific commercial product, process, or service by trade name, trademark, manufacturer, or otherwise does not necessarily constitute or imply its endorsement, recommendation, or favoring by the United States Government or any agency thereof. The views and opinions of authors expressed herein do not necessarily state or reflect those of the United States Government or any agency thereof. 


\section{DISCLAIMER}

Portions of this document may be illegible in electronic image products. Images are produced from the best available original document. 
TABLE OF CONTENTS

Section

$\underline{\text { Page }}$

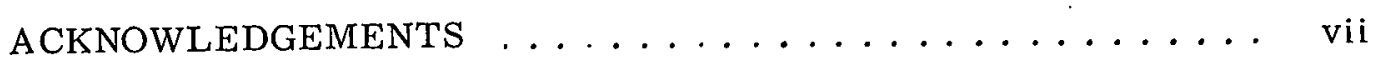

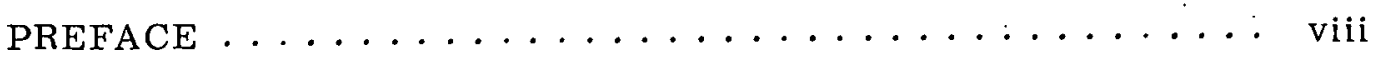

INTRODUCTION AND SUMMARY ............... 1-1

BUILDING SECTOR REQUIREMENTS . . . . . . . . . . . . 2-1

2.1 APPROACH ........................ 2-1

2.2 POTENTIAL INFRARED THERMOGRAPHY (IRT)

MEASUREMENT REQUIREMENTS . . . . . . . . . . . . 2-6

2.2.1 Emissivity Effects................. 2-7

2.2.2 Surface Film Thermal Conductance. . . . . . . 2-16

2.2.3 Heat Transmission and Infiltration Effects...... 2-19

2.3 BUILDING CODES ..................... 2-21

2.4 POTENTIAL USERS AND USES FOR IRT TECHNOLOGY

AND INSTRUMENTATION . . . . . . . . . . . . . . . . . . 2-23

2.4.1 Uses Where Qualitative IRT Results Should Be

Adequate . . . . . . . . . . . . . 2-23

2.4.2 Uses Where Quantitative Results Would Be Required . 2-26

2.5 DEMONSTRATION OPPORTUNITIES ........... 2-27

2.5.1 Demonstration ................ 2-27

2.5 .2 Development ....................... 2-28

2.5 .3 Improvement. . . . . . . . . . . . . . 2-29

2.5.4 Development . . . . . . . . . . . . . . . 2-29

2.5 .5 Measurement ................. 2-30

2.5 .6 Determination ................. 2-30

2.5.7 Alternative Methods ................ 2-31

2.5 .8 Cost Reduction .................. 2-31

2.5.9 Demonstrations . . . . . . . . . . . . . 2-31

2.5. 10 Investigation ................. 2-31 
TABLE OF CONTENTS (Continued)

3.1 RADIATION FORMULA ................... 3-3

3.2 SPECTRAL EFFECTS ................... 3-9

3.3 SURFACE TEMPERATURE ERRORS . . . . . . . . . . . 3-23

3.4 THERMOGRAPHIC INTERPRETATION. . . . . . . . . . . 3-32

3.4.1 Thermographic Resolution ............. 3-38

3.4 .2 Aerial Thermography ............. 3-40

4 CURRENT ELECTRO-OPTICAL TECHNOLOGY . . . . . . . . . 4-1

4.1 SOLID STATE SYSTEMS ................. 4-3

4.1 .1 Displays .................... 4-3

4.1.2 Solid State Detectors . . . . . . . . . . . . . . 4-9

4. 1.3 Solid State Specifications . . . . . . . . . . 4-10

4.2 PYROELECTRIC VIDICON CAMERAS ............ 4-11

4.2.1 Representative Vidicon Camera System . . . . . . . 4-14

4.3 RADIOMETERS ...................... 4 4-19

4.4 AIRBORNE SYSTEMS ..................... 4 4-22

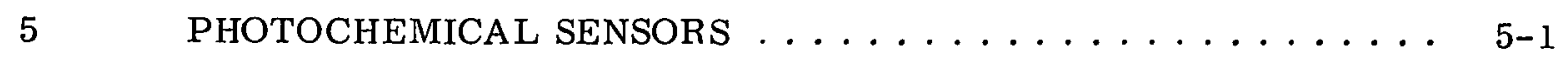

5.1 LIQUID CRYSTAL SYSTEMS ............... . . 5-2

5.2 SEMICONDUCTOR SYSTEMS ............... . . 5-5

5.3 OTHER PHOTOCHEMICAL TECHNOLOGY . . . . . . . 5 5-8

5.3 .1 Silver Halide Films . . . . . . . . . . . 5 5-8

5.3 .2 Vesicular Films ................ 5 . 5-9

5.3.3 Thermochromic Films ............... 5-10

5.4 THERMOGRAPHIC PHOSPHOR SCREEN ......... 5-11

5.5 UPCONVERSION . . . . . . . . . . . . . . . 5 5-11

5.5 .1 Parametric Upconversion. . . . . . . . . . 5-12

5.5 .2 Infrared Quantum Counters ............ 5-13 
TABLE OF CONTENTS (Continued)

Section

6

RECOMMENDED RESEARCH AND DEVELOPMENT . . . . . . . . 6-1

6.1 DEMONSTRATION OPPORTUNITIES . . . . . . . . . 6-1

6.1.1 Summary-Demonstration Opportunities ....... 6 6-2

6.2 QUALITATIVE THERMOGRAPHY ... . . . . . . . . 6- 6-3

6.2.1 Summary-Qualitative Thermography ......... 6-7

6.3 QUANTITATIVE THERMOGRAPHY . . . . . . . . . 6 6-8

6.3.1 Summary-Quantitative Thermography ........ 6 6-12

A ppendix

A $\quad$ STATEMENT OF WORK ................ A-1

iii 
2-1 Surface Conductance for Different 12-Inch Square Surfaces as Affected by Air Movement .................. 2-16

$2-2 \quad$ Cost Requirements . . . . . . . . . . . . . . . 2-24

$3-1 \quad$ Detection Geometry $\ldots \ldots \ldots \ldots \ldots \ldots \ldots$

3-2 Measured Surface Temperature vs $\epsilon_{A} \ldots \ldots \ldots$ 3-8

3-3 Requirements for Use of Stefan-Boltzman Radiation . . . . . . . 3-10

3-4 Atmospheric Transmission, $300 \mathrm{~m}$, Sea Level Path . . . . . . . 3-11

3-5 Spectral Radiant Emittance of a Blackbody . . . . . . . . . 3-13

3-6 Image Band Fractional Radiation $\ldots \ldots \ldots \ldots$. . . . . . . . . .

3-7 Atmospheric Transmission, Midlatitude, Winter, Sea Level . . 3-15

3-8 Atmospheric Transmissivity vs Range .............. 3-16

3-9 Water-Vapor Concentration .................. $3-17$

3-10 Average Atmospheric Transmission, Sea Level, Horizontal

3-11 Average Atmospheric Transmission, Slant Range Path, Midlatitude Winter. . . . . . . . . . . . . . . . . . 3-20

3-12 Window Glass Transmission/Emissivity . . . . . . . . . . 3-21

3-13 Temperature-Emissivity Equivalency . . . . . . . . . . 3-24

3-14 Surface Temperature Reflection Effects (Outside) . . . . . . . 3-25

3-15 Temperature-Emissivity Equivalency (Inside) $\ldots \ldots \ldots$ 3-26

3-16 Surface Temperature Reflection Effects (Inside) . . . . . . . . 3-27

3-17 Outside Thermal Film Resistance $\ldots \ldots \ldots \ldots$ 3-28

3-18 Temperature-Surface Film Equivalency ............ 3-30 


\section{LIST OF ILLUSTRATIONS (Continued)}

$\underline{\text { Figure }}$

$\underline{\text { Page }}$

3-19 Fault Temperature Differences from Typical Inside

Thermographs ......................... 3-33

3-20 Continuous Tone Analog Thermogram .............. 3-37

4-1 IR Inst rumentation Breakdown . . . . . . . . . ..... 4-2

4-2 Thermal Image versus Conventional Photograph.......... 4-5

4-3 Typical Detectors ..................... 4 4-9

4-4 Minimum Resolvable Temperature versus Integration Time . . . 4-13

4-5 Performance of Present and Projected PEV's ........... 4-13

4-6 Basic Block Diagram of Infrared Radiometer . . . . . . . . . 4 4-20

4-7 Energy Loss Survey of Cornell University . . . . . . . . . . . 4-24

$4-8 \quad$ Dwelling Survey $\ldots \ldots \ldots \ldots \ldots \ldots \ldots \ldots \ldots \ldots \ldots \ldots \ldots$

$6-1 \quad$ Cost Requirements ...................... 6 6-2

6-2 An IR Thermography Showing U-Value Averaging . . . . . . . 6-13

6-3 U-Value Averaging Through a Cathedral Ceiling . . . . . . . . 6-14 


\section{LIST OF TABLES}

$\underline{\text { Table }}$

Page

Requirement Options

$1-4$

$2-1$ Material Emissivity

$2-2$

Emittances and Absorptances for a Few Surfaces $2-10$ Total Radiation Emissivities ..

Spectral Transmission: UV, IR; and Colored Glasses . . . . . . . 2-14

2-6 Infrared Window Materials ................... 2-15

2-7 Coefficients of Transmission (U) of Frame Walls . . . . . . . . 2-18

3-1 Component Temperature Error Source . . . . . . . . . . 3-2

3-2 Apparent Emissivity $\left(\mathrm{T}=280^{\circ} \mathrm{K}\right) \ldots \ldots \ldots \ldots \ldots \ldots$

3-3 Surface Temperature Measurement Error (Outside) . . . . . . . 3-31

3-4 Surface Temperature Measurement Error (Inside) . . . . . . . 3-32

4-1 List of Solid State Manufacturers Contacted . . . . . . . . . . . 4-4

4-2 IR Thermographic Systems ................. $4-6$

4-3 List of Pyroelectric Vidicon/Camera Manufacturers Contacted . . . 4-12

4-4 List of Radiometer Manufacturers and Services Contacted . . . . 4-21

4-5 List of Airborne Manufacturers Contacted . . . . . . . . . 4-23

4-6 Airborne Infrared Scanners Available . . . . . . . . . . . 4-27 


\section{ACKNOWLEDGEMENTS}

This contract study was made possible by the U. S. Energy Research and Development Administration. Dr. Kurt W. Riegel, Chief, Technology and Appliances Branch of the Division of Buildings and Community Systems was the Program Monitor. Aerodyne wishes to express its gratitude and appreciation to Dr. Riegel and to Mr. John Cuttica of the same ERDA office for the opportunity to have performed this study.

Aerodyne expresses its appreciation to the NAHB Research Foundation, Inc. and, particularly, to Mr. Robert L. Boyd, for the subcontract work contained in Section 2.

Thermographic instrument information was supplied by appropriate industrial sources. Aerodyne is appreciative of all contributors. The data that is shown, particularly in Section 4, has been reworked slightly in some cases in the interest of providing a common basis for comparison. Performance, and particularly cost, information may not be exact either because the data has aged over the past year or because Aerodyne has reworked the data slightly. Aerodyne hopes, however, that all data is representative. Manufacturers should be contacted directly for latest information.

Aerodyne does not endorse any manufacturer or product over another. Thermographic needs should be clearly understood by the user and the best instrument to satisfy that need should be used. The extent of use of any one manufacturer's product information in this report should not be construed as a preferred approach by Aerodyne. Product information has been used simply as a means of identifying technology that is applicable to building thermography. There is need and room for creative solution to the thermography. Aerodyne hopes that this report will generate this response.

Aerodyne recognizes that some manufacturers and their instruments may not have been mentioned in this study report. It was the intent to be rigorously inclusive. Aerodyne recognizes that this may not have been possible. Any omissions by Aerodyne have not been by intent. 


\section{INFRARED THERMOGRAPHY REQUIREMENTS STUDY FOR ENERGY CONSERVATION}

\section{PREFACE}

Aerodyne Research, Inc. was awarded a contract with the U.S. Energy Research and Development Administration for a study to identify. users (and their needs) of infrared (IR) instrumentation that may be applicable in the measurement of heat gains and/or losses from buildings, and to identify research, development and demonstration opportunities. The work flow diagram for this study is shown below and is intended to provide the following information:

- Identify present and potential users and uses of infrared thermographic technology as related to energy conservation in buildings.

- Identify presently available IR thermographic inst rumentation, techniques, and services, and determine how well it can serve the users and uses identified above.

- Identify the technical opportunities for research, development, and demonstration on new IR thermographic technology that will better serve the users and uses identified above.

Under a subcontract to Aerodyne, the National Association of Home Builders (NAHB) Research Foundation, Inc. has analyzed the building sector requirements, identified the user measurement requirements, and has provided cost guidelines for instrumentation. This work is described in Section 2.

Section 3 contains an analysis of the constraints, requirements, and limitations of measurable parameters. This analysis provides the basis against which an IR instrument survey was conducted and reported in Section 4.

The building sector requirements study indicates the general satisfaction of the user community with the use of IR thermography for qualitative evaluation of heat loss from buildings. It is pointed out that qualitative evaluation requires resolvable temp-

\footnotetext{
* See Appendix for the Statement of Work
} 


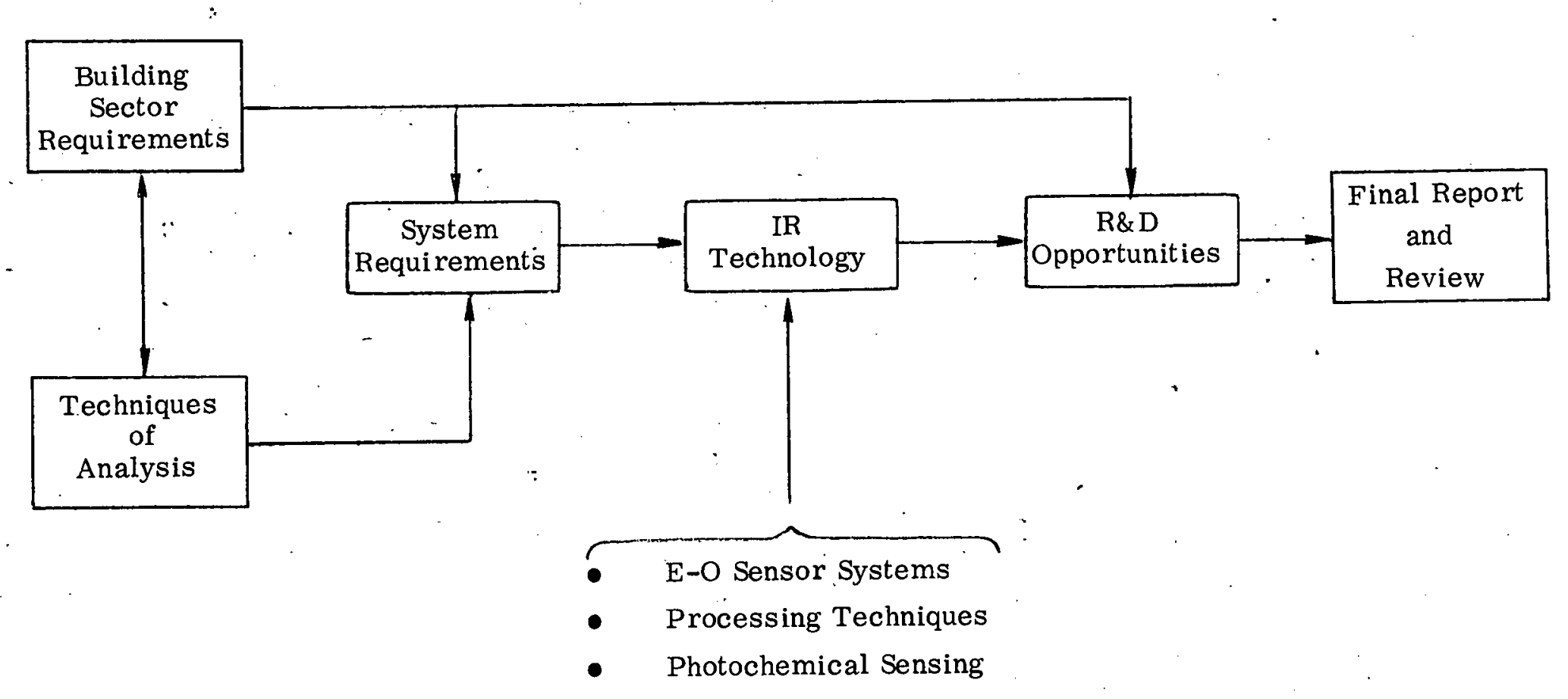

WORK FLOW DIAGRAM 
erature differences of 1 to $3.5^{\circ} \mathrm{C}$. Quantitative evaluation for building code enforcement will require resolvable temperature capability and accuracy of 0.1 to $0.35^{\circ} \mathrm{C}$. Cryogenic thermographic scanning systems as they exist today have the more sensitive capability, but have been used, for the most part, for qualitative heat loss evaluation. If $1^{\circ} \mathrm{C}$ resolution systems can be used to provide the same qualitative information, then the reduced resolution may allow for instrumentation with a 5:1 or better cost saving. Such a reduction in instrument costs should significantly increase the application and use of IR thermography.

In addition, wider use of IR thermography will require education and training. Demonstration programs are needed to develop the art of thermographic interpretation for wider community use. As a part of this 'effort, it will be necessary to demonstrate that thermography using $1^{\circ} \mathrm{C}$ instruments provides essentially the same qualitative information as do $0.1^{\circ} \mathrm{C}$ instruments.

Absolute temperature measurements for quantitative code enforcement and for laboratory use require $0.1^{\circ}$ to $0.35^{\circ} \mathrm{C}$ accuracy. This can be done with IR measurements from the inside of buildings. Outside measurements are limited to $1^{\circ} \mathrm{C}$ uncertainty, however. Accuracies better than this require a temperature computation and instrument calibration that will account for spectral wavelength properties of the atmosphere, background and building materials. Spectral emissivities of building materials must be known to the order of 0.5 percent. A measurement program is required to determine the limitation in emissivity measurement and to evaluate the effect of the nonuniform IR background that is reflected off the structure into the IR thermographic camera.

Recommended research and development includes the need to:

1. Measure spectral radiation parameters such as emissivity that now limit the usefulness of quantitative temperature measu rements.

2. Develop very low cost electro-optical thermal imaging devices for qualitative heat loss evaluation. 
3. Determine spectral optimization of electro-optical the rmal imaging cameras for precise quantitative measurements of heat loss.

4. Develop infrared liquid crystal and semiconductor photographic sensor material and cameras with very low cost thermographic picture potential.

Recommended demonstration includes the need for:

1. Large scale promotional use of thermography.

2. Generation of user manuals explaining interpretation techniques and limitations.

3. Training and perhaps licensing of technicians. 


\section{SECTION 1 \\ INTRODUCTION AND SUMMARY}

Thermal efficiencies of structures are defined by the composite $\mathrm{R}$ value which is the addition of the individual thermal resistance of each layer of construction material (e.g., outside film surface, siding, sheathing, insulation, wall board, and inside film surface) and typically may have values ranging from $\mathrm{R}-10$ to $\mathrm{R}-23$ for insulated walls down to $\mathrm{R}-0.9$ to $\mathrm{R}-6$ for uninsulated walls.

Suggested building codes ${ }^{1}$ would specify average $U$ values (inverse of the thermal resistance, $U \equiv 1 / R$ ) as a function of heating degree days.

To the extent that building codes may require quantitative demonstration of compliance, the question arises as to the means of demonstrating this compliance. In the past, design analysis and in-process inspection has been the only means to demonstrate that the required insulation has been properly installed.

The linal the rmal evaluation of a st ructure or the thermal evaluation of older structures has been somewhat a moot question until recent times. The application of infrared (IR) technology, however, offers the possibility of real-time heat loss/gain evaluation.

R. Munis, et $\mathrm{al}^{2}$ has pointed out that prior to the use of IR radiometric instruments to generate thermographic profiles, the only way to determine temperature was to embed thermocouples in the wall at various points and hope that the temperature at these points was somewhat representative at all other points. The time required to embed the thermocouple, the uncertainty of the temperature measurement because of disturbances caused by contact of the thermocouples with the surface, and the limited accessibility of extensive wall areas all contributed to make this approach wholly unsatisfactory.

\footnotetext{
${ }^{1}$ ASHRAE STANDARD 90-75, "Energy Conservation in New Building Design, " The American Society of Heating, Refrigerating, and Air-Conditioning Engineers, Inc., 2 New York, New York, 1975.

2 Richard H. Munis, et al., "Detecting Structural Heat Losses with Mobile Infrared Thermography, "Cold Regions Research and Engineering Laboratory, Hanover, New Hampshire, 1974
} 
Munis continues to point out some of the advantages of using IR measurement techniques:

1. Measurements can be made quickly over large areas (complete walls) .

2. Measurements can be made at relatively longer distances from a surface without any significant decrease in resolution or accuracy.

3. The surfaces of buildings widely separated geographically may be examined in a short time period.

4. Both inside and outside surfaces may be examined to verify a situation which requires attention.

5. Heat gain as well as heat loss may be established for any building.

The extent to which IR instruments can satisfy the user community is an important part of this study.

IR thermal imaging devices have been, and are presently being used, for fault identification. Such instrumentation is used ${ }^{1}$ in a qualitative manner to reveal visually obscured poor workmanship and/or to show areas of air infiltration and the major heat losses through windows, ventilating ducts, etc.

The use of IR instrumentation for code validation requires a more quantitative evaluation of the environment to determine instrument specifications. Instrument specifications should be determined for all levels of uses according to the requirements . of the job to be done. The sophisticated user may require highly accurate instruments for quantitative validation of building code specifications. On the other hand, instruments for fault identification may be.less accurate. In all cases, the instruments accuracy should be, and only needs to be, compatible with the environmental limitations. This consideration could have a significant impact on instrument cost. If the environment, for example, results in some fundamental limiting performance level from a physics standpoint, then instrumentation accuracy beyond this fundamental limitation results in excessive cost to do the job.

Environmental Research Institute of Michigan Contract CO-04-50233-00 work for the Federal Energy Administration. 
Section 2 contains a detailed analysis of the likely user community and needs, including the possibilities and suggestions for the need of demonstration and education. The material presented here has been prepared by NAHB Research Foundation, Inc. and is a representation of the user community and its understanding of current IR thermography, and its application for the measurement of heat loss/ gain from buildings. In summary, Section 2 indicates that current application is limited to a qualitative evaluation of heat loss only.

The needs and opportunities for exploitation, demonstration, education and training for cost effective use of thermography are discussed in Section 2.5. The extent of the subject contract, however, is to explore research, development and demonstration opportunities. Demonstration opportunities include maximum exploitation of state-of-the-art instrumentation. Research and development opportunities require an examination of basic requirements and the means for implementing instrumentation to satisfy these requirements. Research and development opportunities also require a recognition of fundamental limitations which would restrict the cost effectiveness of new instrumentation.

Section 3 analyzes the physical properties of IR detection to show the fundamental limitation of surface temperature measurements. It is concluded in this section that surface temperatures can be determined in the two IR bands, 3 to $5.5 \mu \mathrm{m}$ and 8 to $12 \mu \mathrm{m}$, to about $1^{\circ} \mathrm{C}$ if measured from the outside. Under ideal conditions it may be possible to do somewhat better than that. The requirements, however, must be carefully weighed against the time and cost to obtain the required accuracy. Temperature measurements can be made to about $0.3^{\circ} \mathrm{C}$ from the inside using 3 to $5 \mu \mathrm{m}$ instrumentation. Temperature measurements of windows and glass doors, however, require proper calibration to account for spectral weighting of the resulting readings.

Table 1-1 summarizes the thermal resolution results obtained in Sections 2 and 3 . The requirements for qualitative evaluation of heat losses should be satisfield with thermal resolutions between $1^{\circ}$ and $3.5^{\circ} \mathrm{C}$ with instrument cost objectives that are significantly less than $\$ 10,000$. Room temperature pyroelectric vidicon systems have this potential if the temperature uncertainty is only $1^{\circ} \mathrm{C}$. Practical 
Table 1-1. Requirement Options

\begin{tabular}{|c|c|c|c|c|c|}
\hline Function & $\begin{array}{l}\text { Required } \\
\text { Thermal } \\
\text { Resolution }\end{array}$ & Cost & $\begin{array}{l}\text { Typical } \\
\text { Inst rument }\end{array}$ & $\begin{array}{l}\text { Limiting } \\
\text { Accuracy }\end{array}$ & Remarks \\
\hline \multirow{2}{*}{$\begin{array}{l}\text { Qualitative } \\
\text { Thermography }\end{array}$} & \multirow{2}{*}{$1^{\circ}-3.5^{\circ} \mathrm{C}$} & $<<\$ 10 \mathrm{~K}$ & $\begin{array}{l}\text { Pyroelectric } \\
\text { Vidicon System }\end{array}$ & $1^{\circ} \mathrm{C}$ & $\begin{array}{l}\text { Demonstrate Adequacy of } \\
\text { Lower Thermal Resolution }\end{array}$ \\
\hline & & $\leq \$ 50 \mathrm{~K}$ & $\begin{array}{l}\text { Cryogenic } \\
\text { Systems }\end{array}$ & $\begin{array}{l}0.3^{\circ} \mathrm{C}- \\
\text { Inside } \\
1^{\circ} \mathrm{C}- \\
\text { Outside }\end{array}$ & Envi ronment Limited \\
\hline \multirow{2}{*}{$\begin{array}{l}\text { Quantitative } \\
\text { Thermography }\end{array}$} & \multirow{2}{*}{$0.1^{\circ}-0.35^{\circ} \mathrm{C}$} & $<\$ 50 \mathrm{~K}$ & $\begin{array}{l}\text { Cryogenic } \\
\text { Sensor System }\end{array}$ & $0.1^{\circ} \mathrm{C}$ & $\begin{array}{l}\text { Determine Adequacy of } \\
\text { Spectral Effects Compen- } \\
\text { sation }\end{array}$ \\
\hline & & $\$ 25 \mathrm{~K}$ & $\begin{array}{l}\text { Pyroelectric } \\
\text { Vidicon System }\end{array}$ & $0.25^{\circ} \mathrm{C}$ & \\
\hline
\end{tabular}


building thermography with such instruments has not yet been demonstrated and will require some feasibility measurements.

Cryogenic thermographic systems that have been used for qualitative thermography cost upwards of $\$ 50,000$. In principle they have thermal resolution capability approaching $0.1^{\circ} \mathrm{C}$ but over a relatively small dynamic temperature range. Over the temperature ranges for building thermography the thermal resolution may be closer to $1^{\circ}$ to $2^{\circ} \mathrm{C}$. This would be adequate for qualitative heat loss evaluation. However, the overriding factor is that the environment limits the measurements to an uncertainty of about $0.3^{\circ} \mathrm{C}$ in inside measurements and about $1^{\circ} \mathrm{C}$ in outside measurements. The resolution potential of high cost cryogenic systems may not actually be required for qualitative thermography. They are, of course, used - but mostly by sophisticated users that are able to afford the high cost and who generally have a quantitative interest potential.

Quantitative measurements to an accuracy of $0.1^{\circ} \mathrm{C}$ will be required for building code enforcement. Cryogenic or room temperature thermographic systems can satisfy such requirements. In order to use them for this purpose, however, it will be necessary to provide environment compensation for spectral emissivity, atmospheric trans-mission and background reflected energy. The extert to which this becomes a possibility can be determined only after a measurement validation of the magnitude and stability of each of these factors.

Section 4 contains an identification of state-of-the-art electro-optical instrumentation that has been used or could be used for thermography. Equipment costs run upwards of $\$ 60,000$ for cryogenic sensor systems down to the order of $\$ 300$ for spot temperature meters. Airborne equipment cost is typically in the $\$ 200,000$ or greater bracket. For the most part use of current instrumentation has been limited to qualitative identification of heat leaks. Relative temperature differences can be measured rather precisely with some of the more sophisticated instruments. The interpretation of the data requires great care, however. Temperature is only one of the radiation parameters as pointed out in Section 3. Thermographic data provide only effective or apparent temperature differences unless emissivity and its effect are properly handled. 
Section 5 contains an evaluation of photochemical sensor camera technology as a possibility for building thermography. Liquid crystal cameras and semiconductor photography have attractive possibilities. Cameras may cost in the vicinity of $\$ 1,000$ with hard copy pictures under $\$ 1$. Before cameras can be considered, however, sensor material must be developed. The requirements on liquid crystal materials are more development oriented. Basic research, however, must be undertaken on semiconductor photographic material to extend (if possible) the spectral response out to the order of $10 \mu \mathrm{m}$ from $4 \mu \mathrm{m}$.

\section{$\underline{\text { Recommended Research and Development }}$}

Section 6 contains the recommendations for research and development opportu-. nities. Section 2 has shown a user community need for low cost, $\$ 1,000$ inst ruments. At the present time only spot temperature measurement devices satisfy this cost requirement. The need, however, is for imaging sensors at this cost. Cryogenic imaging sensors cost between $\$ 5,000$ and $\$ 60,000$. Spatial resolution is higher for the more expensive units, and perhaps needs some improvement for the more inexpensive units. It may be difficult to hold the cost, however, if additional spatial resolution is required.

Pyroelectric vidicon cameras cost between $\$ 6,000$ and $\$ 15,000$. As a compromise, $\$ 6,000$ instruments should be adequate for qualitative building thermography. Further acceptance of IR thermography should allow for even lower cost (perhaps approaching $\$ 1,000$ ) as the market potential grows.

Liquid crystal and semiconductor photographic cameras also have the potential for low cost thermographic imaging systems. The development work required for liquid crystal cameras probably is greater than that which is required for more inexpensive pyroelectric vidicon cameras. Semiconductor photographic cameras are even more remote since basic material research for recording the imagery must be undertaken and proven.

In summary, the opportunity for successful development of low cost thermal imaging cameras for qualitative thermography with cost objectives of $\$ 1,000 /$ unit follows with decreasing order of priority. 


\section{Pyroelectric vidicon cameras \\ 2. Some forms of cryogenic (possibly the rmoelectric temperature) sensors with improved spatial resolution \\ 3. Liquid crystal cameras \\ 4. Semiconductor materials research \\ 5. Semiconductor photographic cameras.}

High cost cryogenic cameras are presently used for qualitative thermographic heat loss evaluation. Semiquantitative evaluation is sometimes attempted but the results often are not too meaningful. Quant itative accuracy of such measurements is limited by the spectral characteristics of the environment including atmospheric transmission, emissivity and nonuniform background reflections from the building into the spectrally sensitive cameras. Present day cameras do have the potential to satisfy the needs of building inspectors for building code verification. It will be necessary, however, to compensate for the environment. The electronic processing required will result from straightforward enginee ring work with no real development risks. The accuracy of any such compensation, however, is not known and will require a measurement program to establish a data base that does not presently exist. It will be necessary, for example, to determine the spectral emissivity of typical building components from 1 to $14 \mu \mathrm{m}$, and to study aging effects and the stability or uncertainty in measured values. Additionally, emissivity must be known to something of the order of 0.005 over the spectral range of the instrument.

The primary motivating factor for precise temperature measurements is perhaps building code validation. Absolute temperature measurements good to the order of $0.1^{\circ} \mathrm{C}$ to $0.25^{\circ} \mathrm{C}$ are required. This will require spectral compensation for the environment in a data processing subsystem. The development of the data processing unit is not difficult once the data base is measured and known. Compensation for the spectral transmission of the atmosphere is minimized with 8 to $12 \mu \mathrm{m}$ instruments. It may well be, however, that all instruments can be spectrally improved to minimize the environmental problems. 
Precise quantitative measurement of heat loss from imaging thermography will require the following action in decreasing priority.

1. Spectral emissivity measurement of building materials, evaluation of aging effects and identification of uncertainty values.

2. Evaluation of the environment through a thermographic measurement program to establish fundamental limitations on temperature measurement accounting for the effect of background reflection and atmospheric attenuation.

3. Spectral optimization of thermographic instruments with respect to the data base generated by Items 1 and 2 .

4. Improvement in inst rument readout. For example, CRT displays over the dynamic temperature range for building thermography are limited to $0.25^{\circ} \mathrm{C}$ and quite often may be as bad as $1^{\circ} \mathrm{C}$. The requirement is for $0.1^{\circ} \mathrm{C}$ readout resolution.

5. Spectral compensation to change from apparent temperature to absolute temperature. 


\section{SECTION 2 \\ BUILDING SECTOR REQUIREMENTS}

NAHB Research Foundation, Inc. as a subcontractor to Aerodyne Research, Inc. was engaged to identify potential users and us es for Infrared Thermography (IRT) in the building sector; to specify the sensitivity and resolution required from the equipment; to determine cost constraints, if any; and to recommend appropriate research, development and demonstration to further the growth and use of IRT in the private sector.

\subsection{APPROACH}

A "personalized form letter" (see pages 2-2 through 2-5 for sample) was sent to individuals selected for their knowledge and experience in their specific field of specialization. Included were home builders, general contractors, insulation contractors, manufacturers of insulation andbuilding materials, trade associations, organizations sponsoring thermal building codes preparation, IRT equipment manufacturers, IRT service organizations (who provide IRT pictures and interpretations to others) and energy suppliers. A number of government personnel involved with evaluation of IRT energy administration, conservation, management or research were also sent letters. Most were contacted by telephone some weeks after the letter, and their reactions sampled.

No rigid techniques for data processing appeared practical. Reactions ranged from enthusiastic responses of "It's the answer to everything in heat-loss, heat-gain analysis, " to insistence that it is too inexact to have any real meaning and therefore anyone implying accuracy in specific temperatures is guilty of misrepresentation and perpetrating fraud.

Consequently, results indicated and values quoted in this report are a product of consideration of all the facts and opinions expressed, and arrival at a considered judgment. No way could be determined to develop a meaningful averaging or other means for completely objective determination of the values to be reported. Notes made during the telephone calls are on file, as are any letters received in response. 


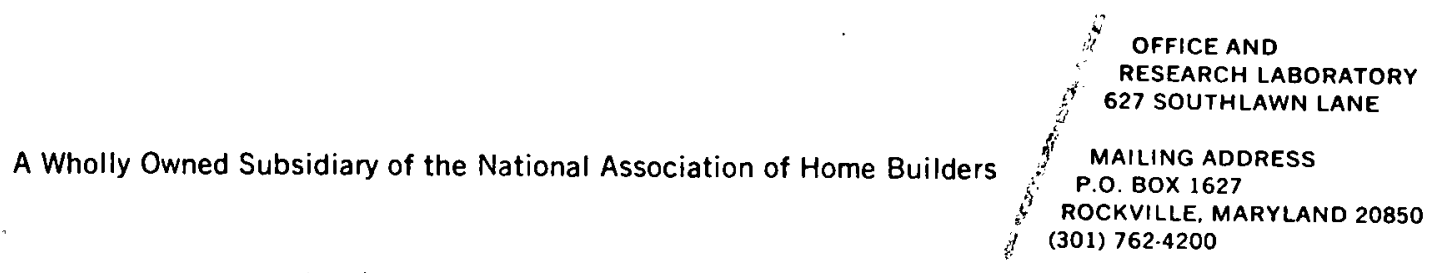

May 21,1976

Mr. Robert McMinn

Sales Manager

Ryan Homes

100 North Wren Drive

Pittsburgh, PA 15243

Dear Mr. McMinn:

Subject: Your Views on Infrared Thermography

We are working on a federal research project to evaluate the requirements, potential users and uses for infrared technology and instrumentation for measurement of heat energy gains and/or losses in the building sector. You have been selected as having exceptional knowledge regarding this subject, and as a qualified spokesman for your important builder activity. May we secure informally from you, your thoughts on the matter?

You probably know of infrared scanning from aircraft to survey large areas quickly. Resultant infrared images, enlarged photographically, show reliable qualitative indications of equal infrared emissions from the areas surveyed. Thus differences in temperature can be deduced for each portion surveyed by its color. More detail is possible by scanning a single building from a vantage point near that building. The same technique may sometimes be used from inside the buildings.

Would you consider all possible potential users and uses for such equipment and/or the resulting thermograms (photographs of isothermal imagery)?

Present techniques identify temperature differences as small as half a degree $F$. between areas with the same (or known but different) emissivities. Who would be satisfied with that level of performance? What other uses and users might become interested with progressively better performance? Don't let present limitations on performance inhibit your comments. Assuming performance was improved (to levels you indicate), what additional uses and users would result? So far, cost and availability of equipment has been disregarded.

Next, if (as now) equipment to do the job has special requirements and is expensive (about $\$ 50,000$ ), which users and uses would remain interested? As portability and cost improve, which others become interested again down to perhaps a $\$ 200$ investment? 
Mr. Robert McMinn

May 21, 1976

Page Two

Present technology locates areas without insulation compared to where at least $R-5$ insulation exists (Like failure to pack between wall framing and window frame). It is not reliable to detect between an insulation level of $\mathrm{R}-11$ and R-9 for example, as used in a wall. You should indicate uses and users that occur to you with the limitations of present technology, but also report those you envision if the technology permitted greater discrimination and better resolution than presently possible.

Building codes tend to increase thermal protection. They tend to performance requirements (as opposed to prescriptive) alone or as an option for compliance. How to measure thermal insulation without disturbing the building or occupants is a problem. Infrared thermography may be the solution. Your estimate of the impact of performance standards on measurement techniques is desired. Conversely, the development of present and improved measurement techniques may affect the code language or laws and means to demonstrate compliance. Your views on thermography compared to other practical methods of compliance demonstration will be appreciated.

Assuming equipment and techniques were developed to meet size, weight and cost levels you consider acceptable, what would you suggest to demonstrate them? The purposes; to inform the public of possible uses and to encourage potential users to use and improve the demonstrated tools. Can you suggest any areas requiring further research, refinement or development? Or any limitations in the proper use of the programs being proposed? If so, inform us of any you see.

It's asking a lot to take time from your busy schedule, Mr. McMinn to reflect on all the facets involved. We can repay you only with sincere thanks for your assistance, by making available the results we distill from your answers and those of other distinguished experts, and by hoping you will experience satisfaction from cooperating in making energy conservation easier and more effective for your fellow countrymen.

Infrared thermography should open opportunities for business and be another tool for existing businesses. Your comments on potentials for either, and ideas on how to publicize thermography for stimulating growth of businesses will be helpful to us.

Several days from mailing this letter, we intend to telephone you to discuss it. We hope you will consider responses during that interval. Your views will be particularly important to us because of your position as a leader among those to whom we feel the implications of thermography are so important. Thank you for your cooperation, Mr. McMinn.

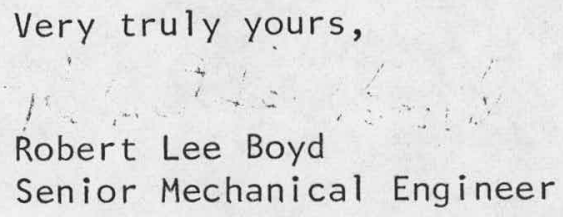




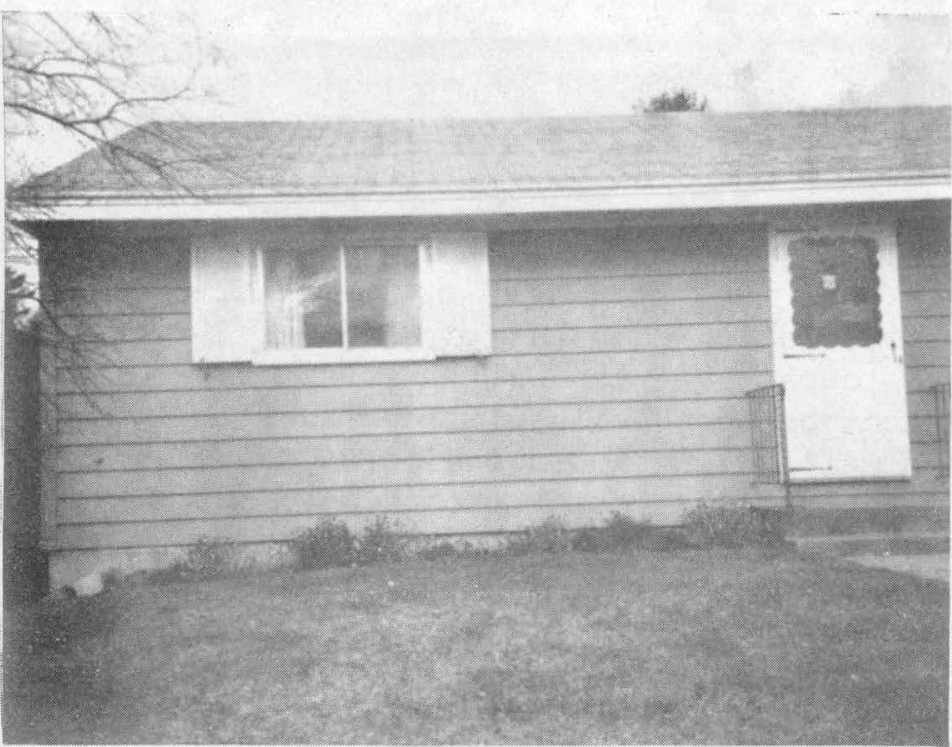

Beneath the Window of a Modern Clapboard House
2.

$$
\begin{aligned}
& - \\
& -9 \\
& -7 \\
& -5 \\
& -5 \\
& -3 \\
& -3 \\
& -1
\end{aligned}
$$

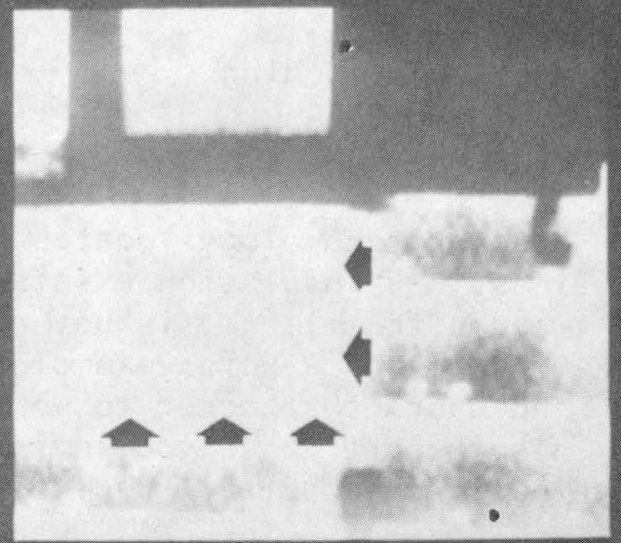

ACA THEaMOVISION०

Arrows point to heat conducted through the wall where a radiator is in contact with the interior wall. Note the obliteration of the pattern of the clapboards.

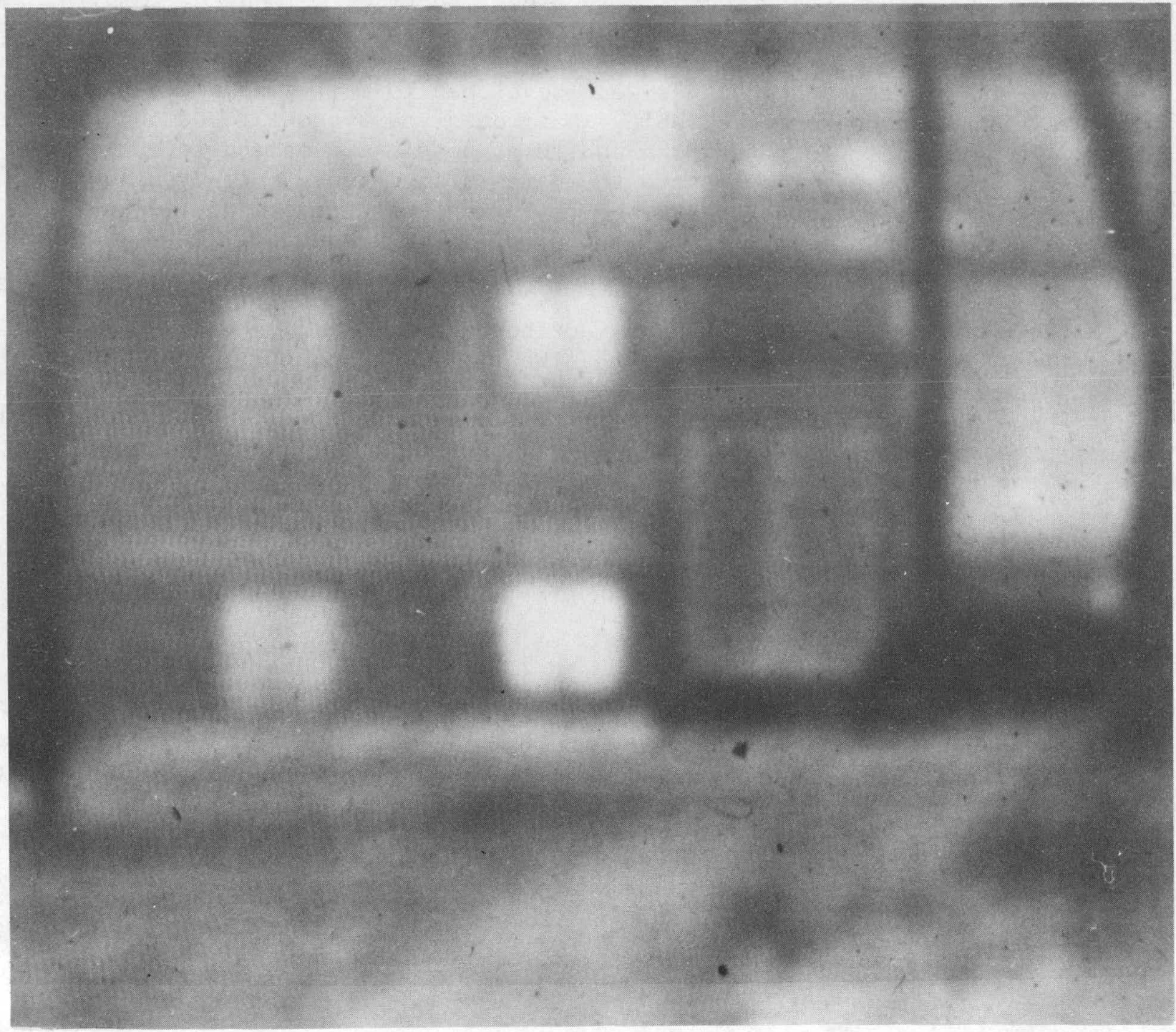

A different building, less resolution as enlarged. 

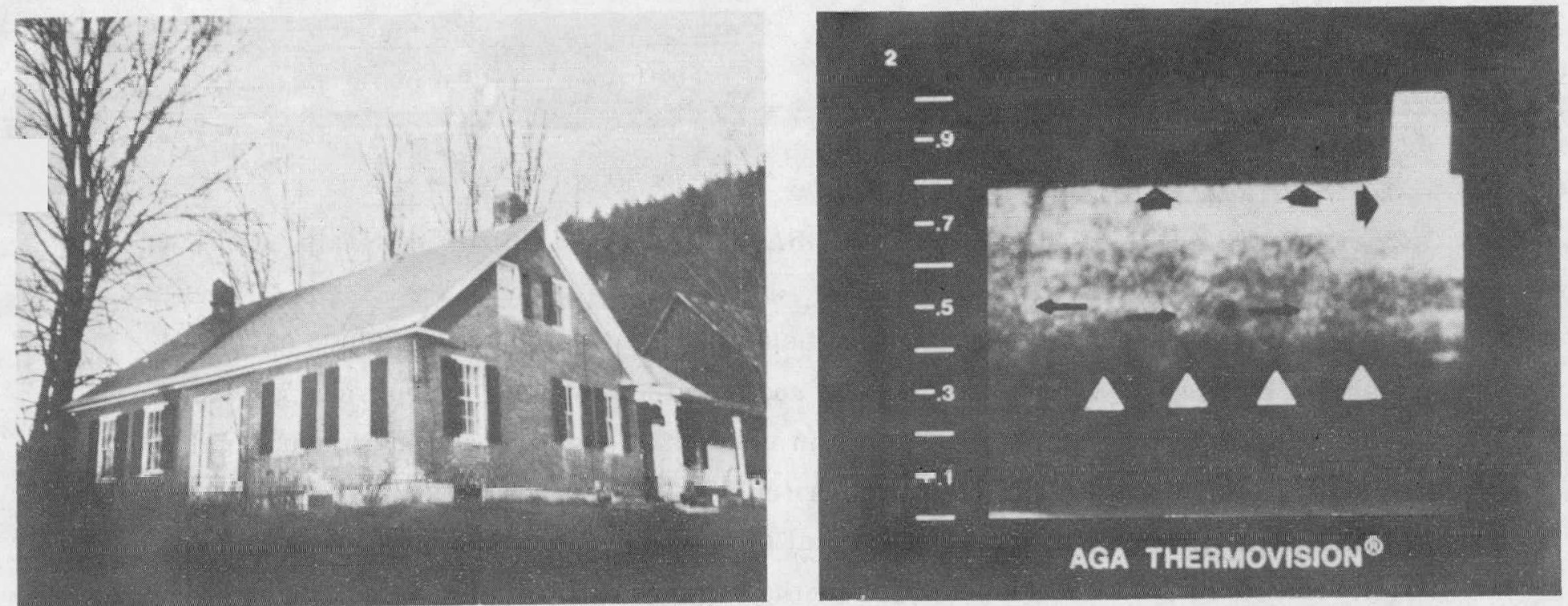

Roof of a Very Old Brick House. Wide vertical black arrows point to the ridge of the roof where heat is escaping because the attic is uninsulated. The large horizontal black arrow points to heat escaping around the chimney flashing. The narrow black arrows point to the roof rafters. The large dark zone at the bottom of the roof, indicated by the white arrows, shows the location of a storage area in the eaves. This storage area appears darker because the cold air is trapped. Heat rises through the uninsulated ceiling of the second-story room to cause the lighter appearance of the greater part of the roof.

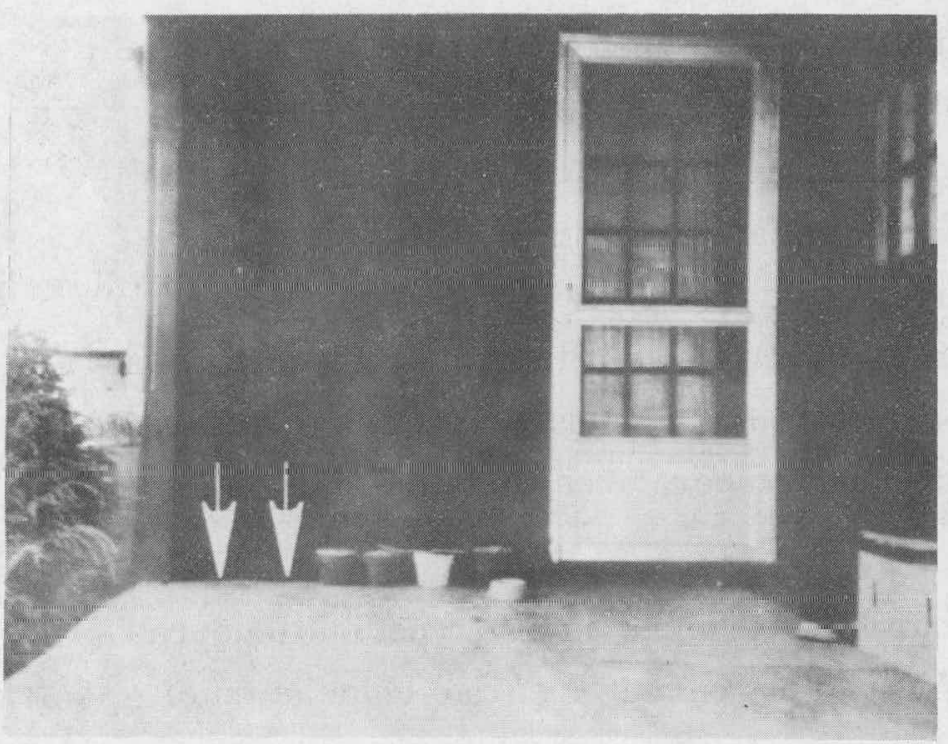

Foundation-Header Joint of Two Frame Houses

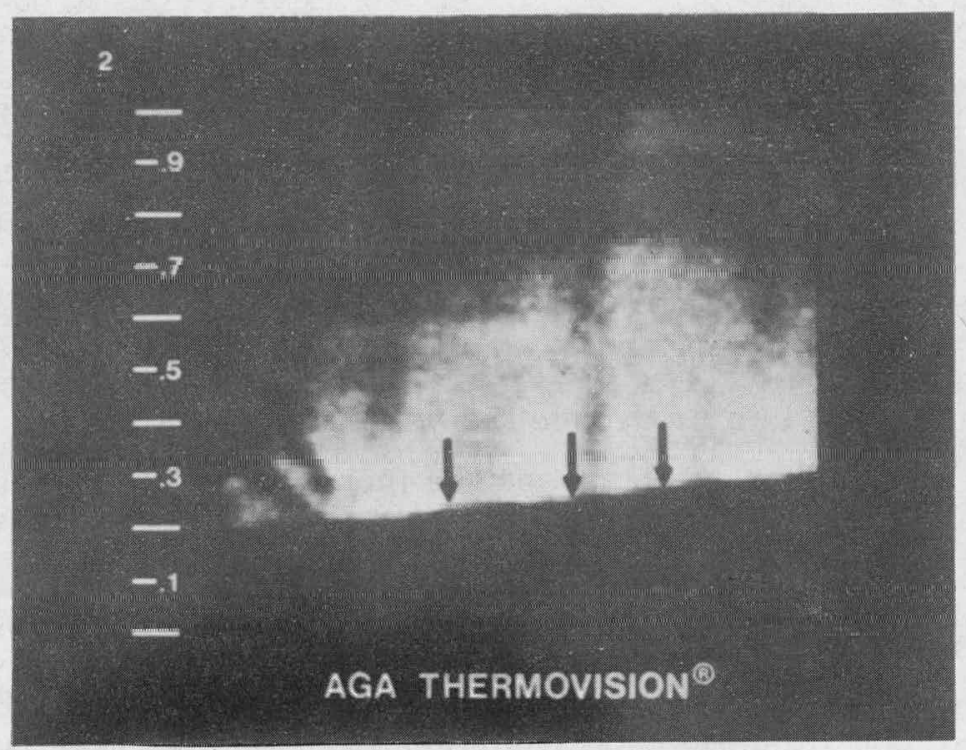

Old House, Exterior. The light area on the exterior of an old asphalt-shingled house shows a loss of heat from the foundationheader joint, a condition resulting from an uninsulated sole plate. 


\subsection{POTENTIAL INFRARED THERMOGRAPHY (IRT) MEASUREMENT REQUIRE - MENTS}

Potential IRT measurement requirements in the building sector include needs for measuring average U-values of walls and roofs and for evaluating separate portions such as window areas, etc. Differences in manner of specifying requirements and, frequently, permitted alternative methods require both averaging and component analysis capabilities. IRT has the potential of conveniently satisfying these needs. Particular advantages over most other methods generally include: (1) no physical contact is necessary; (2) large areas may be surveyed quickly; (3) widely separated buildings may be scanned quickly (mobility of equipment); (4) simultaneous heat gains and heat losses might, under some circumstances, each be established; (5) when necessary, both indoor and outdoor scans can be made; (6) thermographs provide instantaneous results for operator evaluation; (7) thermograms provide hard copy records of results for review, analysis and file uses; and (8) IRT is a good qualitative tool.

As a quantitative instrument, there are substantial difficulties to be overcome in both measurement and utilization of measured values. The sensitivity and reliability of available hardware for measuring the radiant flux appears to be adequate to most tasks if both indoor measurement and outdoor scans are utilized. Nevertheless, the values measured are simply a function of the surface emissivity and temperature. Neither is nor has been accurately determined, and the assumptions necessary to calculate or deduce the values are too broad to be accepted as authoritative values. Section 2.2. 1 discusses the interactions of emissivity and temperatures and the basis of the conclusion just stated.

Assuming the process did yield an accurate determination of the actual temperature of the outdoor surface, that value alone would not permit accurate calculation of the thermal resistance of various areas included within the total area scanned. In Section 2.2.2, the interactions of wind velocity, surface texture and other factors inhibiting accurate determination of film thermal resistances are discussed. Accurate determination of film resistance at each location in the area scanned would permit calculation of U-value and of transmission heat loss (or gain), even though the breakdown into conduction, convection and radiation components remained unknown (and of no real concern in building practice). 
IRT gives readily discernible qualitative indications of infiltration effects, but no reliable quantitative values. Section 2.2.3 discusses the inadequacies of IRT in determination of quantitative heat transmission and infiltration effects.

The accuracy requirement for the most demanding of the users and uses developed is indicated in Section 2.4 below, with discussions in Sections 2.2.1, 2.2.2 and 2.2.3 for each parameter measured. Users and uses requiring only qualitative results will be indicated separately from those requiring quantitative results.

\subsubsection{Emissivity Effects}

The energy flux emitted from a surface is a function of the emissivity of the surface and the absolute temperature of the surface to the fourth power. Also in the radiant flux is that part of it received by the surface which is reflected or re-emitted. A portion of the energy flux is measured by IRT. The IRT camera-detector will normally have a calibration curve ${ }^{1}$ to permit entry at ambient air temperature and read its isotherm units, a function of $\mathrm{T}_{\mathrm{A}}$. Similarly, the isotherm units, a function of a known temperature, $T_{2}$, at a reference point on the object of measurement, can be read. By application in the appropriate equation, the isotherm units of the point of measurement can be determined. Entering the solution of the equation isotherm units into the calibration curve, the surface temperature of the point measured can be read. In this process, emissivities must be used for the point on the object of measurement; for the second point of reference on the object to be measured; and for the surrounding surfaces from which the reflected energy radiated to the surface. These emissivities must all be either measured or assumed.

Emissivities are a function of the specific material of the surface, of the temperature of the surface; and of the condition of the surface (whether smooth or rough, etc.). The distribution of wavelength of emitted radiation is unique to any given material, while the distribution from a theoretical "perfect black body" has a smooth curve.

\footnotetext{
${ }^{1}$ See complete discussion of calibration curve, equations and their uses in "Thermography of Buildings, "Ivar Paljak and Bertil Petterson (translated from Swedish) distributed by Svensk Byggtjanst, Box 1403, S-111 84 Stockholm; Sections 2.3, 2.4.
} 
The detector of the camera has a limited range of wavelengths to which it is sensitive, and the lens system further compresses the wavelength band to which the camera responds. There are numerous sources of published data on emissivities, mostly incomplete, many with incomplete or ambiguous descriptions of the exact nature of the material to which the value applies (like "rough surface, " "strongly oxidized, " or "commercial sheet"). Table 2-1 below indicates values for emissivities for materials and attempts to extract descriptions which might correlate. It can be seen that selection of emissivity is not quite an exact science. As a result, this is passed off in many cases as unimportant, and an assumed value is used.

For example, many say that "untreated building materials" have an emissivity of about $0.90 .^{1}$ On Page 33 of "Thermography of Buildings" (previously referenced) there is indication of a measured value of 0.72 for yellow face brick and of 0.97 for flat grey oil base paint (the lower and upper limit of values tested). To test the assumption of common materials being 0.90 emissivity, against surface temperatures measured using such an assumption, assume yellow face brick is at $0^{\circ} \mathrm{C}\left(32^{\circ} \mathrm{F}\right)$. Equating 0.72 (emissivity) times $(273.16)^{4}$ as being equal to the emissivity of flat grey oil base paint times its unknown temperature to the fou rth power, we solve for the unknown temperature and find it to be $253.55^{\circ} \mathrm{K}$ instead of the $273.16^{\circ} \mathrm{K}$ if our assumption was correct. The difference in emissivities is 0.25 ; in temperatures it is 19.61. Would not this indicate that a difference of one percent (.01) in emissivity has the same effect as about $0.78^{\circ} \mathrm{C}\left(1.41^{\circ} \mathrm{F}\right)$-change in temperature?

Table 2-1 indicates selected extracts from three authoritative sources. Extracts were selected to illustrate possible matches for comparison. However, in most cases there are inadequate data on exactly what is reported to justify comparison as a match.

Page 36 of "ASHRAE Handbook of Fundamentals" ${ }^{1}$ includes a table, reproduced below as Table 2-2, of emittances and absorptances for a few surfaces at $50^{\circ}$ to $100^{\circ} \mathrm{F}$, at $1000^{\circ} \mathrm{F}$ and for solar radiation, respectively.

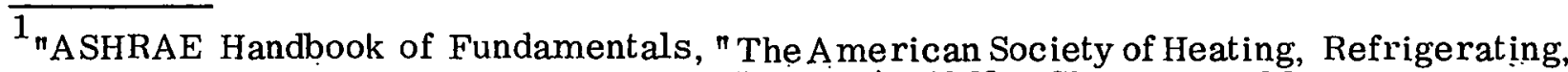
and Air-Conditioning Engineers, Inc., New York, 1972; Chap. 2, Table 1, Section B, p. 357
} 
Table 2-1. Material Emissivity

\begin{tabular}{|c|c|c|c|c|}
\hline \multirow{2}{*}{ Material } & \multirow{2}{*}{$\begin{array}{l}\text { Ref. 1, P33 } \\
\text { Table } 3\end{array}$} & \multicolumn{2}{|c|}{ Ref. 2, Table 182} & \multirow{2}{*}{$\begin{array}{l}\text { Ref. } 3 \text {, Ch. } 30 \\
\text { ASHRAE Hdbk }\end{array}$} \\
\hline & & $\mathrm{t} \quad \mathrm{C}$ & $\epsilon$ & \\
\hline $\begin{array}{l}\text { Plywood, untreated } \\
\text { Wood, planed }\end{array}$ & 0.83 & 20 & $.8-.9$ & \\
\hline $\begin{array}{l}\text { Plasterboard, untreated } \\
\text { Plastic paper, white } \\
\text { Plastic paper, red }\end{array}$ & $\begin{array}{l}0.90 \\
0.84 \\
0.94\end{array}$ & & & \\
\hline Paper, black & & & 0.90 & - \\
\hline Paper, black, dull, & & & 0.94 & \\
\hline Paper, green & . $:$ & & 0.85 & \\
\hline Paper, red : & & 20 & 0.76 & \\
\hline $\begin{array}{l}\text { Paper, white } \\
\text { Paper, yellow }\end{array}$ & & & $\begin{array}{l}.7-.9 \\
0.72\end{array}$ & \\
\hline Oil paint, grey, flat & 0.97 & & & \\
\hline Oil paint, grey, gloss & 0.96 & & & \\
\hline Oil paint, black, flat & 0.94 & & & \\
\hline Oil paint, black, gloss & 0.92 & & $28 \quad 23$ & \\
\hline $\begin{array}{l}\text { Paint, Cadmium, yellow } \\
\text { Paint, chrome green }\end{array}$ & & & $\begin{array}{l}.28-.33 \\
.65-.7\end{array}$ & \\
\hline Paint, cobalt blue & & & $.7-.8$ & \\
\hline Paint, oil, various colors & & 100 & $.92-.96$ & \\
\hline $\begin{array}{l}\text { Varnish, flat } \\
\text { Shellac, black, dull } \\
\text { Shellac, blk, shiny on tin plate }\end{array}$ & 0.93 & $\begin{array}{c}75-150 \\
20\end{array}$ & $\begin{array}{l}0.91 \\
0.82\end{array}$ & \\
\hline Brick, facing, yellow & 0.72 & & & \\
\hline Brick, facing, red & 0.92 & & & \\
\hline Brick, red, rough & & 20 & $.88-.93$ & 0.93 \\
\hline Brick, fireclay & & $\begin{array}{r}20 \\
12 n 0\end{array}$ & 0.85 & \\
\hline $\begin{array}{l}\text { Brick, fireclay } \\
\text { Brick, fireclay }\end{array}$ & & $\begin{array}{l}1200 \\
1000\end{array}$ & $\begin{array}{l}0.59 \\
0.75\end{array}$ & 0.75 \\
\hline Glass & & $20-100$ & $.94-.91$ & 0.94 \\
\hline Glass & & $250-1000$ & $.87-.72$ & \\
\hline Glass, frosted & & $1100-1500$ & $.70-.67$ & \\
\hline Aluminum, polished & & $50-100$ & $.04-.06$ & 0.09 \\
\hline Aluminum, oxidized & $0.22-0.40$ & $20-50$ & $06-07$ & \\
\hline Aluminum, strongly oxidized & & $50-500$ & $.2-.3$ & \\
\hline $\begin{array}{l}\text { Asbestos, board } \\
\text { Asbestos, paper } \\
\text { Asbestos, sláte } \\
\text { Fabric, Asbestos }\end{array}$ & & $\begin{array}{c}20 \\
40-400 \\
20\end{array}$ & $\begin{array}{l}0.96 \\
.93-.95 \\
0.96 \\
0.78\end{array}$ & 0.93 \\
\hline
\end{tabular}

${ }^{1}$ "Thermography of Buildings" (see reference p. 2-7)

2 Mikael A. Bramson, "Infrared Radiation, "A Handbook for Applications (translated from Russian), Plenum Press, New York, 1968.

3 "ASHRAE Handbook of Fundamentals, " (see reference p. 2-8) 
Table 2-2. Emittances and Absorptances for a Few Surfaces

\begin{tabular}{|c|c|c|c|c|}
\hline \multirow{2}{*}{ Class } & \multirow{2}{*}{ Surfaces } & \multicolumn{2}{|c|}{ Total Normal Emittance ${ }^{(a)}$} & \multirow{2}{*}{$\begin{array}{l}\text { Absorptance for } \\
\text { Solar Radiation }\end{array}$} \\
\hline & & At $50-100^{\circ} \mathrm{F}$ & At $1000^{\circ} \mathrm{F}$ & \\
\hline $\begin{array}{r}4 \\
5 \\
6 \\
7 \\
8 \\
\\
9 \\
10 \\
11\end{array}$ & $\begin{array}{l}\text { A small hole in a large box, sphere, furnace, or } \\
\text { enclosure } \\
\text { Black nonmetallic surfaces such as asphalt, carbon, } \\
\text { slate, paint, paper } \\
\text { Red brick and tile, concrete and stone, rusty steel } \\
\text { and iron, dark paints (red, brown, green, etc.) } \\
\text { Yellow and buff brick and stone, firebrick, fire clay } \\
\text { White or light-cream brick, tile, paint or paper, } \\
\text { plaster, whitewash } \\
\text { Window glass } \\
\text { Bright aluminum paint; gift or bronze paint } \\
\text { Dull brass, copper, or aluminum; galvanized steel; } \\
\text { polished iron } \\
\text { Polished brass, copper, monel metal } \\
\text { Highly polished aluminum, tin plate, nickel, } \\
\text { chromium } \\
\text { Selective Surfaces } \\
\text { Stainless steel wire mesh } \\
\text { White painted surface } \\
\text { Copper treated with solution of } \mathrm{NaClO}_{2} \text { and } \mathrm{NaOH} \\
\text { Copper, nickel, and aluminum plate with } \mathrm{CuO} \\
\text { coating }\end{array}$ & $\begin{array}{l}0.97 \text { to } 0.99 \\
0.90 \text { to } 0.98 \\
0.85 \text { to } 0.95 \\
0.85 \text { to } 0.95 \\
0.85 \text { to } 0.95 \\
0.90 \\
0.40 \text { to } 0.60 \\
0.20 \text { to } 0.30 \\
0.02 \text { to } 0.05 \\
0.02 \text { to } 0.04 \\
0.23 \text { to } 0.28 \\
0.92 \\
0.13 \\
0.09 \text { to } 0.21\end{array}$ & $\begin{array}{l}0.97 \text { to } 0.99 \\
0.90 \text { to } 0.98 \\
0.75 \text { to } 0.90 \\
0.70 \text { to } 0.85 \\
0.60 \text { to } 0.75 \\
0.30 \text { to } 0.50 \\
0.05 \text { to } 0.15 \\
0.05 \text { to } 0.10 \\
0 \\
0\end{array}$ & $\begin{array}{l}0.97 \text { to } 0.99 \\
0.85 \text { to } 0.98 \\
0.65 \text { to } 0.80 \\
0.50 \text { to } 0.70 \\
0.30 \text { to } 0.50 \\
\text { (b) } \\
0.30 \text { to } 0.50 \\
0.40 \text { to } 0.65 \\
0.30 \text { to } 0.50 \\
0.10 \text { to } 0.40 \\
0.63 \text { to } 0.86 \\
0.23 \text { to } 0.49 \\
0.87 \\
0.08 \text { to } 0.93\end{array}$ \\
\hline
\end{tabular}

(a) Hemispherical and normal emittance are not equal in many cases. The hemispherical emittance may be as much as 30 percent greater for polished reflectors to 7 percent lower for nonconductors.

(b) Absorbs 4 to 40 percent depending upon its transmittance. 
Tables 2-2 and 2-3 demonstrate substantial changes in emissivities for different temperatures of measurement. The footnotes of Table 2-2 indicate 30 percent difference between hemispherical and normal emittance for metals. Table 2-3 refers to the same as making little difference, even though 20 or 30 percent higher for hemispherical than for normal emittance. Finally, its footnotes indicate uncertainty of the description of the materials may be of the same order.

Table 2-3. Total Radiation Emissivities ${ }^{\text {i }}$

(Radiation at All Wavelengths Included)

\begin{tabular}{|c|c|c|c|}
\hline Class & Material & $32-100^{\circ} F^{(a)}$ & $500-1000^{\circ} F^{(b)}$ \\
\hline $\begin{array}{l}5 \\
6 \\
7\end{array}$ & $\begin{array}{l}\text { METALLIC MATERIALS (CLEAN: DRY) } \\
\text { Highly polished aluminum, silver, gold, } \\
\text { brass, tin } \\
\text { Polished brass, copper, steel, nickel, } \\
\text { chromium, platinum, clean mercury } \\
\text { Dull, smooth, clean aluminum and } \\
\text { alloys, copper, brass, nickel, stain- } \\
\text { less steel, iron, lead, zinc } \\
\text { Rough-ground or. smooth-machined } \\
\text { castings; steel-mill products, sprayed, } \\
\text { metal, molten metal } \\
\text { Smooth, slightly oxidized aluminum, } \\
\text { copper, brass, lead, zinc } \\
\text { Bright aluminum, gilt, or bronze paints } \\
\text { Heavily oxidized and rough iron, steel, } \\
\text { copper, aluminum } \\
\text { NONMETALLIC MATERIALS(c) } \\
\text { White or light colored paint, plaster, } \\
\text { brick, tile, porcelain, paper, } \\
\text { plastics, asbestos } \\
\text { Medium red, brown, green, buff, and } \\
\text { other colors of paint, brick, tile, } \\
\text { inks, clays, stone, concrete, wood, } \\
\text { water } \\
\text { Glass and translucent plastics, oil, } \\
\text { varnish, ice, crystals (d) } \\
\text { Carbon black, tar, asphalt, matte- } \\
\text { black paints } \\
\text { SIMULATED BLACKBODY } \\
\text { A small opening in a large box, sphere, } \\
\text { furnace, or enclosure with high- } \\
\text { emissivity walls }\end{array}$ & $\begin{array}{l}.08-.20 \\
.15-.25 \\
.2-.4 \\
.3-.55 \\
.6-.85 \\
.80-.95 \\
.85-.95 \\
.85-.95 \\
.90-.97\end{array}$ & $\begin{array}{c}.85-.70 \\
.95-.75 \\
.90-.97 \\
\cdots \\
.97-.99\end{array}$ \\
\hline
\end{tabular}

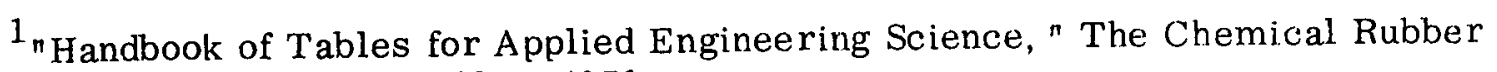
Company, Cleveland, Ohio, 1970. 
Table 2-3. Total Radiation Emissivities (Cont'd)

Notes:

Factors apply to either radiation or absorption.

For a small body in a large enclosure, use the emissivity of the small body only: $\mathrm{F} \epsilon=\epsilon_{1}$.

For rectangles or disks, either parallel or perpendicular and with a common side, use the product of the emissivities: $F \epsilon=\epsilon_{1} \times \epsilon_{2}$.

For infinite parallel planes, concentric cylinders, or large enclosed bodies, use both emissivities in the equation

$$
\text { Fe }: \frac{1}{1 \epsilon_{1}+1 \cdot \epsilon_{2}-1}
$$

It makes little difference whether the values in this table are regarcled as tot al hemispherical emissivity or total normal emissivity. For nonmetals the difference is very small. For metals the hemispherical emittance of a given sample may be 20 or 30 percent above the normal emittance, but in any case the difference between a measured emittance and a typical emissivity may be of the same order as the uncertainty of the description of the material. Moreover, a tolerance for the accuracy of the experimental determination is appreciable. For a thorough discussion see NASA SP-31, "Measurement of Thermal Radiation Properties of Solids, " 1963 (585 pages) and "Thermal Radiation Properties Survey, " G. G. Gubareff, J. E. Janssen, and R. H. Torborg, Honeywell Research Center, Minneapolis, Minn., 1960

(a) For high femperature see Table 5-37 ${ }^{1}$. For cryogenic temperatures see Table 5-36 ${ }^{1}$. For solar absorptivity see Table $2-4$ (th is report).

(b) These values apply only to metals with higher melting points and to heatresistant surfaces. Any contamination greatly increases the emissivity of a metal surface.

(c) Emissivities of very rough surfaces are usually higher than those for smooth surfaces.

(d) See Table 2- 6 (this report) for properties of infrared windows.

Tables 2-4, 2-5, and 2-6 (also from the "Handbook of Tables for Applied Engineering Sciencen $)^{\vec{i}}$ are self-explanatory.

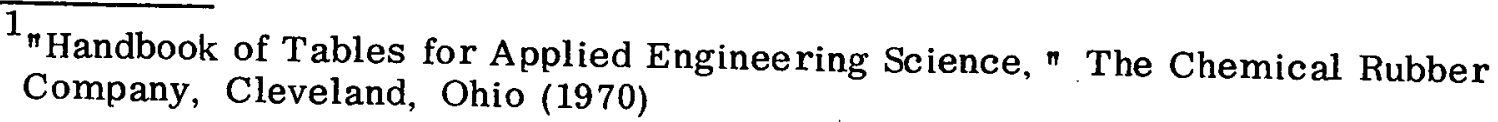


Table 2-4. Solar Absorption Coefficients

Total Absorptivity is given in the range from 0.3 to 2.5 microns for surfaces at atmospheric temperature

\begin{tabular}{|c|c|c|}
\hline Class & Surface Material & Absorptivity \\
\hline 1 & White surfaces: paint, paper, plaster, plastics, white oxides, fresh snow & $0.1-0.3$ \\
\hline 2 & $\begin{array}{l}\text { Light-colored surfaces: paint, paper, plastics, textiles, concrete, wood, } \\
\text { sand, bricks, stone, dry grass }\end{array}$ & $0.25-0.5$ \\
\hline 3 & Darker colors: paint, inks, brick, tile, slate, leaves, rusted iron, soil & $0.4-0.8$ \\
\hline 4 & Black asphalt, tar, slate, carbon, rubber, water & $0.85-0.95$ \\
\hline 5 & Clean, dark metals: iron and steel, lead, zinc; metallic paints & $0.2-0.5$ \\
\hline 6 & $\begin{array}{l}\text { Polished, bright metals: aluminum, silver, tin, magnesium, copper, } \\
\text { chromium, nickel }\end{array}$ & $0.07-0.3$ \\
\hline
\end{tabular}

'Notes:

For a non-metallic surface the long-wave emissivity is higher than the solar absorptivity. The . opposite is true for polished metals.

For metals the absorptivity increases as the temperature of the absorber increases.

With solar simulators the absorptivities may be different from those measured in the sun.

Vapors and air contaminants affect solar absorptivity. 
Table 2-5. Spectral Transmission: UV, IR, and Colored Glasses (See Table 2-6 for infrared window materials.)

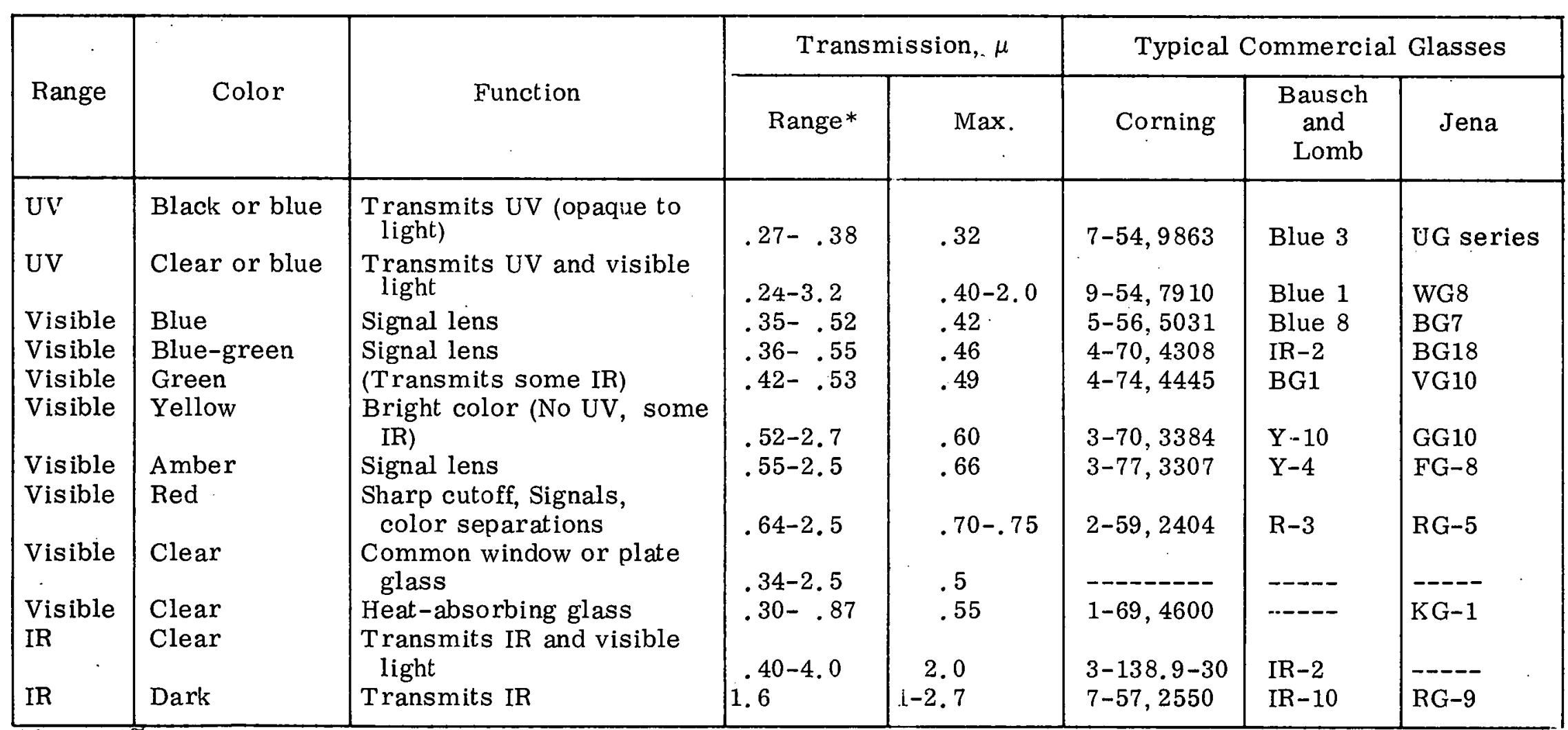

*Over $50 \%$ transmission 
Table 2-6. Infrared Window Materials*

Maximum Wavelength Limits for Transmission Through Window of Practical Thickness

See also Table 2-5

Symbols: $\mathrm{H}=$ hygroscopic; not water resistant $\mathrm{S}=$ soft; easily scratched

\begin{tabular}{|c|c|c|c|c|c|}
\hline $\begin{array}{l}\text { Class } \\
\text { or } \\
\text { Group }\end{array}$ & $\begin{array}{l}\text { Approx. } \\
\text { Trans- } \\
\text { mission } \\
\text { Limits, }{ }^{* *}\end{array}$ & Material or Major Constituent & $\begin{array}{l}\text { Class } \\
\text { or } \\
\text { Group }\end{array}$ & $\begin{array}{l}\text { Approx. } \\
\text { Trans- } \\
\text { mission } \\
\text { Limits, }\end{array}$ & Material or_Major Constituent \\
\hline $\begin{array}{l}1 \\
2 \\
3\end{array}$ & $\begin{array}{l}2-3 \\
4-5 \\
6-8\end{array}$ & $\begin{array}{l}\text { Common glass } \\
\text { Quartz; silica, } \mathrm{SiO}_{2} \\
\text { Lithium fluoride, } \mathrm{LiF} \\
\text { Magnesium fluoride, } \mathrm{MgF}_{2} \\
\text { Sapphire, } \mathrm{Al}_{2} \mathrm{O}_{3} \\
\text { A rsenic trisulfide, } \mathrm{As}_{2} \mathrm{~S}_{3} \quad(\mathrm{H}) \\
\text { Barium fluoride, } \mathrm{BaF}_{2} \\
\text { Calcium fluoride, } \mathrm{CaF}_{2} \\
\text { Sodium chloride, } \mathrm{NaCl}\end{array}$ & 5 & $13-20$ & $\begin{array}{l}\text { Sodium fluoride, } \mathrm{NaF}(\mathrm{H}) \\
\text { Zinc selenide, } \mathrm{ZnSe} \\
\text { Zinc sulfide, } \mathrm{ZnS} \\
\text { Cesium bromide, } \mathrm{Cs} \mathrm{Br} \mathrm{(H,} \mathrm{S)} \\
\text { Cesium iodide, CsI (H) } \\
\text { Potassium bromide, } \mathrm{KBr} .(\mathrm{H}, \mathrm{S}) \\
\text { Potassium chloride, } \mathrm{KCl}(\mathrm{H}) \\
\text { Potassium iodide, } \mathrm{KI}(\mathrm{H}) \\
\text { Silver chloride, } \mathrm{AgCl}(\mathrm{S}) \\
\text { Tellurium bromide, } \mathrm{TeBr}\end{array}$ \\
\hline
\end{tabular}


Possibly sources referenced in the various tables, or other material which could be turned up by literature search, might clarify and refine values for described materials; but wavelength bands and other calibration parameters should match those of instruments and environments. It is concluded that authoritative determination of ambient temperature, reference temperature, emissivity and air film resistance is each required for quantitative measurement by IRT.

\subsubsection{Surface Film Thermal Conductance}

The total thermal resistance to heat flow through a flat floor, ceiling or wall is equal to the sum of the resistances in series. Where the air is in contact with the building section, there is resistance to heat flow between them due to the air film. This air film resistance is markedly affected by air movement. The value of the air film conductance is shown in Figure 2-1 for various materials at air velocities up to $40 \mathrm{mph}$ (thermal resistance is the reciprocal of the thermal conductance). It may be noted that as the velocity increases, the difference in conductance between different

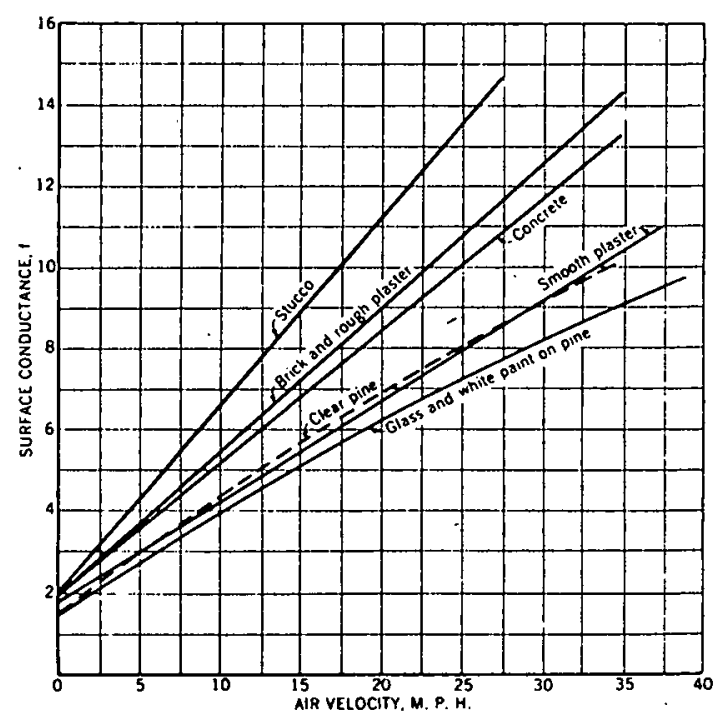

Figure 2-1. Surface Conductance for Diffe rent 12-Inch Square Surfaces as Affected by Air Movement. 
materials increases. The rougher the surface, the greater the slope of the line indicating conductances. The wind velocity assumed in the heating season calculations is $15 \mathrm{mph}$, for which the air film conductance is about 5 for a smooth surface and about 8.8 for a rough one (stucco). These correspond to resistances of 0.20 and 0.11 respectively. The winter outdoor air film in common use is 0.17 . At zero velocity the range of conductances is from about 1.5 to about 2 , and the corresponding resistances are 0.67 and 0.5 respectively. The winter indoor film resistance in common use is 0.61 for ceilings, 0.68 for walls, and 0.92 for floors.

It can be noted that there has been an arbitary selection of an air velocity assumed for winter load calculations. There are appreciable differences in air film resistances shown in Figure 2-1 compared to those in common use. To apply the temperatures developed from thermography, the ratio of the film resistance to the unknown total resistance of the section is proportioned to the ratio of the temperature difference due to the air film alone to the total air temperature difference to calculate the total resistance of the building section. If there was an accurate measurement of the wind velocity at the moment of the thermography exposure, and an exact identity with a specific line of Figure 2-1 (or a similar chart), the surface conductance could be read from the chart. But the (mean) temperature at which the measurements were made, the surface length, and the effect of low temperature radiation from surroundings affect the conductance in a manner not accounted for in such a chart.

It may be concluded that the air film used in calculations is a nominal value; that definition of all factors affecting that value at the time the thermography was made is impractical; and that the value used is an approximation which may be on the order of $\pm 15 \%$.

A simple wall consisting of the elements shown below (Table 2-7) has successive resistances for each layer as tabulated below for: (1) no insulation (with and without correction for framing), and (2) R-11 insulation added, respectively.

Air film resistance is equated with temperature differences to calculate the total resistance of the section. For the uninsulated example, a winter design outdoor air film of 0.17 equated with a calculated 4.58 total thermal resistance* would

\footnotetext{
* Adjusted for framing.
} 
* Table 2-7. Coefficients of Transmission (U) of Frame Walls ${ }^{\text {a }}$

(These coefficients are expressed in BTU per (hour) (square foot) (Fahrenheit degree difference in temperature between the air on the two sides), and are based on an outside wind velocity of $15 \mathrm{mph}_{\circ}$ )

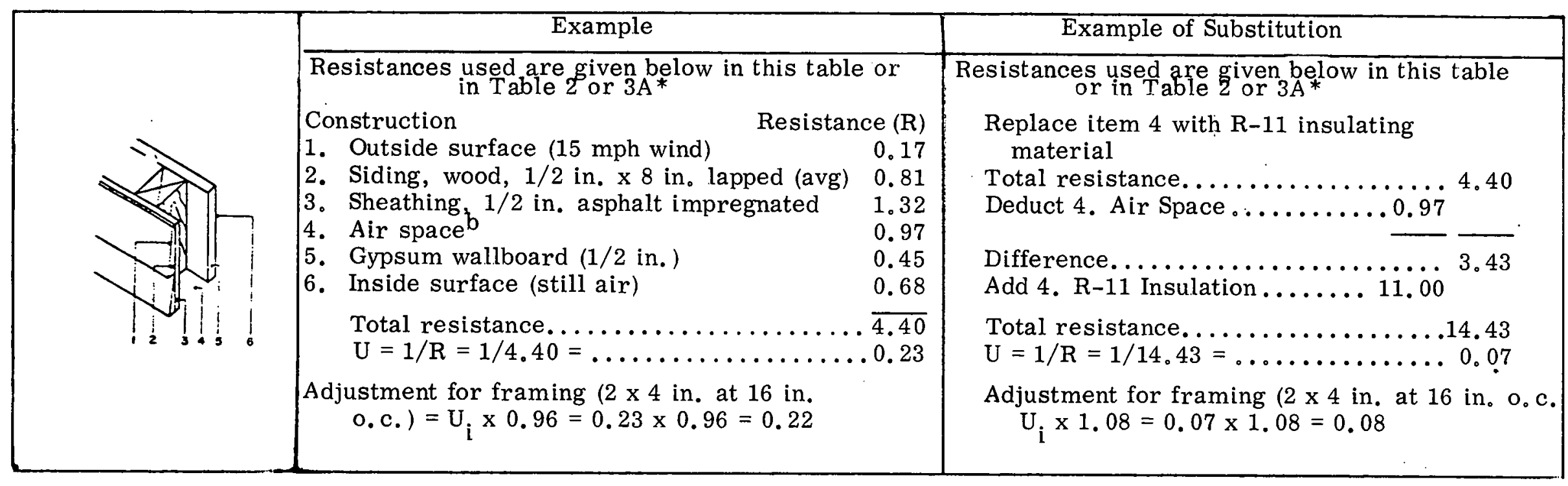

a. See te $t$ section Calculating Overall Coefficients for basis of calculations.

b. To adjust $U$ values for the affect of added insulation between framing members, see Table 5A*

*ASHRAE Handbook of Fundamentals 
mean a difference in temperature between the outdoor air and the outdoor wall surface of $1.11^{\circ} \mathrm{F}$ for a total of $30^{\circ} \mathrm{F}$ between indoor and outdoor temperature.

$$
\Delta{ }_{\mathrm{F}}=\Delta \mathrm{t}_{\mathrm{T}} \quad \overline{\mathrm{R}}_{\mathrm{T}}^{\mathrm{R}} \quad \cdots \quad 30 \frac{0.2 \%}{4.58}=1.11^{\circ} \mathrm{F}
$$

This is barely acceptable for \pm half a degree instrument accuracy With the insulated wall, similar reasoning indicates a difference of only $0.38^{\circ}$.

$$
\Delta t_{f}=\Delta t_{T} \frac{R_{f}}{R_{\Gamma}}=30 \frac{0.17}{13.36^{*}}=0.38^{\circ}{ }^{\circ}
$$

This is unacceptable for \pm half a degree instrument accuracy.

It would siem a logical conclusion that resistances cannot be measured by thermoography outdoors with enough accuracy to attempt to use it as a quantitative tool. It continues to merit use as a qualitative tool, provided the cost is evaluated as satisfactory.

\section{2.?.3 Heat Transmission and Infilt ration Effects}

In Section 2.2.1 it was indicated that there is considerable conflict between values for emissivity of common building material surfaces from various authorities. Using the one with the lowest spread of values (from "Thermography of Buildings, " previously referenced), and discarding bright metals and other materials no: so com moa, or with insignificant area in most structures, values from 0.72 to 0.97 remain. Similar selective consideration of Table 2-2 (page 2-10) laj.ves values between 0.85 and 0.95 for the $50-100^{\circ} \mathrm{F}$ emittances. Early in Section 2.2.1 it was suggested that a $1 \%$ change in emissivity had about the same effect on results as a $1.4^{\circ} \mathrm{F}$ change in surface temperature. If we conclude a range of accuracy of $\pm 6 \%$ accuracy in emissivity, the surface temperature reliability determination would be affected about $8.4 \%$ by the emissivity reliability. Section 2.2 .2 concluded that the air film value was

*Adjusted for framing. 
approximately $\pm 15 \%$ accuracy in use. The combination stretches to about $\pm 25 \%$ accuracy, assuming the surface temperature is such that the deviation arror expected is greater than the outdoor air film temperature difference used to calculate total opaque sectional thermal resistance.

By similar reasoning, we may determine that indicated surface temperatures arrived at for infilt ration (or exfiltration) are not sufficiently accurate to use quantitatively for any of the users or uses discussed in this report. That fact in no way detracts from the very real utility of IRT in locating areas of concern and approximating the order of magnitude of the heat leaks by either transmission or infiltration or exfilt ration.

There are many practical alternatives to IRT in determining the quant itative value of the thermal resistance at an area of concern located in a big picture by IRT. Among these mentioned by Aerodyne in their Introduction and Summary are the touch pyrometer, the portable infrared thermometer (requires no contact with the surface), thermocouple, or the pyroelectric vidicon (no contact required). If the actual value of the thermal resistance has been determined, the heat loss by transmission for the section involved is readily and accurately determined.

Over the years there have been many attempts to arrive at accurate means of determination of infiltration values. In "ASHRAE Handbook of Fundamentals" (referenced previously) the Air Change Method is listed as reasonably precise in residences. Table 1 on page 337 of the handbook provides a base for that method. The footnote suggests that added weatherstripping or storm sash reduce the air change to two-thirds of the values listed. Further text on this method indicates that only half the sum of the infiltration for individual rooms should be used for the total building infiltration (what air enters on the windward side generally leaves on the leeward side).

An alternative method considers the equivalent to double-hung wood windows for which values are given in Table 3 of the above-mentioned handbook. Discussion elsewhere in the text indicates that added weatherstripping or storm windows will affect the infiltration about the same amount. For storm windows with about the same leakage as the prime windows, the combination would have about $30 \%$ less infiltration than 
the prime window alone. A relatively tight storm window applied to a poorly fitted prime window reduces the infiltration to about $50 \%$ of the prime alone.

The above information seems to indicate that the re is considerable lack of accuracy in determination of infiltration. There are already more than enough studies completed or in progress at this time on the subject. If further clarification or recommendation on basis of evaluating infiltration loads is desired, it is suggested a state-of-the-art review with recommendations based on existing technology may be preferable to attempting another basic study.

\subsection{BUILDING CODES}

Building code writers and administrators do not seem to be particularly influenced by IRT measurement techniques in development of or enforcement of codes. In many cases they may recognize the possibility of convenience to contractors, designers and owners in demonstration of compliance through IRT. It appears most would be unwilling to require or permit IRT to be specifically mentioned within their codes. Many believe use of IRT is an option to be evaluated by the local authority having jurisdiction.

IRT might have some advantages, however, in demonstrating compliance with codes (if an accurate quant itative technique could be developed). Of these, two stand out:

(1) Acceptance of thermograms as evidence of compliance allows the building to be completed without having to wait for inspection of thermal treatment before finishing work covers up that thermal treatment.

(2) In the case of arriving at "average for the section" requirement compliance, IRT output might be adaptable to density averaging or electromechanical or computer operations.

How compliance of standards may be demonstrated by design verification, by inspection of construction, and/or measurements through IRT is discussed below. 
(1) Design verification that the materials and application methods specified should result in construction meeting code requirements is a commonly used prerequisite to issuing a building permit. It has been customary to expect on-site inspection to supplement design verification [see (2) below. Entirely adequate directives in plans and specifications, however, do not ensure that materials furnished, application methods directed, or level of workmanship anticipated will be actually realized. There seems to be no reason why IRT, as a required or optional demonstration of compliance, should displace the usual design verification requirement (which provides the designer, builder and inspecting authority an opportunity to observe whether each appears to understand his responsibility to the others regarding the proposed construction):

(2) Inspection of const ruction is a difficult code requirement to administer smoothly. If inspection of thermal construction is required, much of the thermal treatment is hidden from inspection after both indoor and outdoor finished surfaces have been installed. It is likewise apparent that building inspectors cannot afford to schedule visits to the job site until the work is ready for inspection. If inspection is required before the insulation is closed in, there might be a considerable time lapse between the call for inspection of the thermal treatment and actual appearance of the inspector on the job site. Some portions of the work are harder to examine physically at the job site, and applicators, being aware of this, may be less diligent in those areas (which are also harder to install properly). So the inspector might gain by a more complete objective inspection through hard copy IRT surveys (if sufficiently accurate) than by trying to physically examine each part of the building. The insulation contractor and others of the builder team might benefit by being able to continue construction without the delay of waiting for inspection. However, if the IRT reveals inadequacies, the builder team might be required to take expensive and troublesome corrective action such as uncover, repair, then recover the work. A practical alternative is to make thermographs when insulation and rough-in mechanical work are all finished, but interior finishes are not yet begun.

(3) Since the cost of an IRT survey of the finished job must be paid for ultimately by the home or building owner, the benefits should be evaluated against practical costs. 
IRT measurement of an individual structure by aerial survey is usually economically impractical. Local topography seldom permits adequate survey from ground for the roof details necessary for adequate inspection. A "boom bucket" is frequently satisfactory and economical for roof survey.

\subsection{POTENTIAL USERS AND USES FOR IRT TECHNOLOGY AND INSTRUMENTATION}

Potential users and uses for IRT technology and instrumentation in the building sector may be found wherever a localized warmer or cooler area exists on the surface of the building. IRT can spot and may even pinpoint the different temperature locations in such situations.

Uses where present instruments, thermal and spatial resolutions and sensitivities of $0.25^{\circ} \mathrm{C}\left(0.45^{\circ} \mathrm{F}\right)$, when operating in an environment ranging from $-15^{\circ} \mathrm{C}\left(+5^{\circ} \mathrm{F}\right)$ to $+55^{\circ} \mathrm{C}\left(+131^{\circ} \mathrm{F}\right)$, are adequate to the job at hand, and where interpretation and utilization are not inhibited by other unresolved factors (discussed in Sections 2.2.1, 2.2.2 and 2.2.3) are listed with their users below. Following that, other potential users and uses will be cited.

\subsubsection{Uses Where Qualitative IRT Results Should be Adequate}

(1) IRT can provide a sales tool to locate and influence existing building owners. Sensitivity of $1.0^{\circ} \mathrm{C}$ outdoors and $3.5^{\circ} \mathrm{C}$ indoors is the minimum acceptable accuracy. Reduction in cost of equipment or service would probably not be of significant influence in determination to use IRT. Potential use rs are: insulation salespersons; storm window and door salespersons; energy conservation salespersons; energy management salespersons; utilities and energy suppliers; heating and cooling equipment controls salespersons; insulating glass salespersons; remodelers; roof replacement salespersons; roof repair salespersons; flashing, gutter and downspout replacement salespersons; weatherstripping salespersons; and caulking salespersons.

(2) IRT can locate potential applications for energy loss reduction. Sensitivity of $1.0^{\circ} \mathrm{C}$ outdoors and $3.5^{\circ} \mathrm{C}$ indoors is the minimum acceptable accuracy. Equipment or service cost reductions would probably stimulate more widespread use. 
Equipment cost under $\$ 5,000$ and service cost under $\$ 25$ would probably find widespread use. A curve breaking sharply at about $\$ 9,000$ for equipment and $\$ 40$ for service seems likely. See Figure 2-2. Potential users are: Owners or operators of large buildings; owners or operators of large numbers of buildings (government, municipal, institutional, corporate, industrial, cooperative, etc.); owners and operators of smaller buildings, including homes.
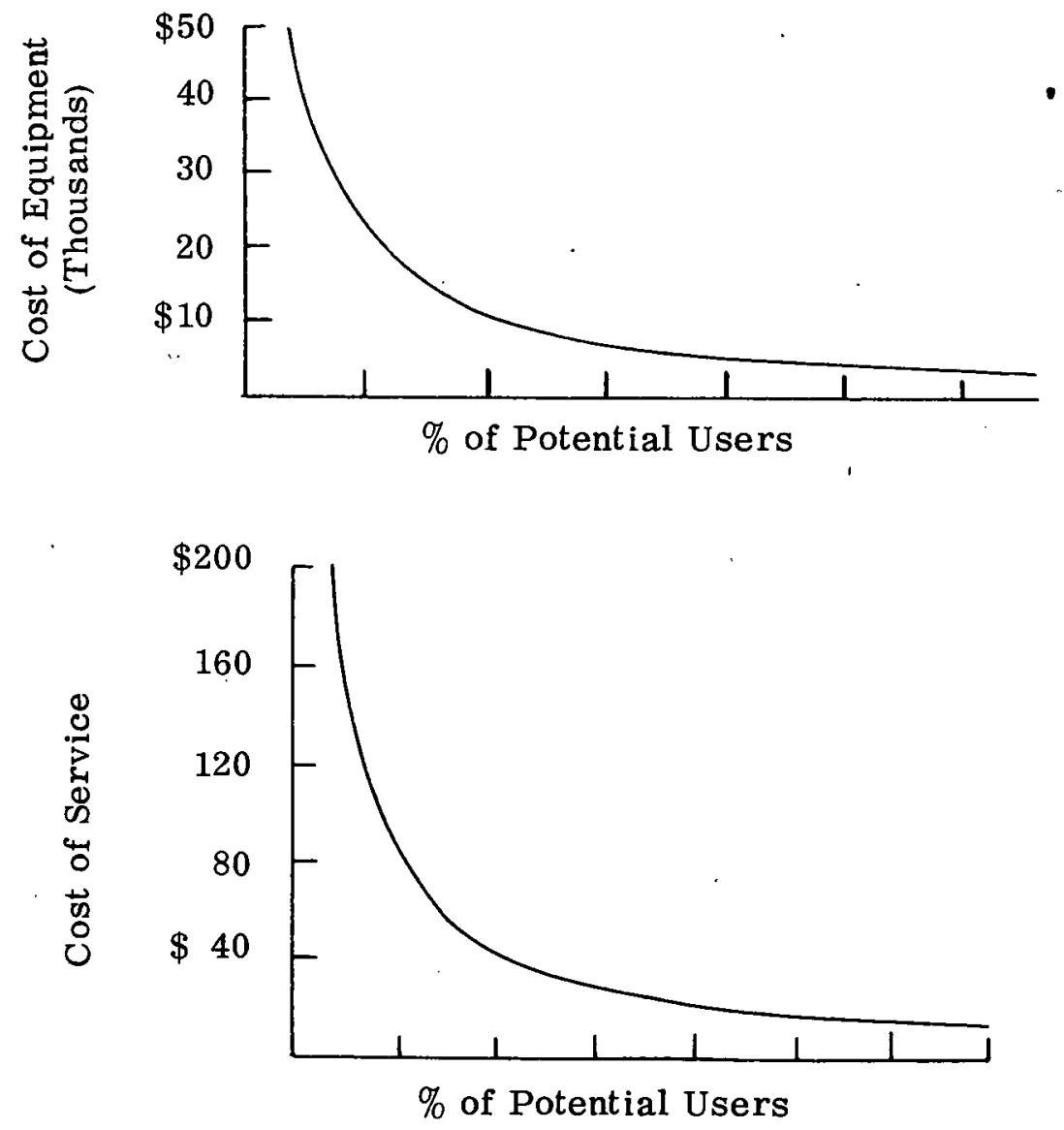

Figure 2-2. Cost Requirements

(3) IRT can demonstrate quality thermal performance in const ruction. Sensitivity of $1.0^{\circ} \mathrm{C}$ outdoors and $3.5^{\circ} \mathrm{C}$ indoors is the minimum acceptable accuracy. Lower limits on sensitivity would be beneficial. Better resolution would be cosmetically beneficial. Potential users are: Insulation subcontractors; home builders; general contractors; window and door assembly (with frame and hardware) manufacturers: remodelers. 
(4) IRT might demonstrate what level of thermal construction exists. Sensitivity of $1.0^{\circ} \mathrm{C}$ outdoors and $3.5^{\circ} \mathrm{C}$ indoors is the minimum acceptable accuracy. Potential users are: Real estate salespersons; appraisers (for loan, insurance, subsidy, welfare); persons qualifying for a preferential utility rate, if applicable; persons qualifying for a higher/lower thermostat setting for winter/summer, if applicable; potential purchasers, lessors or managers of real estate.

(5) IRT can provide information for preliminary evaluation of full-scale models or prototype constructions. Sensitivity of $1.0^{\circ} \mathrm{C}$ outdoors and $3.5^{\circ} \mathrm{C}$ indoors is the minimum acceptable accuracy. Lower limits on sensitivity would be beneficial. Better resolution would be cosmetically beneficial. Potential users are: Architects and engineers involved with design of the building; decision makers for financing, promotion, sale, operation or purchase; suppliers of materials and/or services in const ruction; drapery, blind and curtain salespersons; home builders.

(6) IRT can locate internal sources of heat/cold (radiators, water heaters, coolers, etc.) not insulated from structure or occupied space, but should be. Sensitivity of $1.0^{\circ} \mathrm{C}$ outdoors and $3.5^{\circ} \mathrm{C}$ indoors is the minimum acceptable accuracy. Potential users are: Owners or operators of building; potential purchasers; suppliers of heat/cool source; remodelers.

(7) IRT can locate roof water leaks and (where still wet) follow the water path from each leak to point of emergence from the building. Sensitivity of $1.0^{\circ} \mathrm{C}$ outdoors and $3.5^{\circ} \mathrm{C}$ indoors is the minimum acceptable accuracy. Potential users are: Persons responsible for warranty repairs; owners or operators of building; "bonded roof" or warranty representatives; maintenance supervisors.

(8) IRT might locate insulation damaged from water or other causes. Sensitivity of $1.0^{\circ} \mathrm{C}$ outdoors and $3.5^{\circ} \mathrm{C}$ indoors is the minimum acceptable accuracy. Lower limits on sensitivity would be beneficial. Potential users are: Owners or operators of building; insulation suppliers or applicators; maintenance supervisors; energy management personnel; energy conservation personnel.

(9) IRT can identify opportunities for heat recovery equipment applications. Sensitivity of $1.0^{\circ} \mathrm{C}$ outdoors and $3.5^{\circ} \mathrm{C}$ indoors is minimum acceptable accuracy. 
Lower limits on sensitivity would be beneficial. See Figure 2-2. Potential users are: Heat recovery equipment suppliers; heat recovery system salespersons; owners or operators of the bullding; energy conservation personnel; energy management personnel.

(10) IRT can identify piping, ducts and spaces inadequately insulated from the occupied space or other portions of the building. Sensitivity of $1.0^{\circ} \mathrm{C}$ outdoors and $3.5^{\circ} \mathrm{C}$ indoors is the minimum acceptable accuracy. Potential users are: Insulation salespersons; owners and operators of the building; maintenance personnel; potential buyers; home builders; energy conservation personnel; energy management personnel.

\subsubsection{Uses Where Quantitative Results Would Be Required}

Quantitative results may be required to demonstrate compliance with a specification; with a recommendation on a voluntary basis; or with a code on a mandatory basis. Present IRT technology does not provide sufficiently accurate determinations for pass or fail judgments as has been discussed previously, particularly in Section 2.2. Later discussions will indicate some alternatives to IRT for evaluating quantitative resistances, as well as some possibilites for improving the accuracy of IRT measurements and subsequent calculations by (1) better emissivity data; (2) better air film resistance data; (3) minimizing effects of surrounding emissions; and (4) minimizing effects of solar storage (time lag effect on structure).

To suggest the possibilities if quantitative results were sufficiently accurate, and to indicate the necessary accuracies, the following additional uses are presented:

(11) IRT might, if sufficiently accurate, demonstrate code compliance (or supplement other evidence of compliance). Sensitivity of $0.1{ }^{\circ} \mathrm{C}$ outdoors and $0.35^{\circ} \mathrm{C}$ indoors is the minimum acceptable accuracy. Emissivity within \pm 0.01 is required. Air film within \pm 0.02 outdoors and \pm 0.07 indoors is required. Potential users are: Building contractors; owners or operators of building; architects and engineers of building; code compliance inspectors; energy conservation personnel; energy management personnel. 
(12) IRT might provide a service opportunity for small businesses to be formed or by which to expand. Costs, sensitivity, accuracy and resolution affect the opportunities open to the new business. Potential users are: People who want to own their own business; organizations offering small business assistance.

(13) IRT might provide detailed evaluation of full-scale models or prototype constructions. Sensitivity of $0.1^{\circ} \mathrm{C}$ outdoors and $0.35^{\circ} \mathrm{C}$ indoors is the minimum acceptable accuracy. Emissivity within \pm 0.01 is required. Air film within \pm 0.02 outdoors and \pm 0.07 indoors is required. Potential users are: Architects and engineers involved with design of the building; owners and operators of the building; designers and operators of heating/cooling system; energy conservation personnel; energy management personnel; home builders; general contractors; heating/cooling system suppliers building component suppliers.

\subsection{DEMONSTRATION OPPORTUNITIES}

\subsubsection{Demonstration}

Industry figures contacted for their views on IRT generally knew that infrared thermography was being used for analys is of potential energy conservation measures. Except for those directly involved in supplying the equipment or thermographic services, hardly any really understood the strengths and limitations of IRT. As a result. even among those who have been surprised at the accuracy of thermograms revealing misses in insulation application that "just couldn't have occurred, " there are reservations about endorsement because it is known that there are limitations, though apparently those limitations are not understood.

It is proposed that as soon as practical, steps be taken to accumulate existing usable examples of film sequences (or material convertible to film) showing both thermographs and thermograms in use in the field. Sequences should involve both black and white and color thermography examples. Emphasis should be on demonstration of before and after insulation examples and on good workmanship in new construction, but examples of skips and misses are an essential part of the requirement. It should be borne in mind that every effort should be made to promote an att itude of 
acceptance by workmen for thermography as a demonstrator of their good workmanship rather than a detector of oversights or poor workmanship.

Collected sequences may be put to immediate use in training technicians how to make and interpret thermographs and thermograms. They can also be used in the preparation of a film for general audiences. Starting with groups involved with buildings, the general film audiences are: Contractors; mortgage lenders; code writers; code enforcers; apprentices; energy suppliers; building maintenance personnel; building material suppliers; building management personnel; heating/cooling equipment suppliers; building operation personnel; real estate salespersons; public relations personnel; journeymen, marketing personnel; home builders; students.

The other end of the range of users for the film demonstration includes those relatively least involved with buildings: Social organizations; service organizations; young married groups; Boy Scouts; Over 30's clubs; future farmers; Four-H clubs; fraternal organizations; professional organizations; senior citizen organizations; Golden Age clubs; trade groups; singles clubs; Girl Scouts; Explorers; Over 40's clubs.

The film should be instructive, entertaining, and capable of being understood by persons twelve years of age and older.

Inquiries have indicated most service organizations and manufacturers from the IRT indust ry would be most cooperative in loaning material they have available, and perhaps in assisting in development of more. Other forms of demonstration have been considered, and will be discussed in more detail when significant input to this phase of the work has been experienced. It appears at this time that this proposed demonstration would be more effective in all respects, and most significantly more cost effective, than any other form of demonstration considered.

\section{5 .2 Development}

Establish guidelines for training and licensing or certifying proficiency, or otherwise qualifying that certain technicians are capable and objective. By selection of the range of temperature and the base temperature of that range, thermograph results can be slanted very significantly whatever way the operator decides to slant 
them. In the interpretation of the results there are even greater opportunities for distortion. A required level of instruction plus test of performance to ensure a specified level of competence in operation of equipment and interpretation of results would seem to be desirable. Potential sponsors and operators for such a development are numerous among several different groups of trade or professional organizations, educational institutions, non-profit or not-for-profit organizations or a combination from among them. A new organization formed for the purpose is yet another possibility. This proposed development should (like the proposed Demonstration) be started as soon as practical. A most urgently needed part of the instruction is a clear demonstration to the technician of the misleading effects that can come from:

(1) Solar effects, often extending beyond 5 to 8 hours after the sun is no longer shining on the test area.

(2) A mbient radiation, the reflection of which is added to the radiation emitted from the test surface.

(3) Use of inaccurate emissivity of the surface being tested in calibration of the system and in interpretation of results.

(4) Use of inaccurate air film values in the interpretation of results.

\subsubsection{Improvement}

Improve accuracy of determination of air leakage loads. Because air leakage (infiltration from natural causes) and net ventilating losses are inexactly treated in the professional literature, there is an urgent need for a good, rational, realistic and accurate means of evaluating outdoor air loads. This might involve the use of IRT in conjunction with other technologies, if IRT techniques alone are not made sufficiently accurate.

\subsubsection{Development}

For a given indoor temperature, together with a given outdoor temperature and specified outdoor wind condition, a chart can be prepared showing the approximate 
outdoor surface temperature and corresponding heat losses for assumed air films, assumed emissivities and various total resistances. The $R_{T}{ }^{\prime}$ s chosen should include several across a broad spectrum, and all "code compliance" levels.

\subsubsection{Measurement}

Existing measurement technology appears adequate for qualitative work. From indoors, with 30 degrees or more difference between indoor and outdoor temperatures, IRT can discriminate within $10 \%$ (for example, identifying as a difference, an R-i wall compared to an R-20 wall). It is believed the quant it ative possibilities could be materially improved by planting a temperature-controlled "standard" of known emissivity (at target area, subject to wind and ambient conditions of the target). When the temperature of the standard is controlled to the temperature of concern in the target, the resultant data may permit a more accurate determination of the target emissivity and of the film resistance for both "standard" and target. Investigation of these possibilities for making outdoor measurements approach the accuracy of indoor measurements would appear worthwhile.

\subsubsection{Determination}

What seems to be the most popular IRT instrument in use operates by detecting a wavelength range of emissions of 2 to $5.6 \mu \mathrm{m}$. Ordinary window glass is somewhat transparent to some of these wavelengths, so the detector "sees" the surface of inside partitions of the room as well as the outside surface of the glass. Air is nearly opaque to part of this band; therefore that portion of the emission is absorbed by the air before reaching the detector.

Other equipment is operated successfully at 8 to $11 \mu \mathrm{m}$, at 8.2 to $9.3 \mu \mathrm{m}$, and at 10.4 to $12.5 \mu \mathrm{m}$. The pros and cons of the various wavelength bands should be explored from equipment use and from the interpretation viewpoint to illuminate factors affecting possible chcices. 


\subsubsection{Alternative Methods}

Alternative methods of measuring indoor and outdoor surface temperatures may show methods for improving accuracy or reducing cost of equipment and/or use of equipment for objectives desired. Touch pyrometers, noncontact portable infrared thermometers, line scan cameras, or other devices may be used to quantify the various areas which the thermographs have identified qualitatively but cannot adequately quantify with sufficient accuracy. Investigation of possible alternatives to replace or supplement IRT may prove fruitful.

\subsubsection{Cost Reduction}

Cost reduction (unit cost for a thermographic analysis) appears likely with increased volume of work and additional "competitors" in the field. The impact on the IRT industry and upon users of IRT, due to cost reductions, should be determined.

\subsubsection{Demonstrations}

Demonstrations of faults in thermal. system applications not available from examples already filmed (or filmed in the process of items discussed earlier) should be built into a construction; definitive photographs, thermographs and thermograms of those particular defects should be made for later use and reference. After they are duly reproduced on film, it is believed the defects could well be discarded. The advantages of readily portable filmed examples are believed to make holding of building sections with actual defects available for demonstration unnecessary.

\subsubsection{Investigation}

Some very real benefits may be possible from analysis of various building types one, two and three years after construction is completed. Such analysis can reveal what thermal leaks, if any, develop that were not there at time of completion. Measures to be taken during construction to combat development, or inc rease in heat leaks later, can be developed as a result of such studies. Whether corrective action on the building studied is practical would be decided based on analysis of the individual building. The real benefit from the study would be recommendations developed for construction practices to minimize thermal effects from aging of buildings. 


\section{SECTION 3 TECHNIQUES OF ANALYSIS}

A primary performance parameter characterizing an IR imaging system is the thermal resolution observed on the display. Thermal resolution may be defined in several ways. In the practical usage of IR thermography it is the minimum temperature difference between two adjacent objects (or resolution elements) that is discernible by an observer looking at the display. It is in part, then, subject to the observer's subjective observation of the displayed scene. A more quant itative measure treats the video signal and defines thermal resolution as noise equivalent temperature for a signal-to-noise of unity. The latter is useful to define range limitation with respect to minimum signal. We are not faced generally with this situation in IR building thermography and will then forego a signal-to-noise analysis of IR inst ruments. The practical significance of this is that, for the most part, manufacturers' data only exist in terms of the resolvable temperature at the display thus precluding a more rigorous . quantitative evaluation of thermal resolution.

It will be necessary, however, to consider environmental effects on the accuracy of temperature measurements. Manufacturers' specifications usually lump accuracy and thermal resolution together to provide one number that does not differentiate between the two. It is a number that describes the inst rument's ability to resolve two objects of known temperature difference with all other radiation and transmission parameters being equal. In order to measure temperature gradients of an unknown source it will be necessary to account for the effect of all other parameters that give rise to measured radiation variance. Incorrect handling of radiation parameters will give rise to temperature measurement errors.

Table 3-1 depicts the nature of the problem by showing a form of a temperature error budget. Manufacturers generally describe their total instrument error as Item $B$. This is very reasonable because any further consideration must take into account the specific application.

The application of IR instruments for temperature gradient evaluation of buildings requires that the parameters shown in Item $\mathrm{A}$ be accounted for. Any uncertain- 
Table 3-1. Component Temperature Error Source

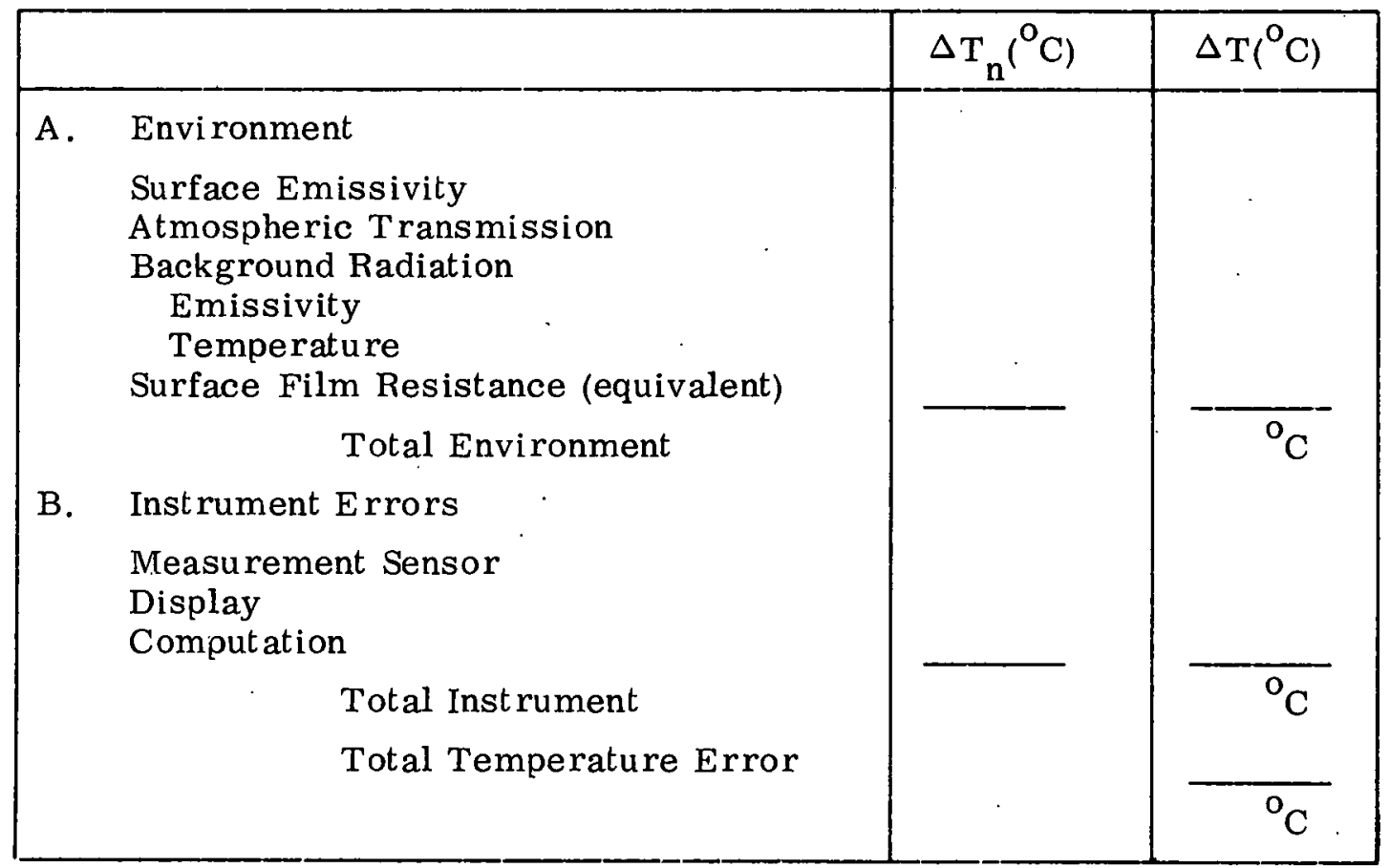

ties in the knowledge of (or compensation for) these parameters will give rise to temperature measurement errors even if the instrument, ideally, had no errors or limitations. Temperature measurement errors consist of the sum of Items A and B in Table 3-1. If the instrument errors are small with respect to the environmental errors, then the application is environmentally limited. Temperature measurement accuracy can be improved only by better knowledge of (and compensation for) environmental parameters. Alternatively, for a given environmental situation instrument errors need only be as good as the environmental application. Better instruments only give greater accuracy to a bad measurement and at increasing instrument cost.

The analysis below shows in fact that building thermography is environmentally limited. The remaining portion of Section 3 evaluates the environmental errors from an analytic standpoint. It will become clear that a measurement-program will be necessary to validate the numbers that were used. 


\subsection{RADLATION FORMULA}

An IR radiometer measures the amount of energy in its field of view that is incident on the instrument and that falls within the spectral passband of the instrument. This situation is illustrated by Figure 3-1.

At any instant of time there is a focal plane resolution elemental area, $A_{D}$, that subtends a small surface object target area, $\Delta A$, at a stand-off range, $R$. The complete IR picture is the composite of all adjacent elemental areas derived either by two-dimensional mechanical scanning of a single detector element, one-dimensional mechanical scan of a line array of detectors or electronic scan such as in an IR vidicon. This is not of great significance to the user. It is of importance, however, to an understanding of that which is measured.

An IR radiometer measures incident energy, $\left(\mathrm{H}_{\mathrm{D}}\right)$, or the radiation, (W), from an object that is focused in the focal plane. It does not measure temperature except as it may be derived from a temperature measurement. The superficial use of an IR radiometer to measure temperature follows from the Stefan-Boltzman blackbody radiation law that states that an object at temperature $\mathrm{T}$ has a total radiation expressed as $\mathrm{W}=\sigma \mathrm{T}^{4}$ watts per square $\mathrm{cm}$ of radiation surface where $\sigma=(5.6686) 10^{-12}$ watts $\mathrm{cm}^{-2} \cdot \mathrm{deg}^{-4}$ is the Stefan-Boltzman constant and $\mathrm{T}$ is expressed in degrees Kelvin.

If, in Figure $3-1$, the object plane resolution element size is $\Delta \mathrm{A} \mathrm{cm}{ }^{2}$, then the radiation that is imaged on the focal plane is

$$
\mathrm{W}=\sigma \Delta \mathrm{AT}^{4}
$$

The radiometer, in this case, measures temperature directly. Since, however, the radiometer only receives a portion of the energy that is radiated, it is necessary to have an even more detailed description of the problem.

If the radiation surface is lambertian, then the blackbody radiation is given as

$$
\mathrm{W}=\frac{\sigma \mathrm{T}^{4}}{\pi} \frac{\text { watts }}{\mathrm{cm}^{2} \mathrm{sr}} .
$$




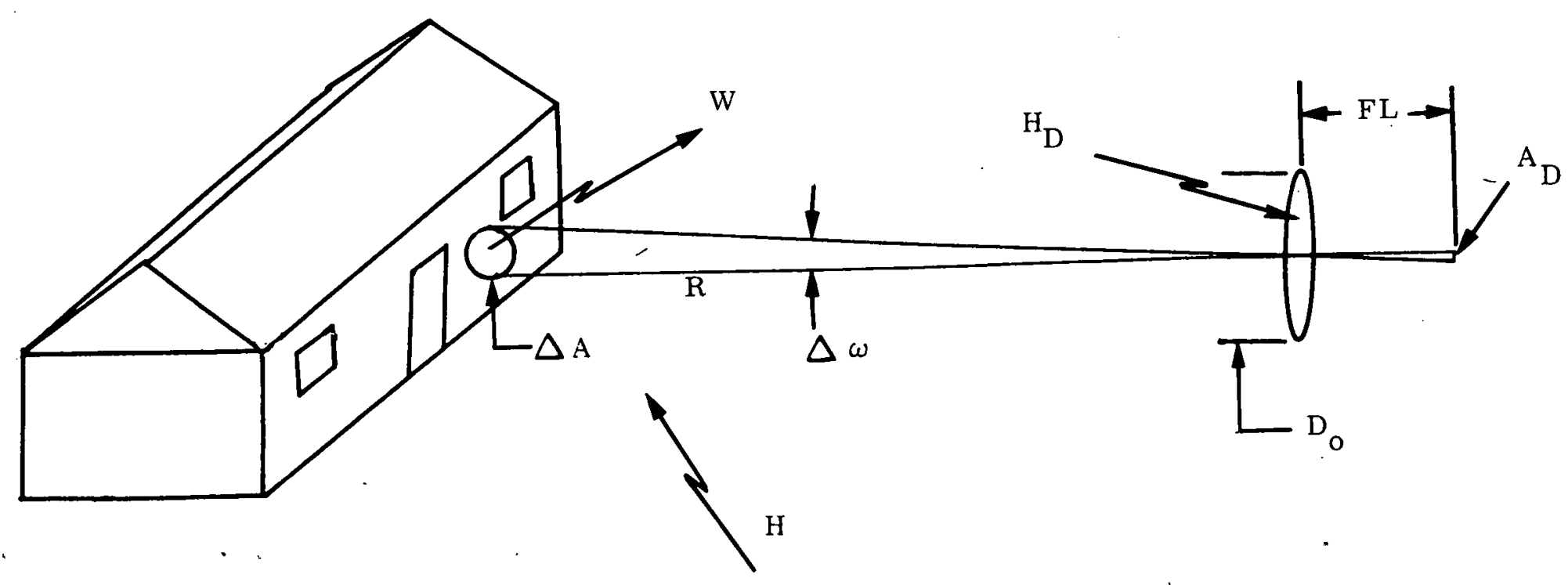


The optical instrument subtends the solid angle (as seen from the source)

$$
\frac{\mathrm{A}_{\mathrm{O}}}{\mathrm{R}^{2}}=\frac{\pi \mathrm{D}_{\mathrm{O}}^{2}}{4 \mathrm{R}^{2}} \mathrm{sr}
$$

where $A_{0}$ is the optical lens area of diameter $D_{0}$.

If the atmospheric transmission coefficient is $\tau_{a}$, average over the blackbody and instrument spectrum and the instrument optical transmission is $\tau_{0}$, then the energy that is incident at the focal plane from a blackbody radiator of area $\Delta A$ is

$$
\mathrm{H}_{\mathrm{D}}=\left(\frac{\sigma \mathrm{T}^{4}}{\pi} \frac{\mathrm{watts}}{\mathrm{cm}^{2} \mathrm{sr}}\right)\left(\Delta \mathrm{Ac \textrm {cm } ^ { 2 }}\right)\left(\tau_{\mathrm{a}}\right)\left(\frac{\pi \mathrm{D}_{\mathrm{o}}^{2}}{4 \mathrm{R}^{2}} \mathrm{sr}\right) \tau_{\mathrm{o}}
$$

The instantaneous field of view of the radiometer $\Delta \omega$ is a design fabrication characteristic of the particular instrument which can be expressed as

$$
\Delta \omega=\frac{{ }^{A} \mathrm{D}}{(F L)^{2}}=\frac{\Delta \mathrm{A}}{\mathrm{R}^{2}}
$$

where $F L$ is the instrument focal length.

Whence

$$
\begin{aligned}
\mathrm{H}_{\mathrm{D}} & =\frac{\sigma \Delta \omega \tau \mathrm{a}^{\top} \mathrm{o}_{\mathrm{o}}^{2}}{4} \mathrm{~T}^{4} \\
& =\mathrm{KT}^{4},
\end{aligned}
$$

if $\Delta \omega, \tau_{\mathrm{a}}^{\prime}, \tau_{\mathrm{o}}$ and $\mathrm{D}_{\mathrm{o}}$ are all known constants over the spectral passband of the detector. 
The radiometer then gives a measure of the object plane temperature when properly calibrated, but with an accuracy determined by the error in the knowledge of the atmospheric transmission and the extent to which the object surface departs from a blackbody radiator.

There are other physical facts that cloud these considerations to an even greater extent. To the extent that the object surface is not a perfect blackbody radiator, it is described as

$$
W \neq \sigma \mathrm{T}^{4}
$$

but,

$$
\mathrm{W}=\sigma \in \mathrm{T}^{4}
$$

where $\epsilon$ is the emissivity. The processes of absorptivity $(\alpha)$, reflectivity $(\rho)$ and transmission $(\tau)$ now must be accounted for according to the expression

$$
\alpha+\rho+\tau=1 \text {. }
$$

For an opaque wall, $\tau=0$ whence

$$
\alpha+\rho=1
$$

Kirchoff's radiation law states that the absorptivity equals the emissivity, $\alpha=\epsilon$, whence

$$
\rho=1-\epsilon \text {. }
$$

An object of emissivity $\epsilon$ then has self-radiation and also reflects the radiation of surrounding s.ources. Rather than using Equation (2), it is more descriptive to note that the element at area $\Delta \mathrm{A}$ in Figure 3-1 radiates 


$$
\mathrm{W}=\sigma\left[\epsilon_{\mathrm{S}} \mathrm{T}^{4}+\left(1-\epsilon_{\mathrm{S}}\right) \int_{\Omega} \epsilon_{\mathrm{A}} \mathrm{T}_{\mathrm{A}}{ }^{4}\right]
$$

per normal steradian for surface emissity $\left(\epsilon_{S}\right)$ and temperature $\left(T_{S}\right)$.

The hemispherical solid angle integral in Equation (3) is a representation of the nonuniform background consisting of buildings, trees, ground and sky, each component with its own emissivity $\left(\epsilon_{A}\right)$ and temperature $\left(\mathrm{T}_{\mathrm{A}}\right)$ plus reflectivity contribution. Temperature, $\mathrm{T}_{\mathrm{A}}$, of each radiating object may differ from the atmospheric ambient temperature that is used in computing the thermal resistance of the wall. If we equate the sold angle integral to an equivalent average, $\epsilon_{A}$ and $T_{A}$, then Equation (3) may be written as

$$
\mathrm{W}=\sigma\left[\epsilon_{\mathrm{S}} \mathrm{T}_{\mathrm{S}}^{4}+\left(1-\epsilon_{\mathrm{S}}\right) \epsilon_{\mathrm{A}} \mathrm{T}_{\mathrm{A}}^{4}\right]
$$

which should be used for the generation of Equation (1) rather than the simple expression

$$
\mathrm{W}=\sigma \epsilon_{\mathrm{S}} \mathrm{T}_{\mathrm{S}}^{4}
$$

If Equation (4) is not handled properly; then the radiometer, by using Equation (1), gives a measured temperature $T_{M}$ ? shown plotted in Figure 3-2 as a function of $\epsilon_{A}$ for a value of $\mathrm{T}_{\mathrm{S}}=300^{\circ} \mathrm{K}$ and $\epsilon_{\mathrm{S}}=0.85 . \mathrm{T}_{\mathrm{S}}$ can be determined from a knowledge of $\mathrm{T}_{\mathrm{N} \text {. }}$ if the other parameter values are known. Otherwise there is a measurement error

$$
\Delta \mathrm{T}=\mathrm{T}_{\mathrm{M}}-\mathrm{T}_{\mathrm{S}}
$$




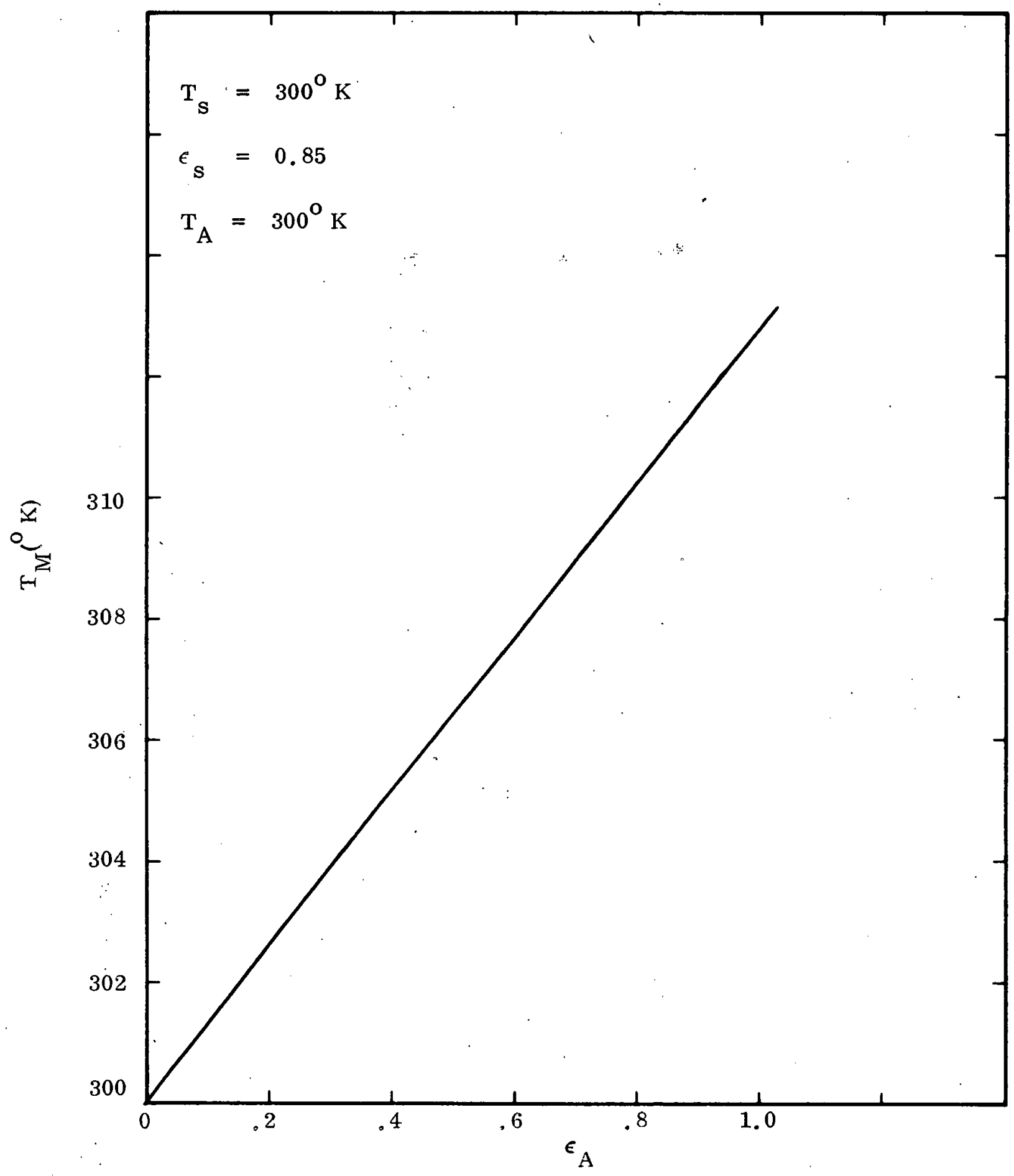

Figure 3-2. Measured Surface Temperature vs $\epsilon_{A}$ 


\subsection{SPECTRAL EFFECTS}

A far greater problem in using a radiometer to determine temperature, however, lies in proper handling of the spectral characteristics of each parameter. Use of the equation $\mathrm{W}=\sigma \epsilon \mathrm{T}^{4}$ implies spectral independence of the other variables, for example, as depicted in Figure 3-3. Actually,

$$
\mathrm{W}=\sigma \mathrm{T}^{4}=\int_{0}^{\infty} \mathrm{W}(\lambda, \mathrm{T}) \mathrm{d} \lambda
$$

where $W(\lambda, T)=\frac{2 \pi c^{2} h}{\lambda^{5}}\left(e^{h c / \lambda k T}-1\right)^{-1}$ with the expression and constants described as Planck's radiation law. Plank's expression must be used if there is any element in the problem that has spectral limitations or significance. The use of Equation (1), for example, implies that the spectral response of the detector element is extremely wide-theoretically infinite. This is far from the case. It will be seen below that the form of Equation (1) that must be considered is

$$
\mathrm{H}_{\mathrm{D}}=\int \frac{\mathrm{W}_{\lambda}}{4} \tau_{\mathrm{a}}(\lambda) \tau_{\mathrm{o}}(\lambda) \mathrm{R}(\lambda) \mathrm{D}_{\mathrm{o}}^{2} \Delta \omega \mathrm{d} \lambda
$$

where

$$
\mathrm{W}_{\lambda}=\epsilon_{\mathrm{S}}(\lambda) \mathrm{W}\left(\lambda, \mathrm{T}_{\mathrm{S}}\right)-\left[1-\epsilon_{\mathrm{S}}(\lambda)\right] \epsilon_{\mathrm{A}} \mathrm{T}_{\mathrm{A}}^{4}
$$

and $R(\lambda)$ is the detector spectral response to the extent that the background can still be represented by a spectrally independent uniform background. $\tau_{0}$ and $\mathrm{R}$ both are characteristics of particular inst rumentation.

The need for spectral considerations begins with atmospheric transmission. Figure 3-4 shows transmission over a $300 \mathrm{~m}$ path ${ }^{1}$. The four atmospheric transmission windows are clearly seen: $\overline{1}$ "Handbook of Military Infrared Technology, " Office of Naval Research, Washington,
D.C., 1965 . 


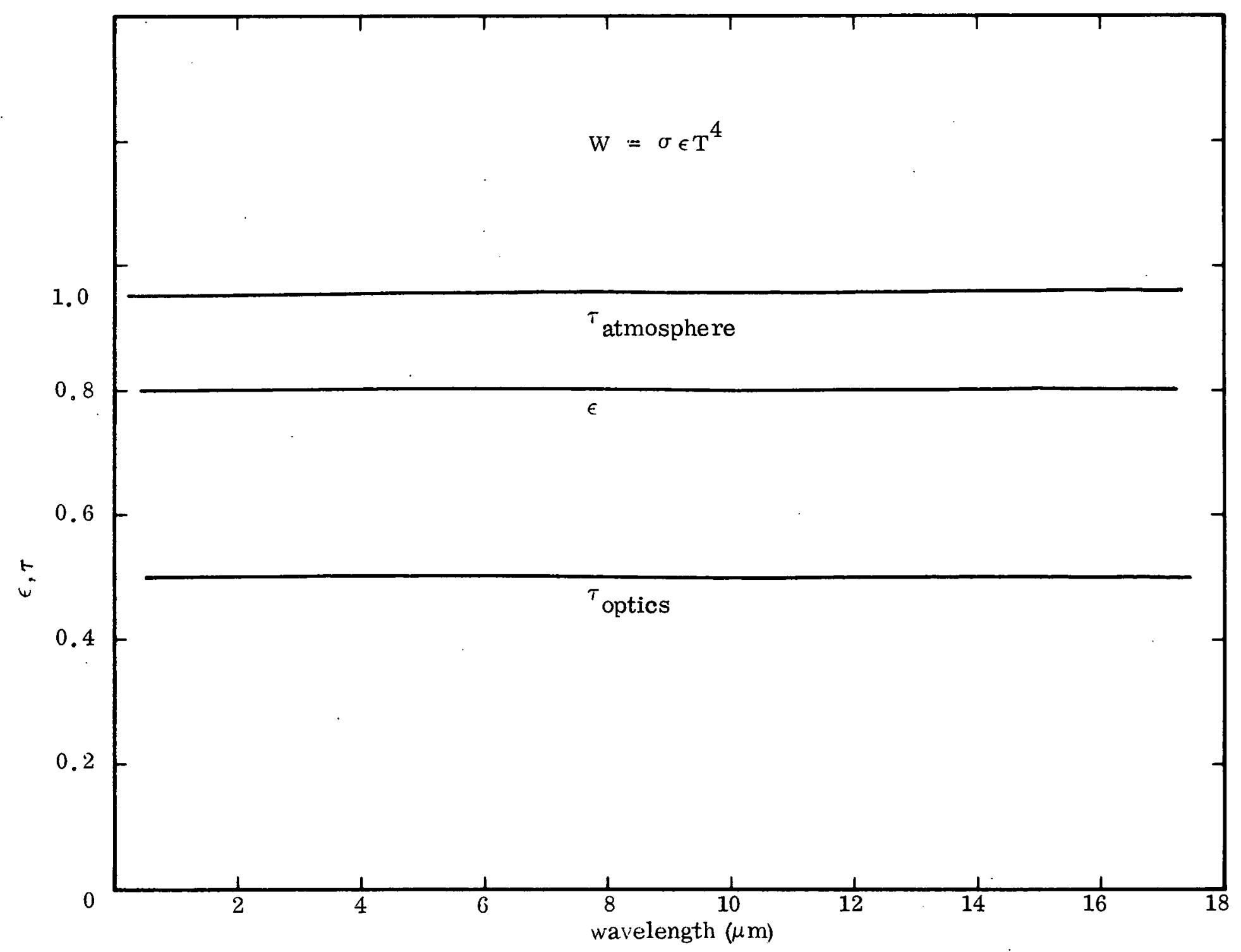

Figure 3-3. Requirements for Use of Stefan-Boltzman Radiation 

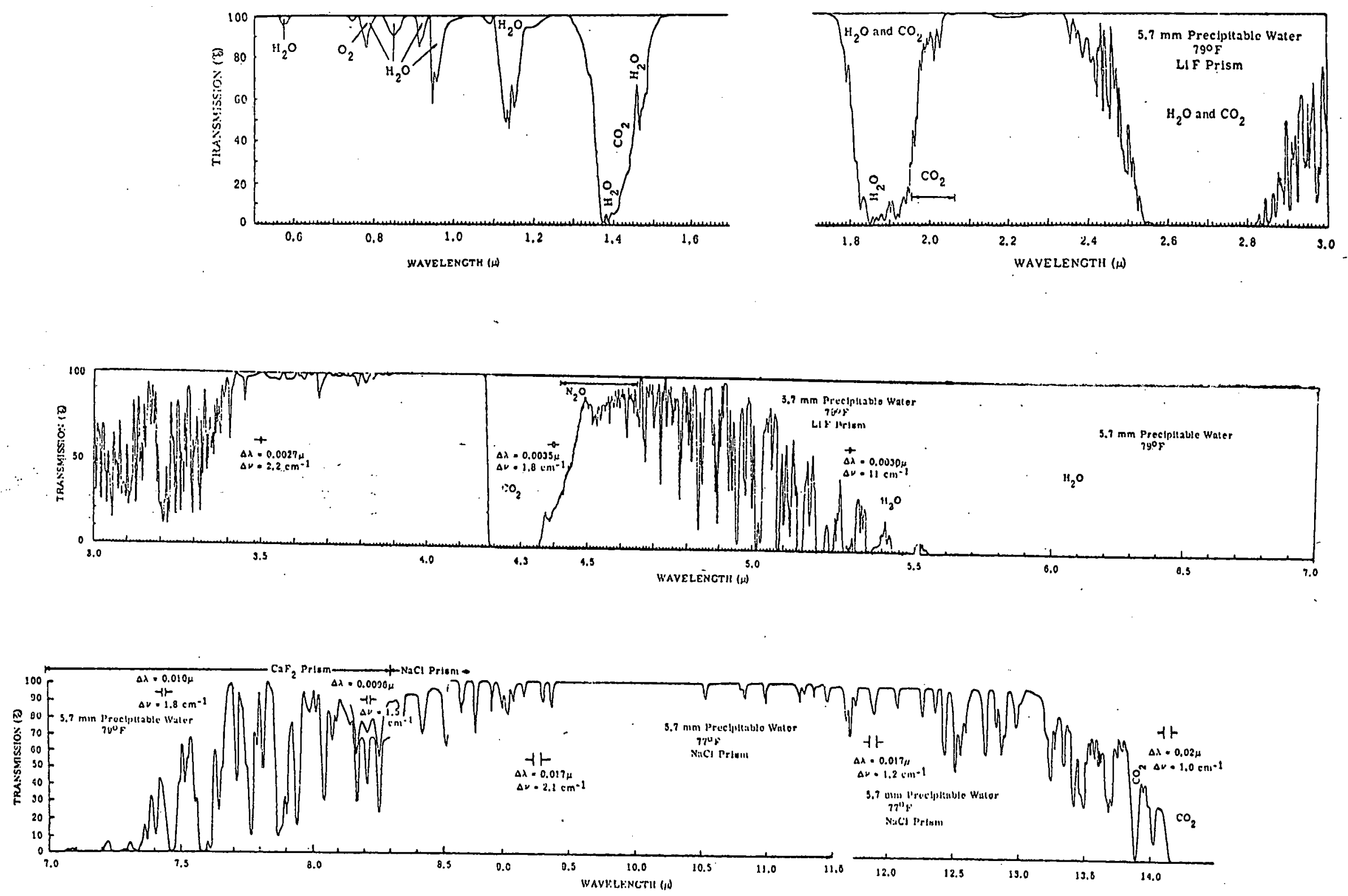

$\stackrel{0}{1}$

Figure 3-4. Atmospheric Transmission, $300 \mathrm{~m}$, Sea Level Path 
1. Visible out to the very near IR $(1.2 \mu \mathrm{m})$

2. 2 to $2.5 \mu \mathrm{m}$

3. 3 to $5.5 \mu \mathrm{m}$

4. 8 to $14 \mu \mathrm{m}$.

For purposes of thermal imagery the last two IR bands are of the most interest. Figures 3-5 and 3-6 show the energy in the midwave IR (MWIR) band ( 3 to $5.5 \mu \mathrm{m}$ ) and in the long wave IR band. At room temperatures, $2 \%$ of the blackbody energy lies in the MWIR band and 25\% in the LWIR band (neglecting the effects of atmospheric attenuation).

Ground-based thermal imaging of buildings will take place at ranges of the order of $40 \mathrm{~m}$. A better representation of atmospheric transmission is shown in Figure 3-7 for meteorological visibility of $5 \mathrm{~km}$. Figure 3-8 shows a computergenerated plot of the atmospheric transmission in the 2.5 to $6.5 \mu \mathrm{m}$ found at sea level distances of $10,20,30$ and 40 meters $^{1}$. At these short ranges the transmission is still very nonlinear in the 3 to $5.5 \mu \mathrm{m}$ band and is spectrally flat in the 8 to $14 \mu \mathrm{m}$ band.

The integrated effect of the atmospheric transmission is to create an effective or equivalent uncertainty in surface emissivity as described below. The magnitude of the uncertainty may be such as to result in an equivalent temperature measurement error of $0.62^{\circ} \mathrm{C}$ in the 3 to $5.5 \mu \mathrm{m}$ band. If temperature measurements are to be made within an error uncertainty of 0.1 to $0.35^{\circ} \mathrm{C}$ for quantitative purposes, then some deterministic compensating factor must be found. The most straightforward approach is to make the measurements in the 8 to $14 \mu \mathrm{m}$ band. This certainly minimizes the atmospheric transmission problem.

Atmospheric transmission in the 5 to $7 \mu \mathrm{m}$ region of the IR spectrum is strongly dependent on water content. Figure 3-9 shows water vapor concentration derived and extrapolated from the AFCRL Handbook of Geophysics and Space Environment (1965). Water content is low at the low ambient temperatures where outside thermography normally is done.

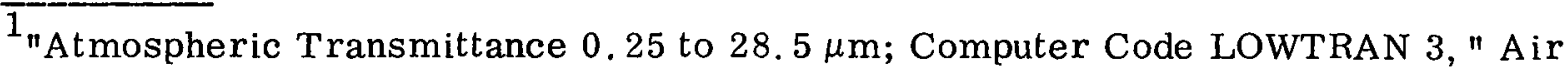
Force Cambridge Research Laboratories; 7 May 1975.
} 


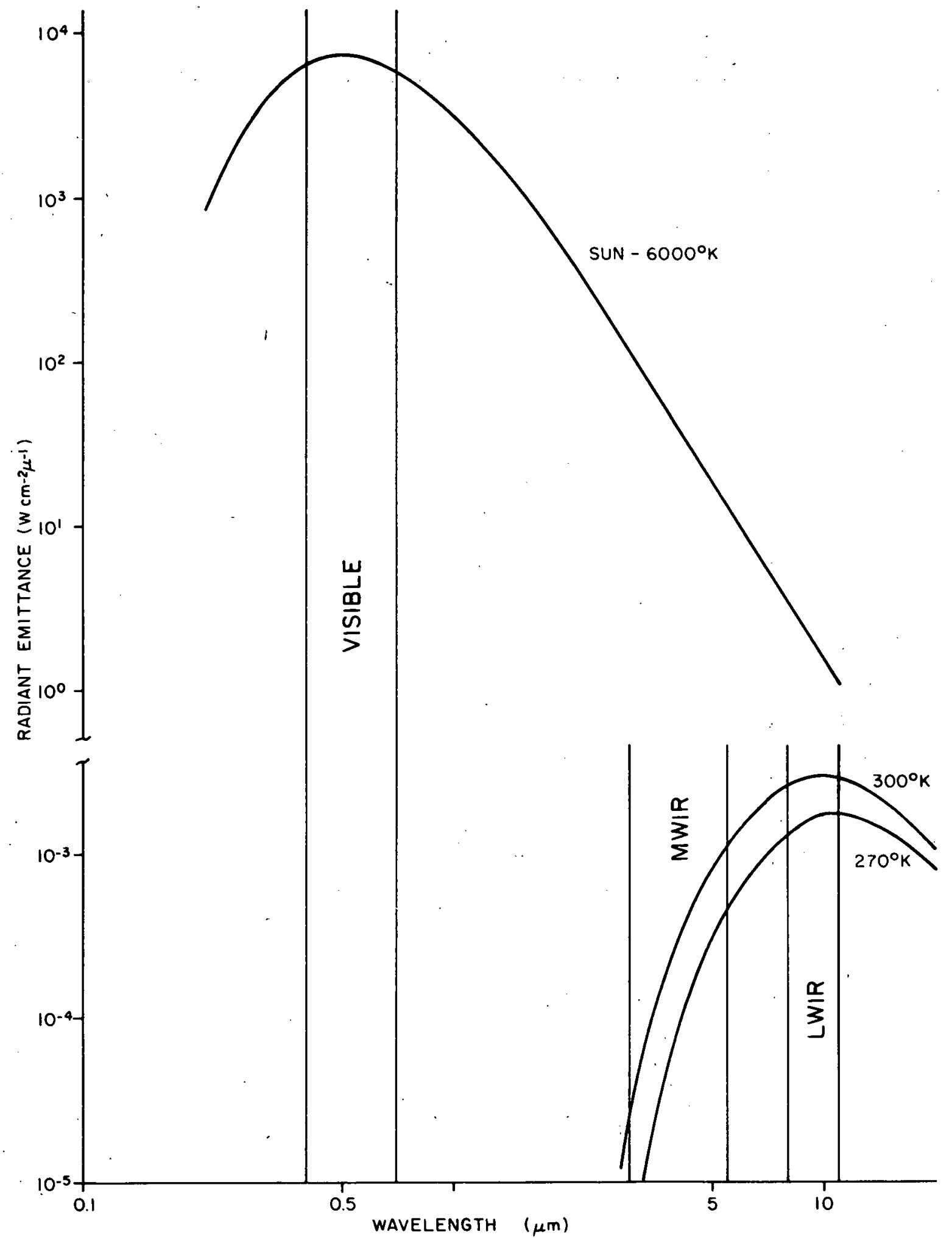

Figure 3-5. Spectral Radiant Emittance of a Blackbody 


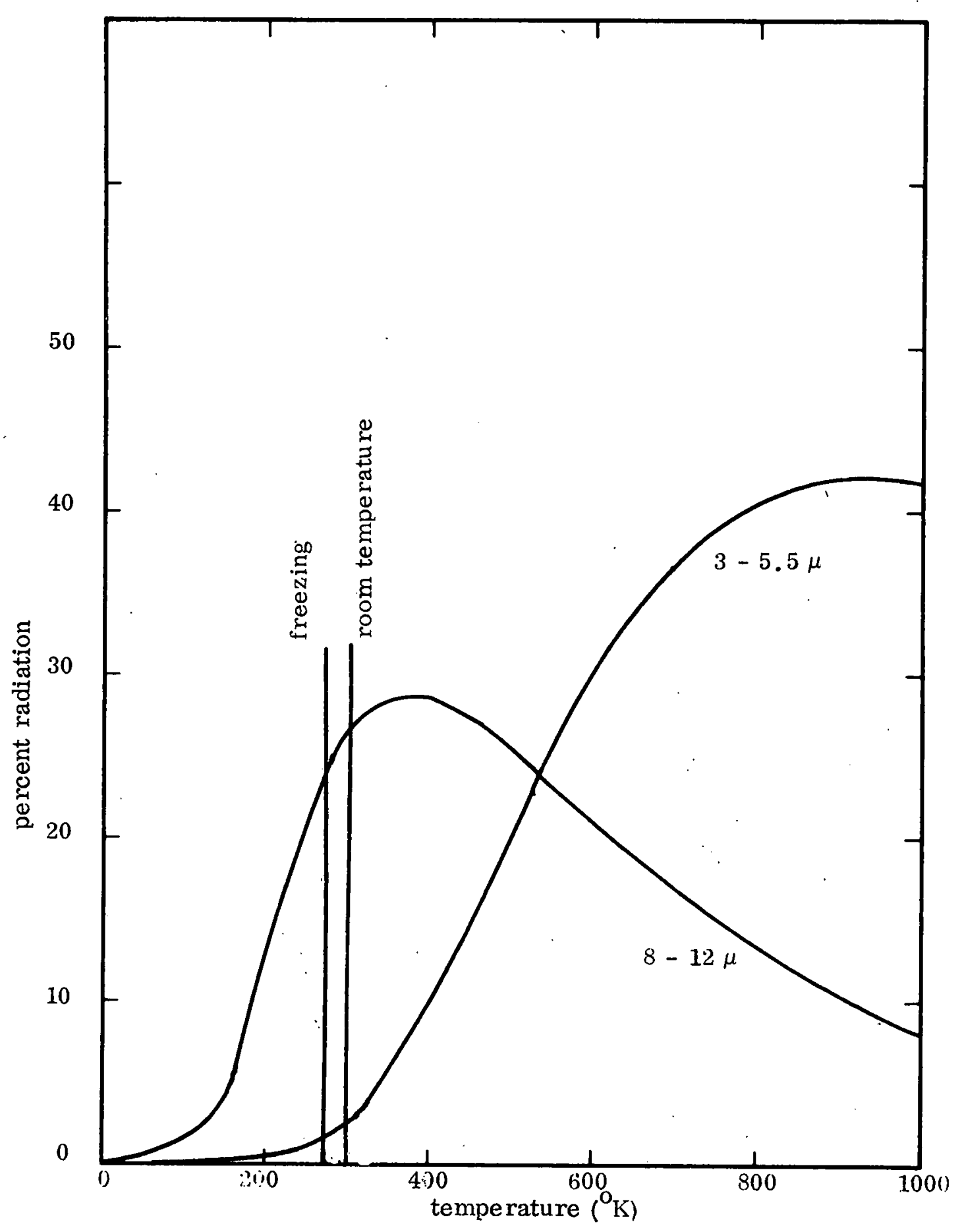

Figure 3-6.: ' Image Band Fractional Radiation 


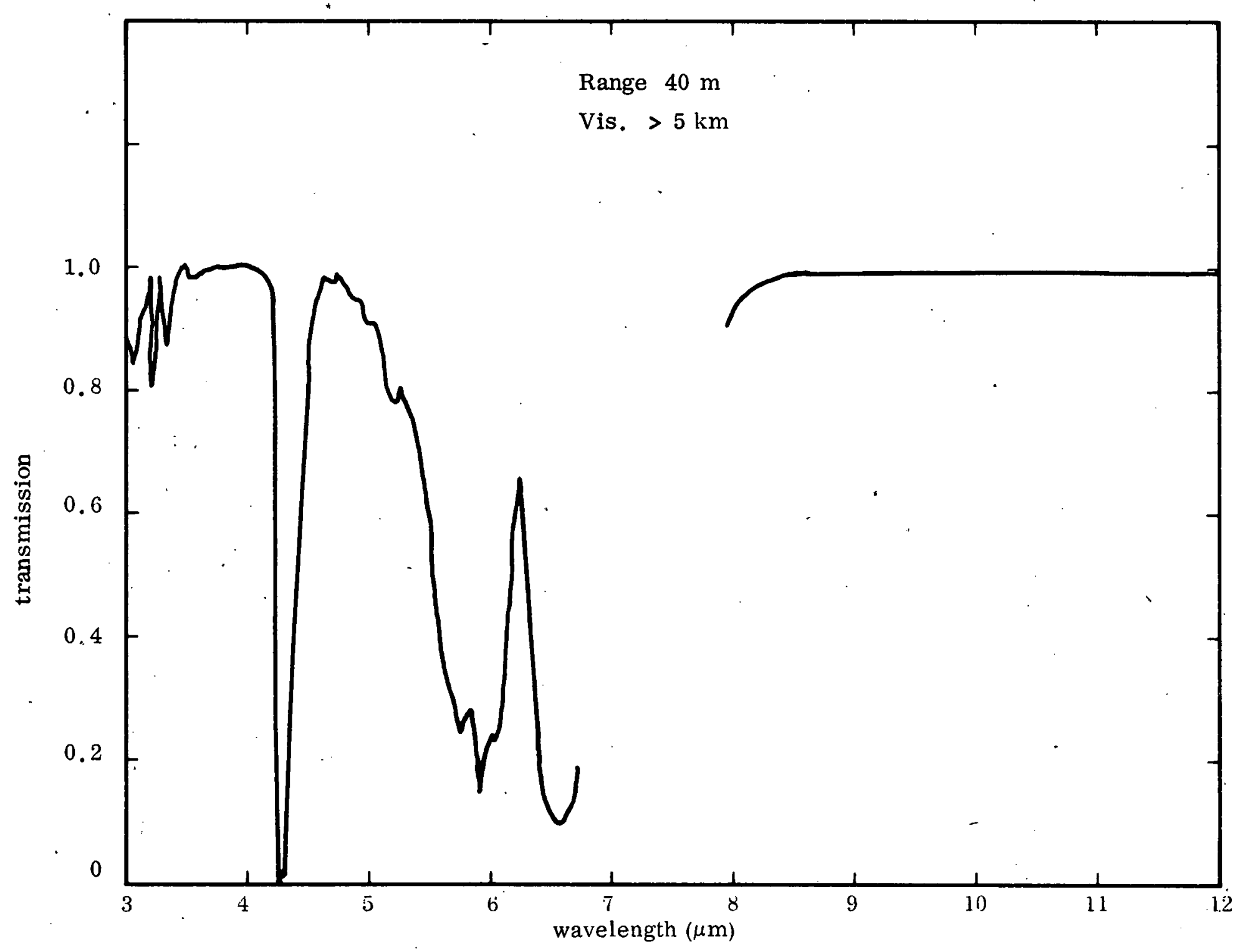

Figure 3-7. Atmospheric Transmission, Midlatitude, Winter, Sea Level 


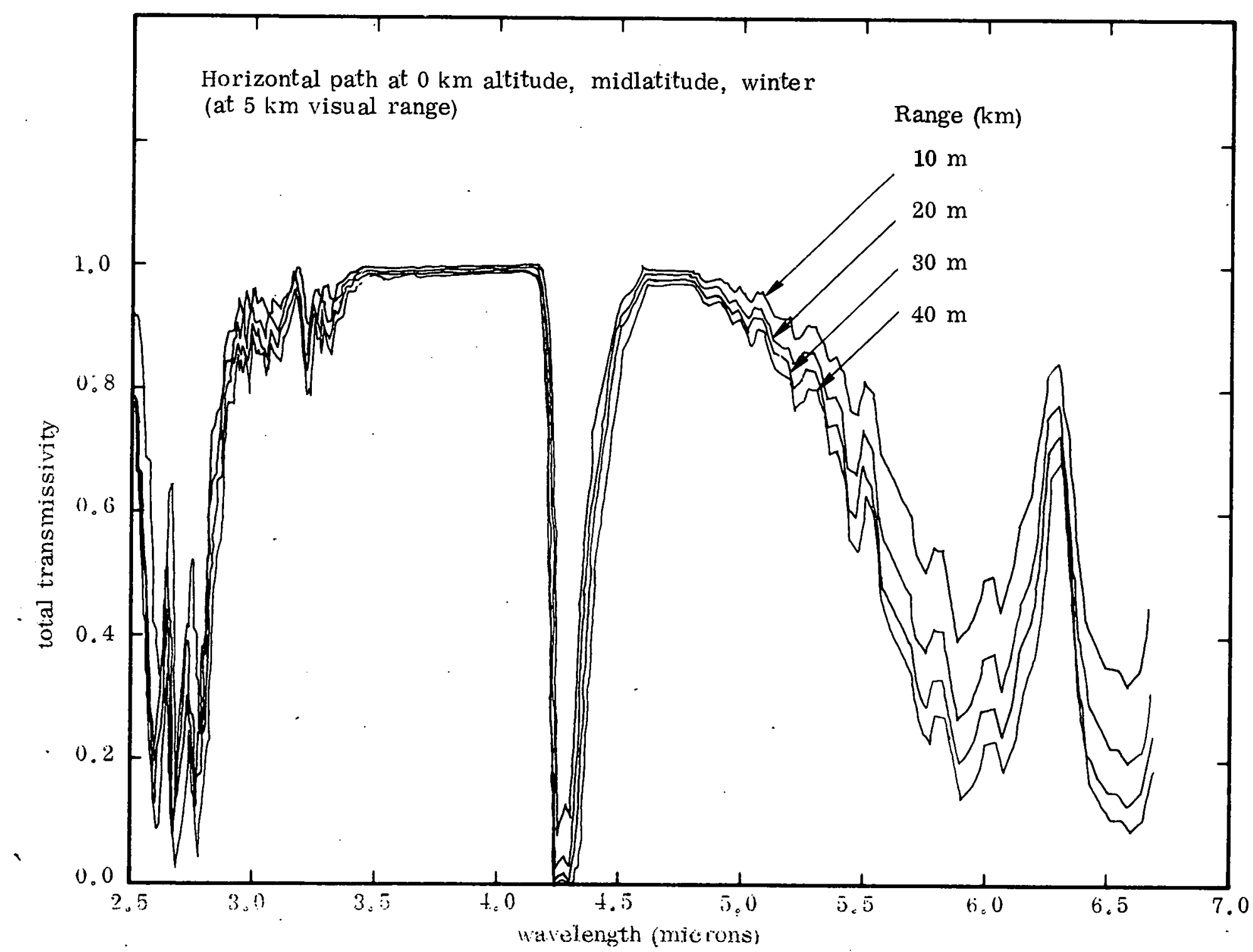

Figure 3-8. Atmospheric Transmissivity vs Range 


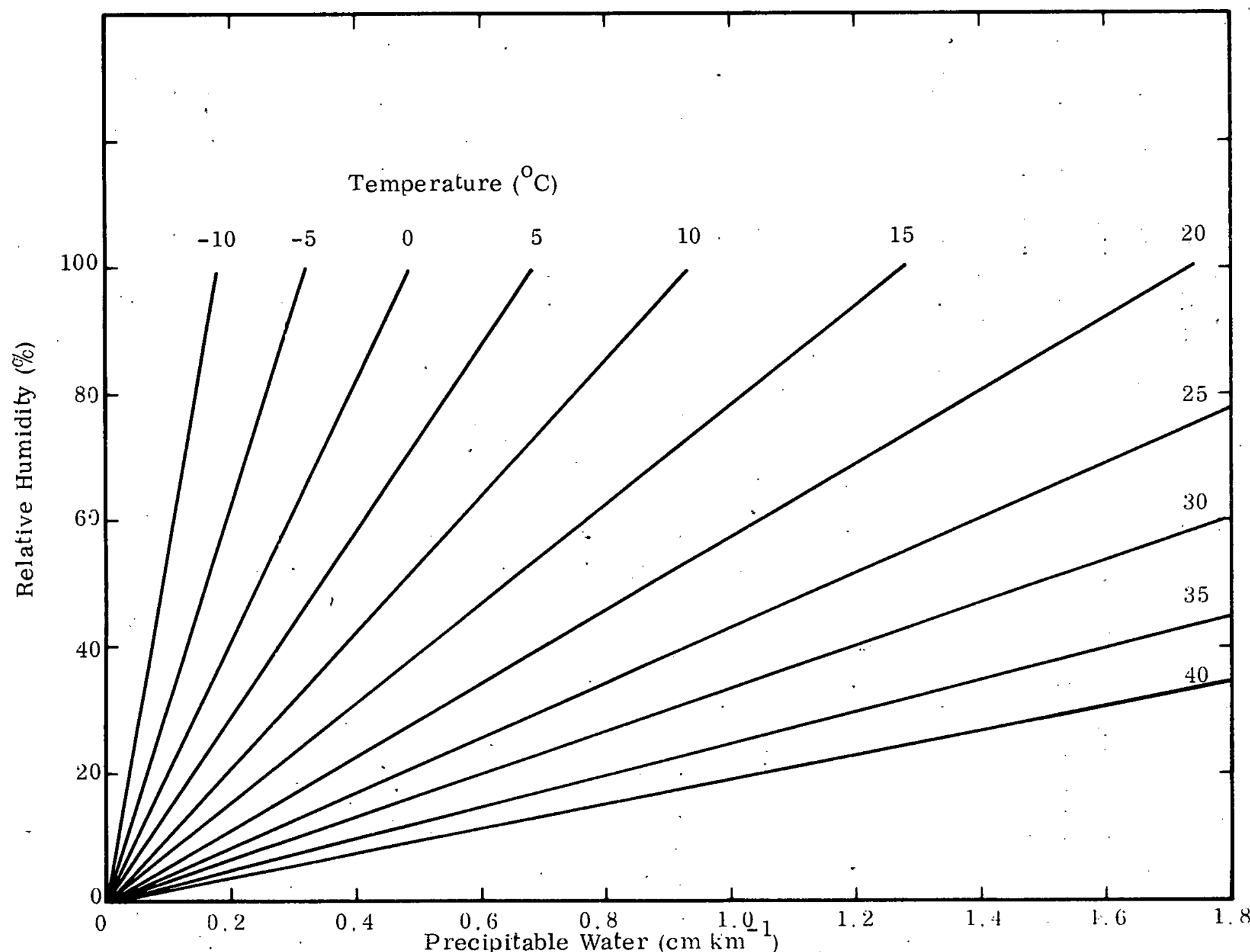


The AFCRL computer code for atmospheric transmission has a midlatitude winter model with a temperature of $272.150^{\circ} \mathrm{K}\left(-0.85^{\circ} \mathrm{C}\right)$. Aerodyne has run this program for relative humidities of $20 \%$ and $95 \%$ to derive data similar to Figure 3-7 at ranges out to $40 \mathrm{~m}$. The integrated transmission over the operating wavelength bands is of interest and is shown in Figure 3-10. In the 3 to $5.5 \mu \mathrm{m}$ band, atmospheric transmission must be known and/or compensatable to an uncertainty of about 0.01 for precision temperature measurement. Figure 3-10 shows that instrument range and relative humidity both must be known. Both are easily determinable and could be inserted into a thermographic unit through potentiometers on the control panel. The calibration data and gain adjustments would have to be determined for each specific inst rument.

The atmospheric transmission problem is, again, minimized, if not eliminated, by using 8 to $12 \mu \mathrm{m}$ instrumentation.

The data shown in Figure 3-10 is based on an elaborate model of the atmosphere developed by the Air Force Cambridge Research Laboratories. Aerodyne's use of LOWTRAN 3 indicates that the uncertainty of any spectral line can be $10 \%$. The results are expected to be accurate to about $1 \%$, which is adequate.

The atmospheric transmission problem must be applied also in airborne measurements if, in fact, the same quantitative temperature information is required. Figure 3-11 shows average transmission over the two spectral bands, 3 to $5.5 \mu \mathrm{m}$ and 8 to $12 \mu \mathrm{m}$, from an altitude of $500 \mathrm{~m}$. If atmospheric transmission is to be compensatable to $1 \%$ uncertainty, then calibration data must be generated as a function of temperature, relative humidity, altitude and nadir look angle in both the 8 to $12 \mu \mathrm{m}$ and 3 to $5.5 \mu \mathrm{m}$ bands.

The other spectrally sensitive parameter is emissivity. Emissivity almost always is used as a constant, but with a value that is quite different from one building material to the next. There is a special concern with window glass, however. Glass, of course, is transparent in the visible out to the near IR and is opaque beyond $5 \mu \mathrm{m}$. If we assume negligible reflectivity, then $\epsilon+\tau=1$ and the emissivity of glass ${ }^{1}$ is shown in Figure 3-12.

\footnotetext{
1"Thermography of Buildings, " National Swedish Building Research Summaries, T 14: 1972
} 


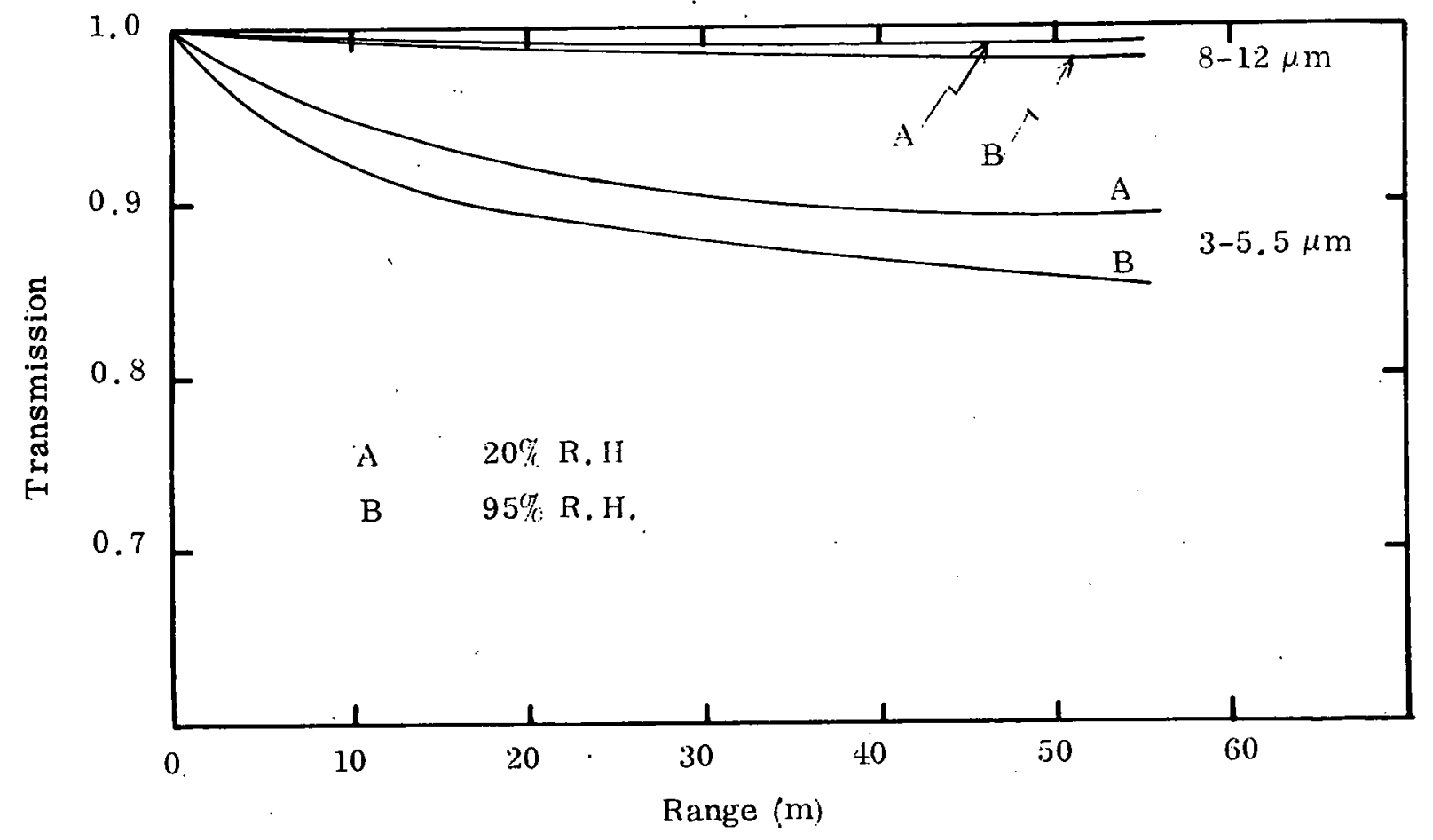

Figure 3-10. Average Atmospheric Transmission, Sea Level, Horizontal Path, Midlatitude Winter 


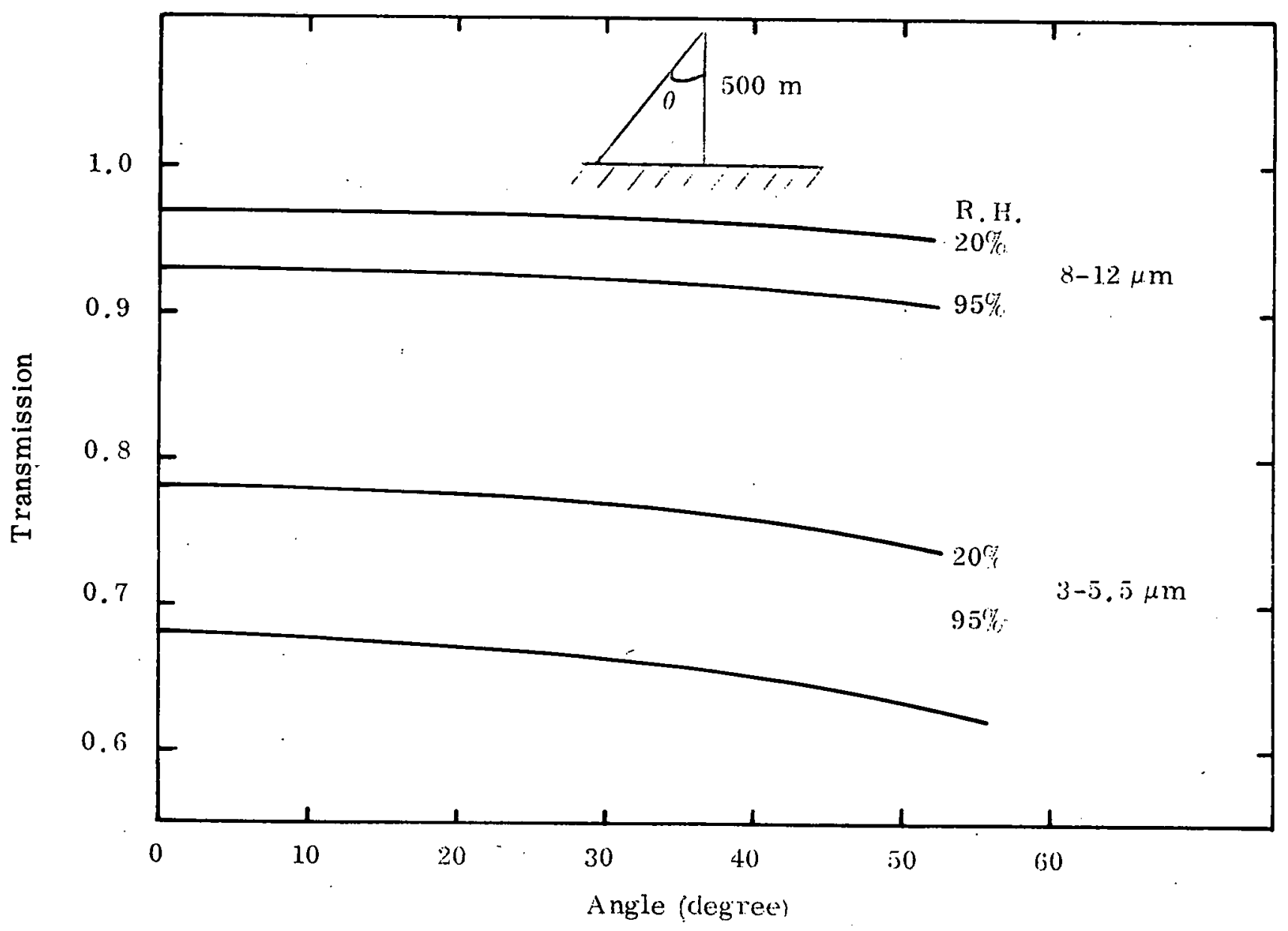

Figure 3-11. Average Atmospheric Transmission, Slant Range Path, Midlatitude Winter 


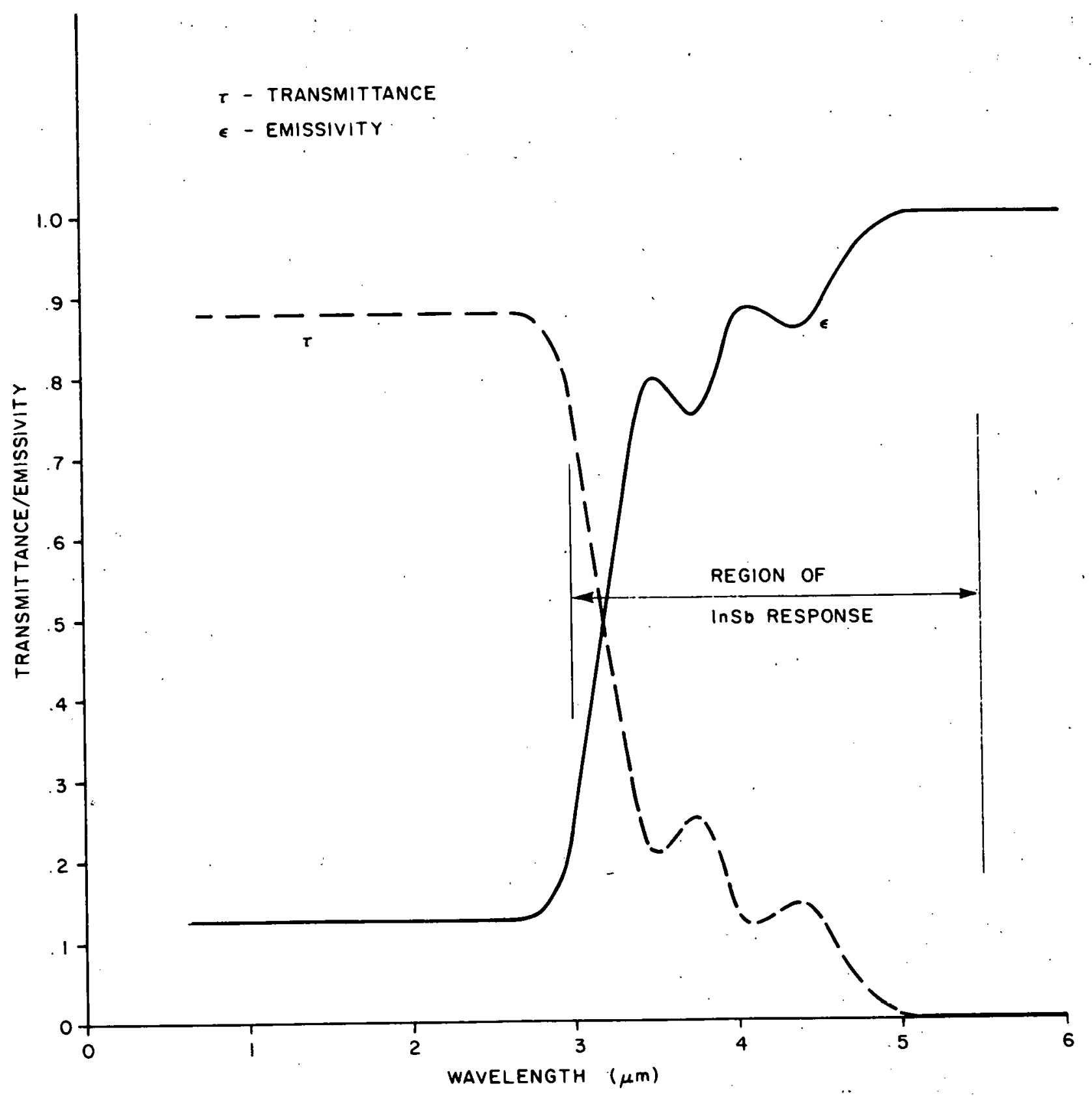

Figure 3-12. Window Glass Transmission/Emissivity 
In its simplest form, as stated previously, a radiometer may be calibrated to read temperature according to the simple relation $W=\sigma \mathrm{T}^{4}$. If it is known that the surface emissivity has a value $\epsilon$ (a constant), then the temperature as measured by the radiometer must be adjusted by the fourth root of emissivity-a simple procedure.

The emissivity, however, becomes more formidable when we consider the above spectral effects. One approximate method of handling the problem is to lump all spectral effects into an "effective" or "apparent" emissivity according to the expression

$$
\bar{\epsilon}=\frac{\int_{\lambda_{1}}^{\lambda_{2}} \tau_{a}(\lambda) \epsilon(\lambda) w_{\lambda} d \lambda}{\int_{\lambda_{1}}^{\lambda_{2}} w \lambda d \lambda}
$$

The results of this exercise are shown in Table 3-2 for the two spectral bands 3 to $5.5 \mu \mathrm{m}$ and 8 to $12 \mu \mathrm{m}$ for the different parameter combinations shown. It is clear from this table that there is considerable variation in the effective emissivity in the 3 to $5.5 \mu \mathrm{m}$ band whereas there is nearly no spectral variation in the 8 to $12 \mu \mathrm{m}$. If the 3 to $5.5 \mu \mathrm{m}$ band is used, then the uncertainty in the knowledge of $\bar{\epsilon}$ is quite high.

Table 3-2. Apparent Emissivity $\left(\mathrm{T}=280^{\circ} \mathrm{K}\right)$

\begin{tabular}{|l|c|c|}
\hline$\underline{\underline{\epsilon}}$ & $\underline{3-5.5 \mu \mathrm{m}}$ & $\underline{8-12 \mu \mathrm{m}}$ \\
\hline$\epsilon$ & 1 & 1 \\
$\epsilon_{\mathrm{a}}$ & 0.9 & $\sim 1$ \\
$\epsilon_{\text {Glass }}$ & 0.86 & 1 \\
$\epsilon_{\text {Glass }}{ }^{\mathrm{a}}$ & 0.74 & $\sim 1$ \\
$\tau_{\mathrm{a}}^{\mathrm{W}(\lambda, \mathrm{T})}$ & 0.78 & $\sim 1$ \\
$\epsilon_{\text {Glass }}{ }^{\mathrm{a}} \mathrm{W}(\lambda, \mathrm{T})$ & 0.75 & $\sim 1$ \\
\hline
\end{tabular}




\subsection{SURFACE TEMPERATURE ERRORS}

The error in surface temperature measurement is derived from an evaluation of the partial derivatives of $\mathrm{W}_{\lambda}$ from Equation (4) to give

$$
\begin{aligned}
\Delta \mathrm{W}= & \frac{\partial \mathrm{W}_{\lambda}}{\partial \mathrm{T}_{\mathrm{s}}} \Delta \mathrm{T}_{\mathrm{s}}+\frac{\partial \mathrm{W}_{\lambda}}{\partial \epsilon_{\mathrm{s}}} \Delta_{\mathrm{s}}+\frac{\partial \mathrm{W}_{\lambda}}{\partial \epsilon_{\mathrm{A}}} \Delta \epsilon_{\mathrm{A}} \\
& +\frac{\partial \mathrm{W}_{\lambda}}{\partial \mathrm{T}_{\mathrm{A}}} \Delta \mathrm{T}_{\mathrm{A}}
\end{aligned}
$$

If we set $\Delta W=0$ to derive equivalency in the error terms, then the equivalent errors in $\Delta \epsilon_{\mathrm{S}}, \Delta \epsilon_{\mathrm{A}}$ and $\Delta \mathrm{T}_{\mathrm{A}}$ are shown in Figures 3-13 thru 3-16. If, for example, we allow $0.1^{\circ} \mathrm{C}$ error in $\mathrm{T}_{\mathrm{S}}$ due to each of the parameters $\epsilon_{\mathrm{S}}, \epsilon_{A}$ and $\mathrm{T}_{\mathrm{A}}$ for outside measurement, then the allowable errors in each are $\Delta \epsilon_{S}=0.0075(3-5.5 \mu \mathrm{m})$, $\Delta \epsilon_{\mathrm{A}}=0.024$ and $\Delta \mathrm{T}_{\mathrm{A}}=1^{\circ} \mathrm{C}$.

Figures 3-13 through 3-16 treat the ambient background as uniform. The data base does not exist to determine representative values for average emissivity and temperature. Emissivities were measured ${ }^{1}$ to an accuracy of $3 \%$ in a controlled laboratory where the background consisted of bare walls and floors. The only variation in the room was the camera operator. A typical room, however, has furniture, walls broken by pictures and doorways, rugs, heat sources including radiators and light bulbs. The best way to assess these effects is by a measurement program. Pending such a program we have assumed representative values for emissivity and temperature within a room. In the generation of Figures 3-16 and 3-17 on inside measurement we let the emissivity of the surface to be measured, $\left(\epsilon_{S}\right)$, and of the background, $\left(\epsilon_{\mathrm{A}}\right)$, to be equal to 0.85 . We have allowed a $3 \%$ uncertainty in $\epsilon_{\mathrm{S}}$ and about $5 \%$ in $\epsilon_{A}$ to account for the nonuniform background. A $5 \%$ uncertainty in $\epsilon_{A}$ is probably quite conservative. We have assumed an ambient temperature of $300^{\circ} \mathrm{K}$ $\left(27^{\circ} \mathrm{C}\right)$ for both the wall to be measured and the uniform background. Variations in background temperature have been handled by assuming ambient background temperature uncertainties of $2^{\circ} \mathrm{C}$.

"Thermography of Buildings, " National Swedish Building Research Summaries, T 14: 1972 


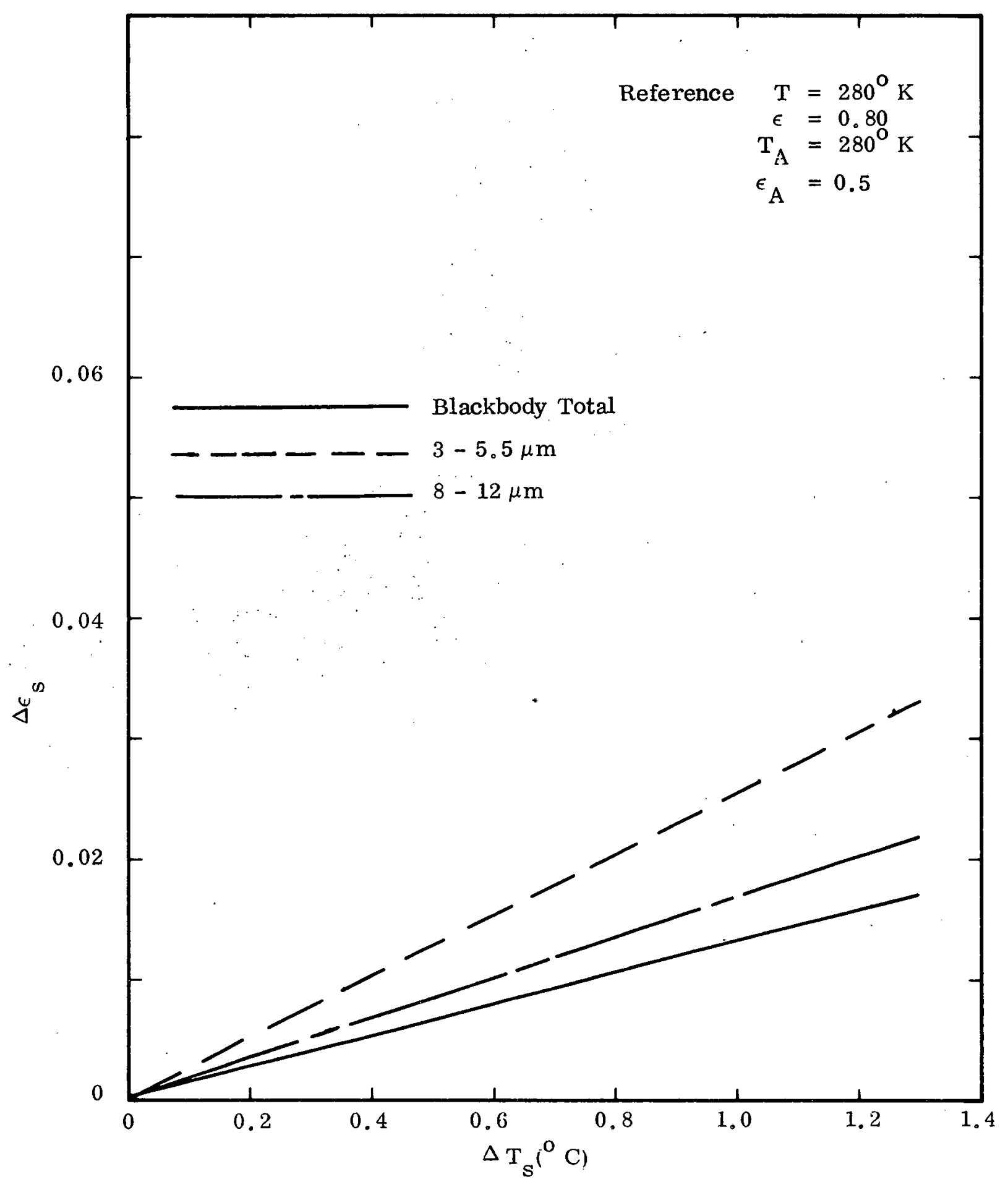

Figure 3-13. Temperature-Emissivity Equivalency 


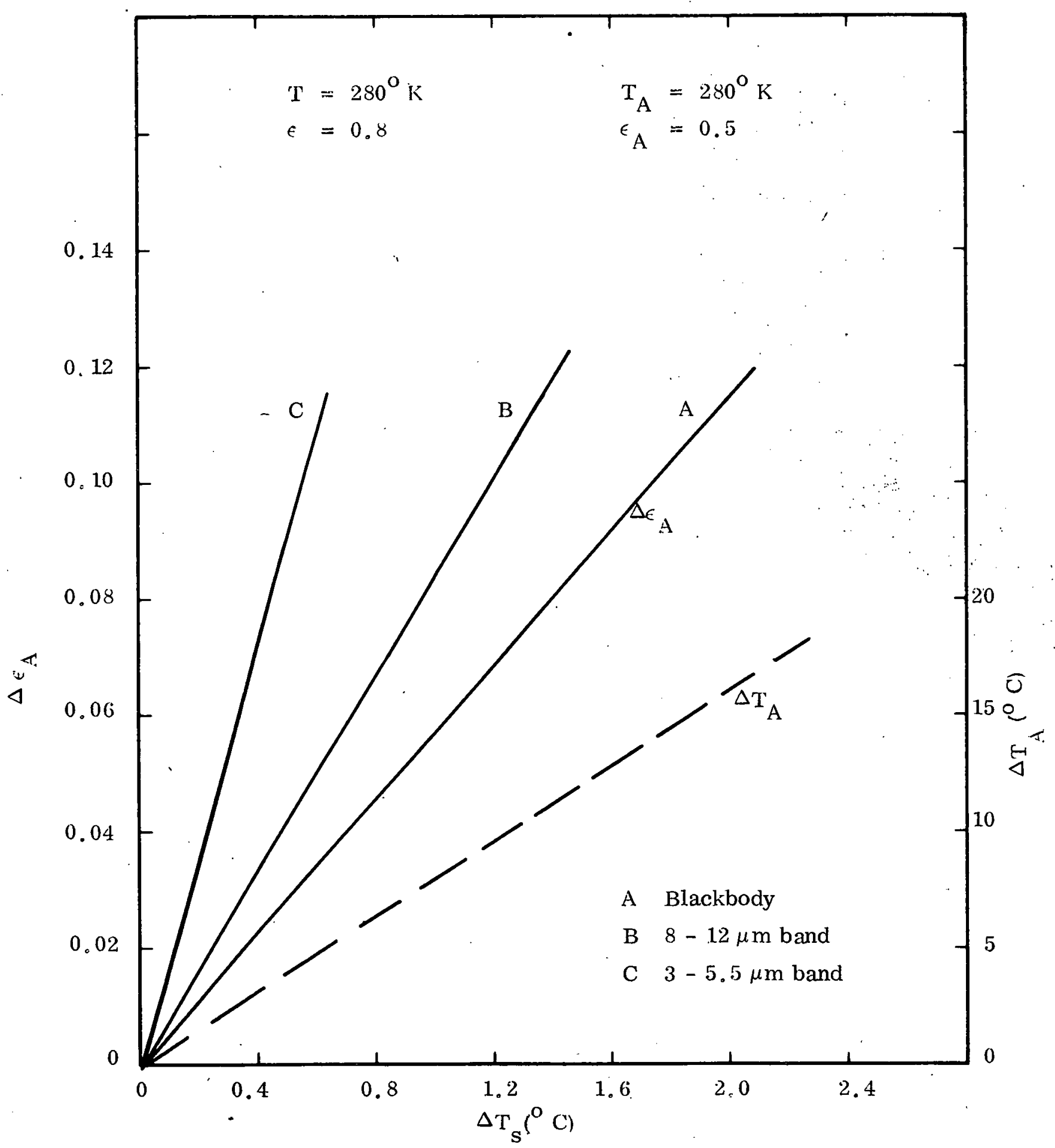

Figure 3-14. Surface Temperature Reflection Effects (Outside) 


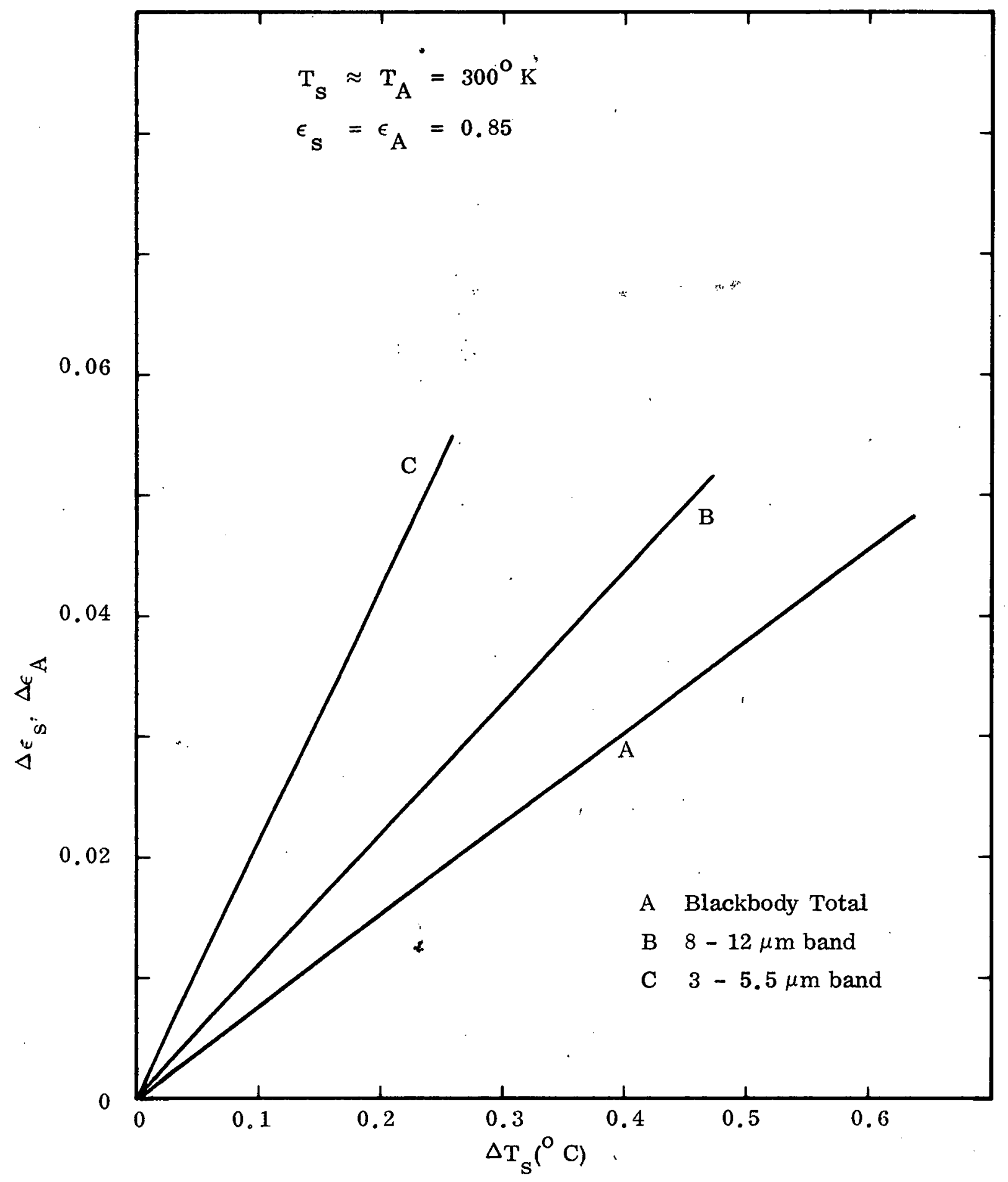

Figure 3-15. Temperature-Emissivity Equivalency (Inside) 


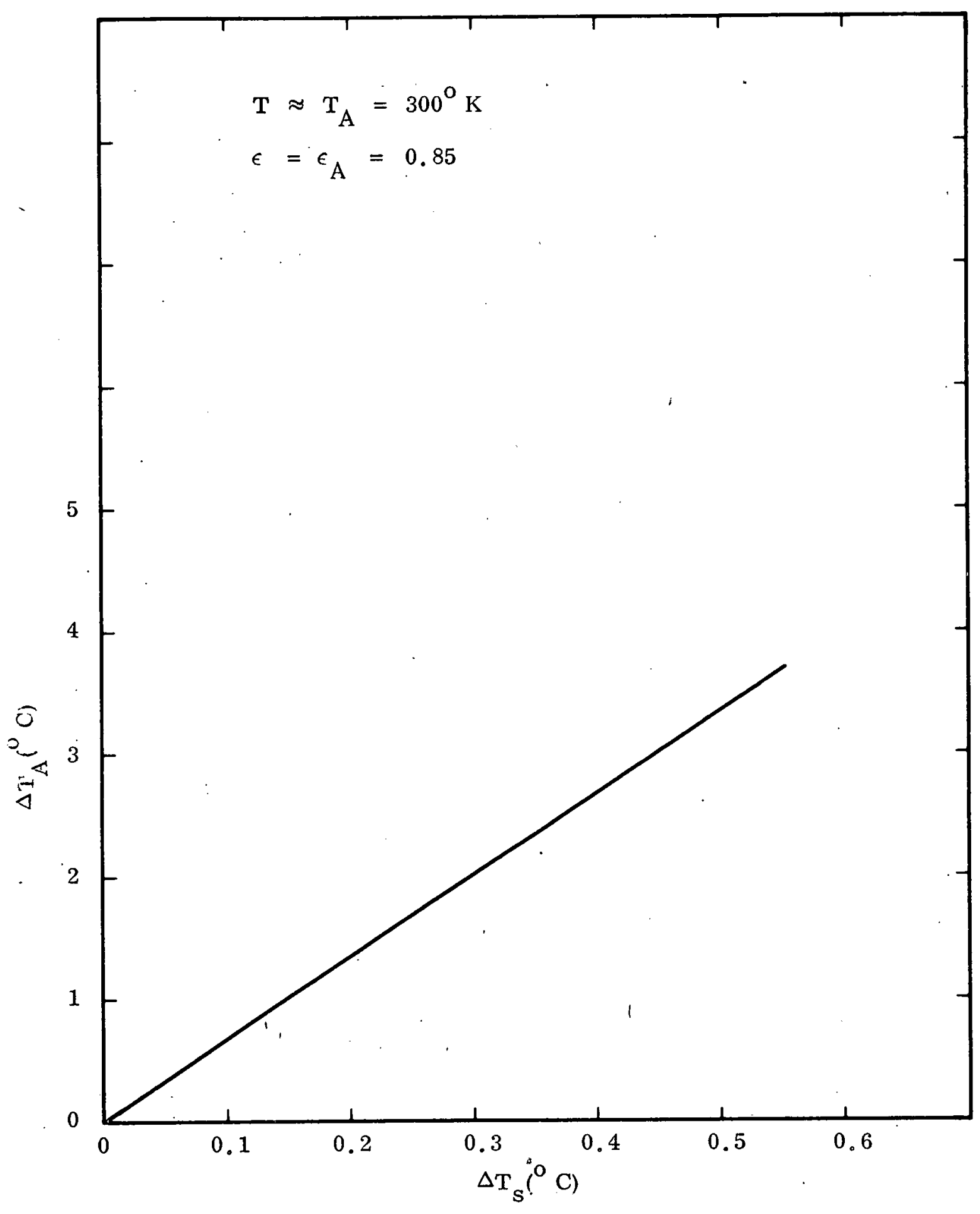

Figure 3-18. Surface Temperature Reflection Effects (Inside) 


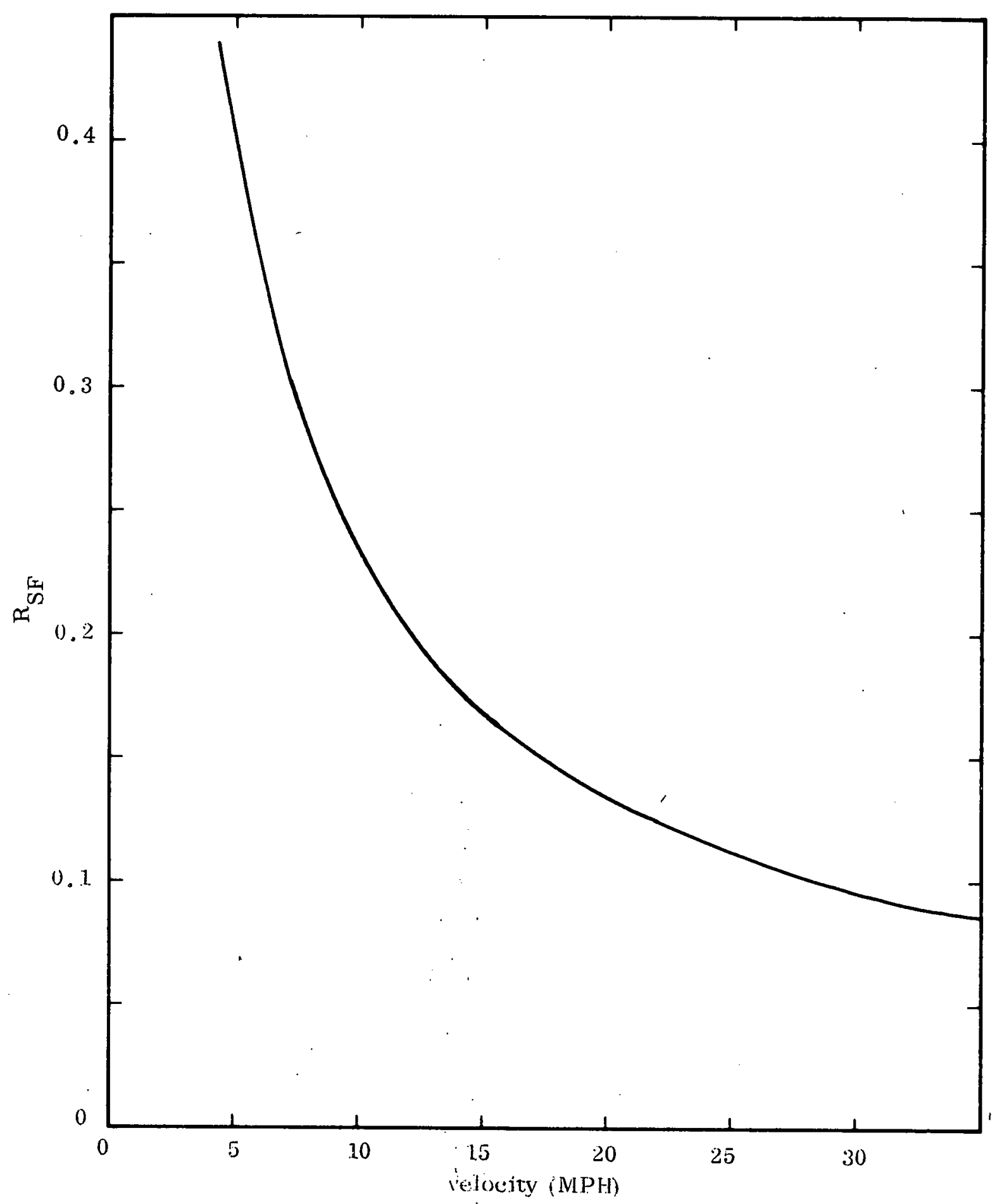

Figure 3-17. Outside Thermal Film Resistance 
The error analysis for outside temperature measurement is a good deal more tenuous. The background is composed of buildings, automobiles, trees and shrubs, the sky, and (in the wintertime) snow-covered landscape. The data in Figu res 3-13 through 3-16 have assumed a surface measurement emissivity of 0.8 and an average background emissivity of 0.5. The uncertainty in $\epsilon_{A}$ could be quite large. We have assumed a value of 0.1 for $\Delta \epsilon_{A}$ to demonstrate, perhaps, a conservative contribution to temperature measurement error from this cause. The uncertainty in knowledge of wall emissivity is assumed to be $3 \%$. Outside ambient temperature was assumed to be $280^{\circ} \mathrm{K}\left(7^{\circ} \mathrm{C}\right)$;

It may be noted here that the 8 to $12 \mu \mathrm{m}$ spectral background tends to be more uniform than does the 3 to $5.5 \mu \mathrm{m}$ background. This may be inferred from Figure 3-5. Other anomalies which should be considered in outdoor measurements are diurnal heating patterns and air mass radiation along the measurement path into the IR instrument. Because of the lack of an adequate data base, a more rigorous treatment of nonuniform outside backgrounds does not appear warranted at this time. The need for a measurement program to study all of these effects is perhaps self-evident.

The other two parameters that can be shown to have a temperature equivalency error are the atmospheric attenuation $\tau_{\mathrm{a}}$ and surface film resistances $(\mathrm{R}) \mathrm{s}^{\cdot}{ }{ }_{\mathrm{a}}$ ' if not implicit to an evaluation of an effective surface emissivity, can be handled in the manner shown below.

The surface film resistance described in Section 2.1.2 is a function of wind velocity, surface texture and shape. If we assume the nominal value of 0.17 for a wind velocity of $15 \mathrm{mph}$, then the effect of wind velocity ${ }^{1}$ is shown in Figure 3-17. to a first order approximation. If, for example, the error in the knowledge of wind velocity is $5 \mathrm{mph}$, then the error in surface film thermal resistance is about 0.05 . This can be related to an equivalent error in surface temperature as depicted in Figure 3-18.

$\overline{1_{E} . R . ~ G . ~ E c k e r t ~ a n d ~ R . ~ M . ~ D r a k e, ~ J r ., ~ " H e a t ~ a n d ~ M a s s ~ T r a n s f e r, ~ " M c G r a w-H i l l, ~}$ 1959. 


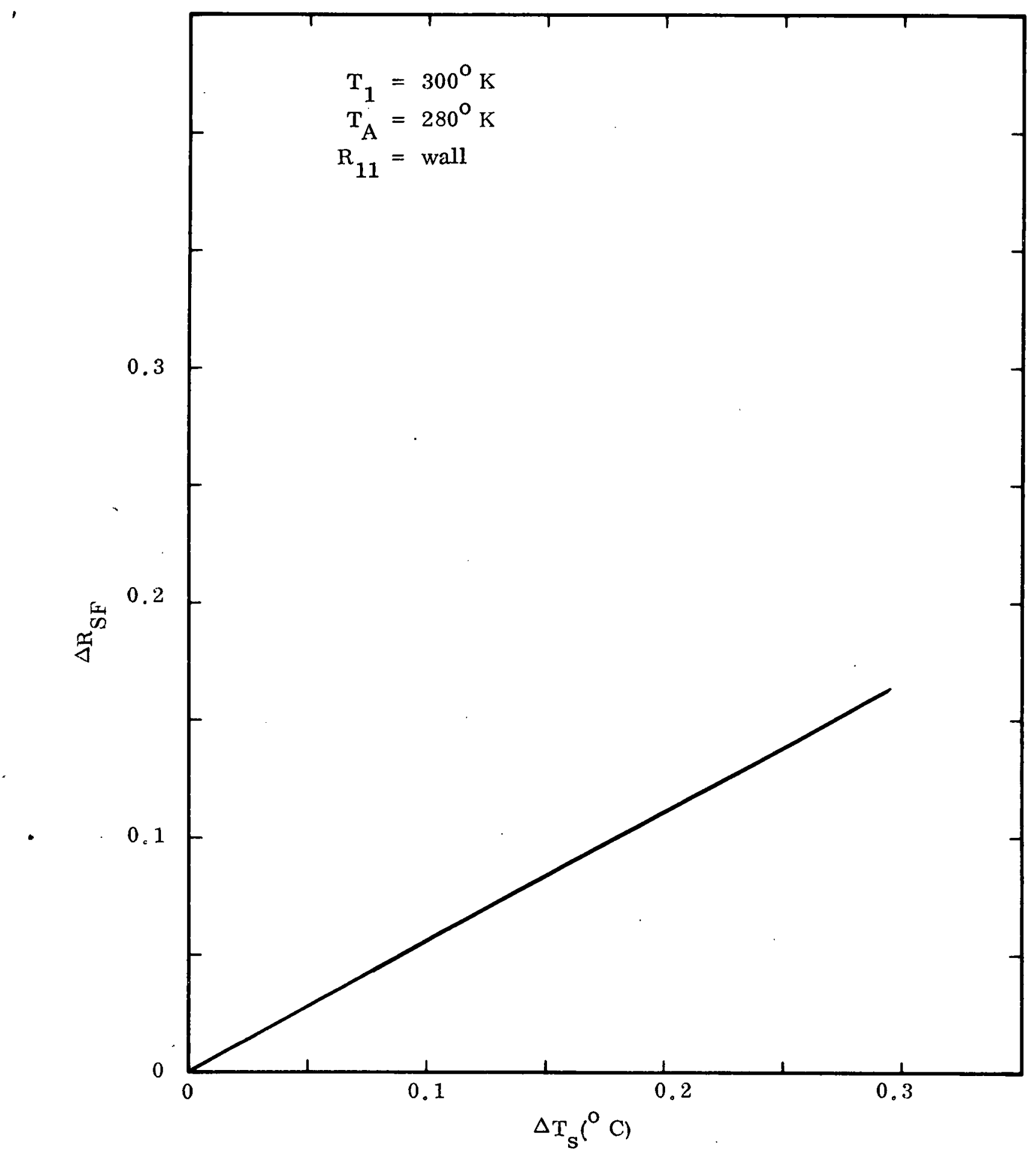

Figure 3-18 Temperature-Surface Film Equivalency 
All of the above errors now can be combined to derive a total surface temperature error budget. This is done in Tables 3-3 and 3-4 assuming parameter independence that allows the RMS summation as shown. The error values are representative and perhaps realistic. The tables show that surface emissivity is the most sensitive parameter. We have used a value of 0.05 in the 3 to $5.5 \mu \mathrm{m}$ band to account for the nonlinear effects of glass. In both spectral bands, however, it is necessary to show by measurement that emissivity can be known well enough to allow for the temperature determination better than $1^{\circ} \mathrm{C}$.

For quantitative code enforcement purposes it may be necessary to measure surface temperature to an accuracy of 0.1 to $0.3^{\circ} \mathrm{C}$. For fault detection, however, ${ }^{\circ} \mathrm{C}$ instrumentation may be adequate. The Swedish ${ }^{1}$ thermography work shows an exhaustive catalogue of typical thermographs. Walls were constructed with deliberate but representative faults. The report shows almost 450 temperature difference measurements. The smallest temperature difference that was measured was $0.6{ }^{\circ} \mathrm{C}$,

Table 3-3. Surface Temperature Measurement Error (Outside)

\begin{tabular}{|l|c|c|c|c|}
\hline \multirow{2}{*}{ Error Source } & \multicolumn{2}{|c|}{$3-5.5 \mu \mathrm{m}$} & \multicolumn{2}{c|}{$8-12 \mu \mathrm{m}$} \\
\cline { 2 - 5 } & Value & $\Delta \mathrm{T}\left({ }^{\circ} \mathrm{C}\right)$ & Value & $\Delta \mathrm{T}\left({ }^{\circ} \mathrm{C}\right)$ \\
\hline Surface Film Resistance & 0.02 & 0.04 & 0.1 & 0.04 \\
Background $\epsilon$ & 0.1 & 0.56 & 0.1 & 1.2 \\
Background Tempe rature & $2^{\mathrm{o}}$ & 0.24 & $2^{\circ}$ & 0.24 \\
Surface $\epsilon$ & 0.025 & 0.34 & 0.025 & 0.76 \\
Atmospheric Trans- & 0.05 & $\frac{0.62}{1.06}$ & 0 & 0 \\
mission $\Delta \tau_{\text {a }}$ & & 1.45 \\
\hline
\end{tabular}

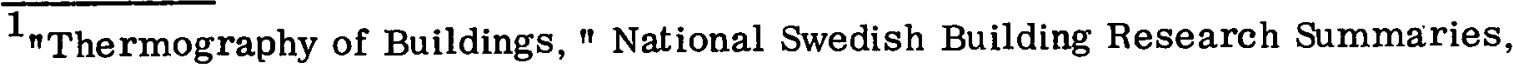
T14: 1972 .
} 
Table 3-4. Surface Temperature Measu rement Error (Inside)

\begin{tabular}{|l|c|l|l|l|}
\hline \multirow{2}{*}{ Error Source } & \multicolumn{2}{|c|}{$3-5.5 \mu \mathrm{m}$} & \multicolumn{2}{c|}{$8-12 \mu \mathrm{m}$} \\
\cline { 2 - 5 } & Value & $\Delta \mathrm{T}\left({ }^{\circ} \mathrm{C}\right)$ & Value & $\Delta \mathrm{T}\left({ }^{\circ} \mathrm{C}\right)$ \\
\hline Surface Film Resistance & 0.07 & 0.14 & 0.02 & 0.14 \\
Background $\epsilon$ & 0.05 & 0.24 & 0.05 & 0.46 \\
Background Temperature & $0.5^{\circ}$ & 0.08 & 0.5 & 0.08 \\
Surface $\epsilon$ & 0.025 & 0.12 & 0.025 & 0.23 \\
Atmospheric Trans- & 0 & $\underline{0}$ & 0 & $\underline{0}$ \\
mission $\Delta_{\tau}$ a & 0.31 & & 0.54 \\
\hline RMS Total & & 0.34 & \\
\hline
\end{tabular}

and the largest was $27.2^{\circ} \mathrm{C}$ with a distribution shown in Figure 3-19. The Swedish IR thermographic unit is reported to have a $0.1^{\circ} \mathrm{C}$ accuracy. The display resolution and the dynamic range of the instrument, however, over the operating temperature measurement range results in thermal resolution of the order of $1^{\circ} \mathrm{C}$. On some of the range scales the thermal resolution may be as good as $0.5^{\circ} \mathrm{C}$. The data shown in Figure 3-19, nevertheless, suggests the possibility of adequate information for fault detection with $1^{\circ} \mathrm{C}$ instrumentation. This could have a significant cost impact on instrumentation.

\subsection{THERMOGRA PHIC INTERPRETATION}

The requirements for IR thermography from a user's standpoint, parametric limitations of the environment and quantitative possibilities have been discussed above. The selection and use of IR thermographic instruments should be based on these factors. Given the proper selection of a thermographic system, however, its value will ultimately be in the use or misuse of the data. Problems in thermographic interpretation may arise from unskilled subjective users. These problems will increase as instrumentation costs decrease and become more available to a wider user 


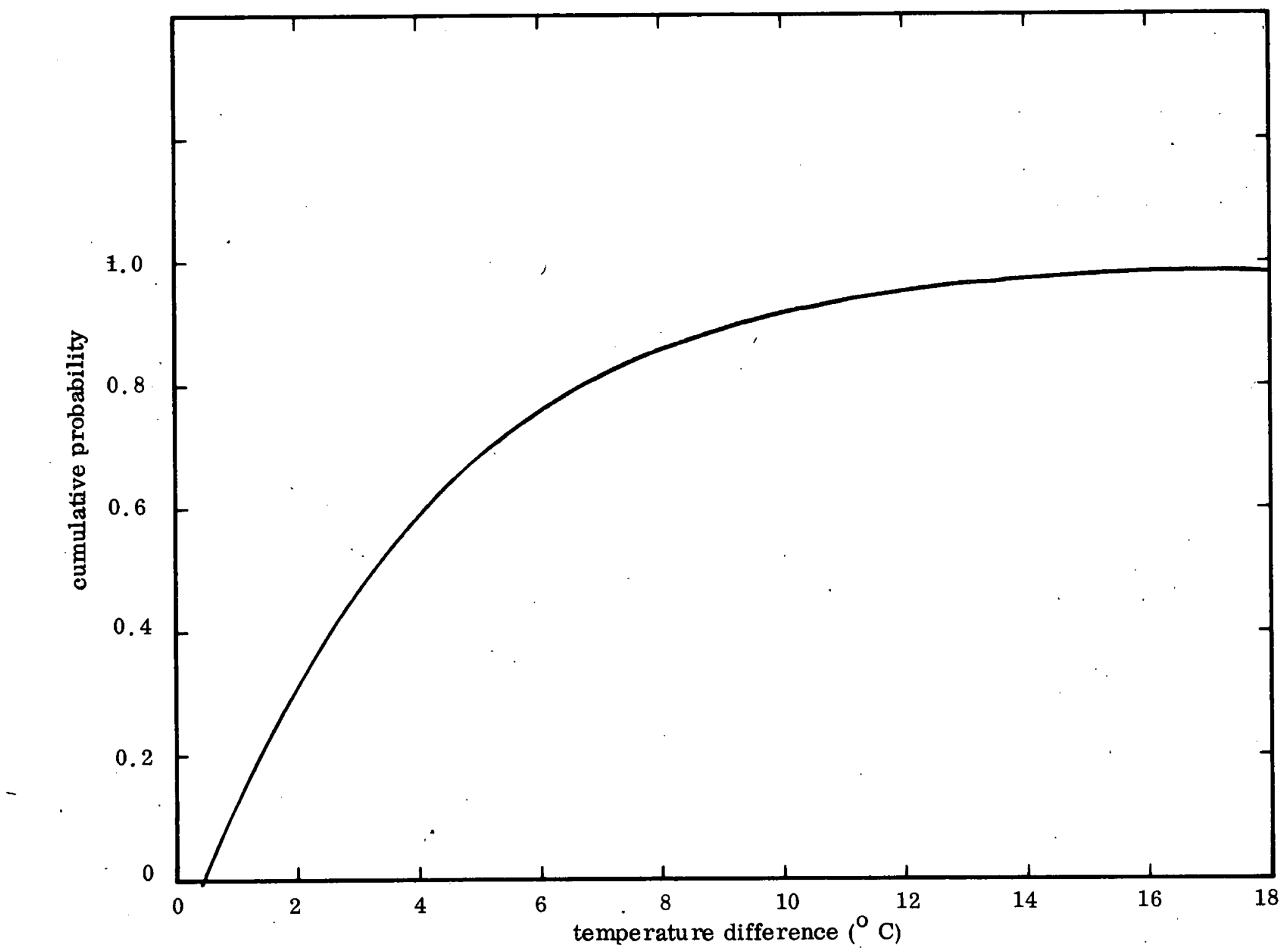<smiles>[Ge]=[GeH2]</smiles>

Figure 3-19. Fault Temperature Differences from Typical Inside Thermographs 
community. Present day users tend to be conscientious, skilled, applicationoriented engineers who are aware of the formative stages of thermography. This will not always be the case. The need for training in thermographic interpretation may be established by the current user community. Interpretation tools and techniques may evolve from this community to move from subjective to a more deterministic evaluation. Much progress has been made in this direction already. More progress is necessary. The concept of temperature measurement, display and interpretation must be understood in a clear manner. The requirements for thermal stabilization must be developed. The problems of sollar heating, variable air temperatures and wind velocity all create transient thermal gradients in a wall which could lead to erroneous interpretation. Thermal equilibrium is required which may limit the evaluation to cloudy days or nighttime operation. More work needs to be done to evaluate these effects including the impact of thermal time lags.

The bridge between qualitative and quantitative thermography must be made to begin to answer some questions of practical import. Thermographic pictures may be impressive. The home owner, however, is really interested in knowing how much energy is being wasted and what it means in terms of dollars. Improvement costs and the break-even time, if the improvements are made, are of interest to the home owner.

Skilled analysts may be able to answer some of these questions as they apply their thermographic expertise to a more detailed home inspection. Quantitative measurements would aid them significantly.

Infrared maps of a building are generated by optical scanning techniques in a TV-type display. Typically, the end product of these scanners is a photograph of a CRT presentation of the two-dimensional scan. Quite often a Polaroid picture provides the hard copy recording. Cold temperature film problems become a logistic problem for outdoor operation in the winter. The film problem can be minimized if the IR camera is operated from within a van. Alternatively the video data may be recorded on magnetic tape or disc. Hard copies may be produced at a later time in the laboratory from the recorded data. Many other advantages or opportunities become 
possible for processing from a recorded video signal. Such possibilities will be outlined below.

Almost all thermographic data are expressed in terms of temperature. Interpretation is based primarily on temperature gradients within an imaged scene. If two sections of a wall have different insulation properties, then there will be differing temperature profiles. A temperature difference will, in fact, exist and can be measured in a rather precise'manner. Temperature differences then may be related to construction details.

In some of the earliest thermographic work AGA generated a library of thermograms of simulated building faults. Wall sections were fabricated with built-in faults, e.g., missing insulation. Laboratory controlled temperature differences across the wall allowed for the collection of thermograms with recorded isotherms measurable to an accuracy approaching tenths of a degree Celcius. With a library of such thermograms, one could subsequently compare a building thermograph with the data bank to identify probable faults in construction.

For the most part the the rmographic work in this country has rested on the individual user to learn by experience. Perhaps because of building code requirements and practices, construction details tend to become uniform. IR signatures, then, may be identifiable with construction practices. Heating system pipes running through walls are recognizable. Heat sources under windows may be recognized as recessed radiators rather than as faulty installation of insulation. Infiltration around window and door frames may be recognizable as areas in need of caulking. Heat loss through ventilation openings may be identified and evaluated. Wall studs may be seen by their IR signature characteristics including spatial qualities. Insulation installation workmanship may be evaluated.

There has been and will continue to be a very wide use for qualitative thermography of the type suggested above. The free exchange of thermographic information among the more capable user community that exists today will result in knowledgable interpretive material. The systematic promotion of this exchange should be of great benefit in establishing accepted standards. 
Just as in any visual photograph, an IR thermogram has "picture qualities" that convey information. In the case of thermograms, the information conveyed is one of relative heat loss/gain. A visual photograph generally is not used for quantitative information. An IR thermogram need not have quantitative information to show construction problems. An IR thermogram may be misleading, however, if the dynamic range of the CRT display or the photographic hard copy should saturate at low temperature levels. White spots on a thermogram are associated with large heat losses. Many high contrast white spots on a thermogram could lead to a subjectivity erroneous conclusion. Thermograms made on a relatively "warm winter day" may contain more information than on an extremely cold day if, in the latter case the display on the photog raphic hard copy saturates. The latter will be much more dramatic if it conveys the impression of "heat pouring out."

The same attention should be directed to thermographic dynamic range as to the avoidance of underexposure or overexposure of visual photographic pictures.

The context of qualitative thermographic data discussed above is for the examination and evaluation of individual buildings for construction details. Qualitative thermography for large area surveillance has some interesting possibilities, also. Aerial thermography allows for house-to-house comparison and has been seen to have powerful appeal ${ }^{1}$ and potential. Home owners can observe an IR aerial strip thermograph with their home identified against a visual strip photograph. A direct thermal comparison of their home with adjacent homes may show, quite dramatically, the thermal inefficiency of their own home. (Reference Figure 3-20 as provided by Daedulus.) The Daedalus gyro stabilized aerial thermographic camera was vanmounted and provides 1 inch resolution at $100 \mathrm{ft}$ distance. The building shown is a two-story residential home constructed with brick on the lower level and aluminum siding on the top. Continuous tone analog thermogram with the light tones represents the warmer areas. Extensive heat losses are evident on the entire first story which is uninsulated. Also note the losses along the upper level floor joists and roof eaves. An insulation void is evident between the studs adjoining the left window. The aluminum framed windows and glass areas are dark and reflect the cold, clear sky background.

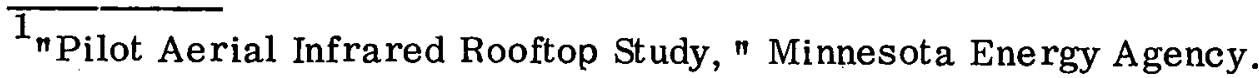




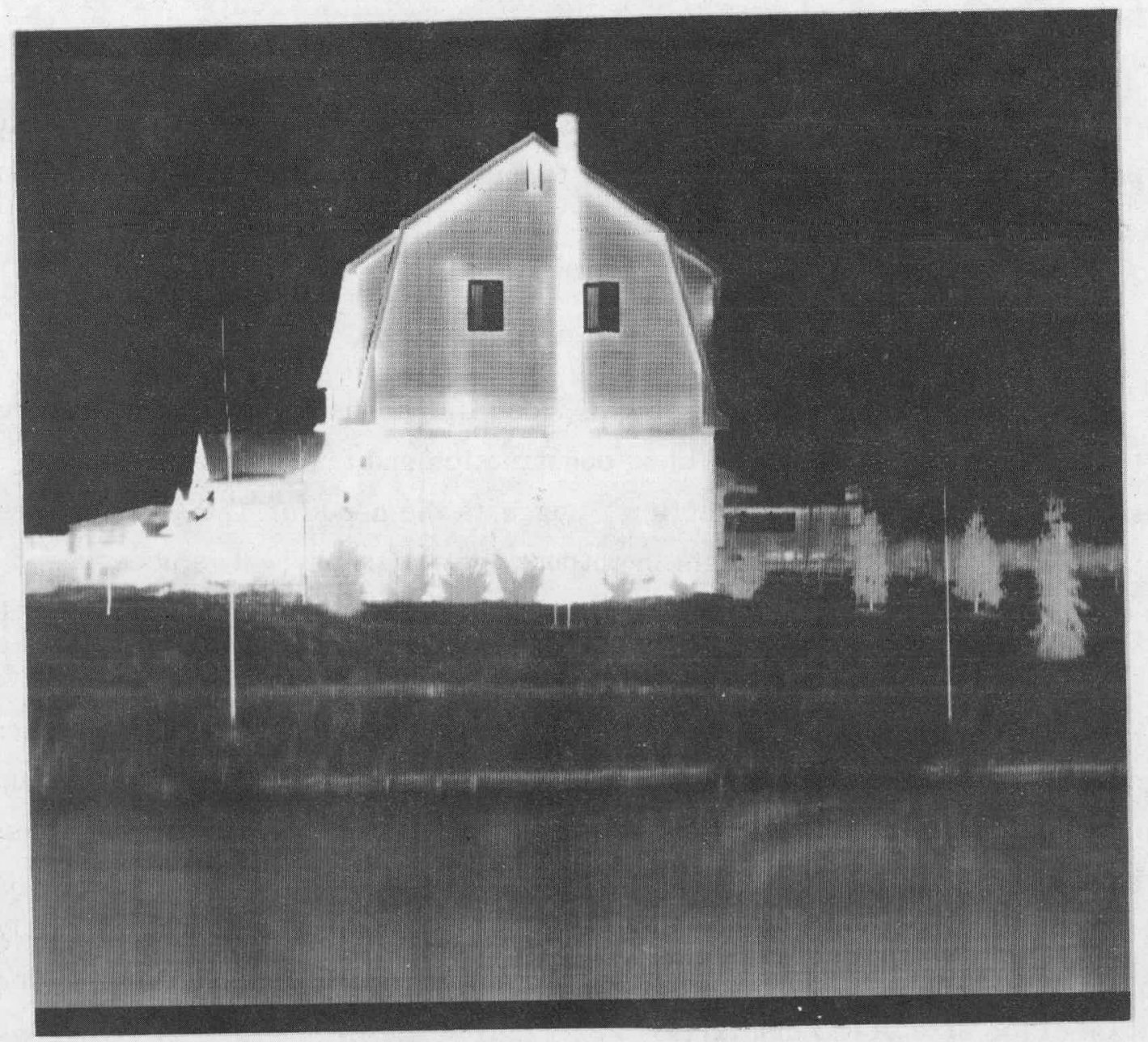

Figure 3-20. Continuous Tone Analog Thermogram

A color-coded, temperature calibrated image is also available. A color bar scale is such that each color port rays a $5^{\mathrm{O}} \mathrm{F}$ temperature inc rement in the $26-56^{\circ} \mathrm{F}$ range. Black and white tones represent temperatures below and above these temperatures. All values are for apparent blackbody radiation temperatures and do not account for surface emissivity.

Most of the brick face in Figure 3-20 radiates greater than $51^{\circ} \mathrm{F}$. The heat losses associated with the floor joists and roof eaves are in the order of $46-56^{\circ} \mathrm{F}$. The rest of the upper level siding is in the $36-41^{\circ} \mathrm{F}$ range. The outside ambient air temperature was $30^{\circ} \mathrm{F}$ at the time of data acquisition. 
A large area van survey may reveal problem areas for detail analysis using smaller portable thermographic units. Local governments may conduct such surveys and subsequently encourage home owners to undertake further analysis that would lead to a thermal improvement program.

\subsubsection{Thermographic Resolution}

Cathode Ray Tube (CRT) display of video line scans contains temperature information that may be related to building construction and fault characterization. The NAHB Research Foundation in Section 2 suggests the need for $1^{\circ} \mathrm{C}$ thermal resolution to satisfy such qualitative analysis in outdoor thermography. It is necessary, then, that the minimum resolvable temperature (MRT) difference on a display be at least $1^{\mathrm{O}} \mathrm{C}$.

MRT is defined as an operator's ability to recognize or resolve a difference in temperature between two objects that are close together spatially. From a human factors standpoint the definition would include the size of the object(s) with respect to the number of spatial resolution elements that are subtended on the display. For building thermography the latter refinement is not of great significance. MRT is a subjective determination that varies with the skill of the operation. It is also a function of the size of the display.

MRT for any particular inst rument is specified by the manufacturer. The higher quality instruments show MRT that are $0.1^{\circ}$ or $0,2^{\circ} \mathrm{C}$. Some care should be exercised in the use of such information, however. MRT depends on the object temperature and the dynamic range of the measurement display. For building thermography work the dynamic range of the measurement with most instrumentation is such that MRT is greater than $0.1-0.2^{\circ} \mathrm{C}$ and may be closer to $1^{\circ} \mathrm{C}$. This should be adequate for all building qualitative thermography.

Thermographic systems with small displays are display limited. Some users prefer to record the video data on magnetic tape for subsequent playback through scan converters, if necessary, on larger screens. Screens as large as 16 " have been 
used before other human factor considerations became important. Spatial resolution on the display may deteriorate and become unacceptable. TV line scan compatability of IR instruments is perhaps desirable to minimize some of these display problems.

In its simplest form, qualitative thermography should not require that temperature numbers be derived. The operator should be aware of the fact that his display will allow for an MRT of at least $1^{\circ} \mathrm{C}$. He also desires a near linear response over the full object temperature range; i.e., he does not want temperature saturation.

A more sophisticated user may, however, begin to do some computer analysis of the video signal. The amplitude of the video signal is proportional to effective temperature. Temperature differences may be shown on black and white displays as isotherms or may be quantized for color rendition. Color quantization levels often are $1-2^{\circ} \mathrm{C}$ but could be adjusted to smaller values in expanded video signal processing.

The above discussion describes approaches to thermographic interpretation that is in current use. Thermographic analysis is largely qualitative. Semiquantitative processing of effective temperatures is as described. It is perhaps important to reemphasize that temperature differences or gradients may be determined fairly accurately by direct video processing. The interpretation of measured surface temperature as absolute or actual surface temperatures, however, is subject to the uncertainties described in Section 3.3. The radiation from a surface with $\epsilon=0.8$ and $\mathrm{T}=280^{\circ} \mathrm{K}$ is the same, as from a surface with $\epsilon=0.85$ and $\mathrm{T}=275.8^{\circ} \mathrm{K}$. Without a priori information of emissivity, then, there could be a $4.2^{\circ} \mathrm{C}$ difference in surface temperature. The effect of the component of background reflected energy that is also measured by thermography changes this somewhat as discussed in Section 3. 3 .

Interpreting thermographic data for absolute temperature is required for quantitative determination that will lead to computation of $R$ values. It is unlikely that CRT display information can be used. Direct processing of the video signal with spectral compensation as described in Section 3.2, however, is possible. It is not realizable at the present time, however, because of uncertainties in the parameters that require compensation. 


\subsubsection{Aerial Thermography}

A complementary supplement to ground-based thermography is provided by large area aerial surveys. There are distinctive differences between these two approaches that make them very complementary to each other if the characteristics, capabilities and limitations are clearly understood.

The spatial resolutions of current ground-based and aerial thermographic instruments, for the most part, are about the same, namely of the order of $2.5 \mathrm{mr}$. Ground-based instruments resolve about 1 square inch of wall area at a distance of $30 \mathrm{ft}$. There is no loss of detail due to image motion if the thermographic instrument is held steady (e.g., tripod mounted). These instruments can resolve small area imperfections in walls but have limited use for roof/ceiling evaluation from the outside simply because of poor viewing angle.

Aerial thermography does not provide for the same ground resolved distances. If the spatial resolution is $2.5 \mathrm{mr}$, then the thermographic instrument will resolve about $7 \mathrm{sq}$. $\mathrm{ft}$. of surface area at a slant range of $1000 \mathrm{ft}$ looking down at an angle of $30 \mathrm{deg}$. from vertical. The thermographic readings average the energy that is radiated and reflected over $7 \mathrm{sq}$. ft. areas. This compares with $1 \mathrm{sq}$. inch in the ground measurement case. The aerial resolution may be even worse and requires recognizing that static resolution of aerial cameras is degraded by dynamic motion of the camera caused by (1) inadequate line-of-sight stabilization, and (2) flight path velocity. Gyro stabilization will eliminate most of the smear effects in Item 1 that would otherwise arise from angular rates of the aircraft and from vibration. Item 2 sometimes can be compensated by "aided rate" techniques. In both cases, however, there will be some residual dynamic errors that will degrade the static resolution. The effects of both also will be minimized for increasing frame rate of the camera. It is desirable, then, to operate at near TV frame rates.

The dynamic motion effects on spatial resolution can be minimized also by an optimum choice of flight altitude, velocity and look-down angle for any particular instrument. The user should be aware of all of these factors before taking thermographic data from the air. 
The spatial resolution of aerial thermographic data is about three orders of magnitude poorer than ground thermography in terms of ground resolved area. Aerial thermography is good for large scale, large area qualitative heat loss evaluation. Large area flyovers may result in low cost per home thermography. The data is most useful for identifying homes with poor ceiling insulation but may not locate small area, faults.

Aerial thermography could be a relatively inexpensive way of conducting large area surveys by: (1) municipalities, (2) federal agencies, (3) utility companies, and (4) insulation manufacturers. Once thermally poor rooftops are located, the home owners may be shown the thermographic picture of their roof. They may see how thermally poor their homes are with respect to neighboring homes. In many cases this would provide the opportunity for a thermal improvement analysis of their home. Poorly insulated ceilings probably mean poorly insulated walls, also. The details of a home inspection program may be shown by the higher resolution ground thermographic instruments.

Aerial thermography requires some awareness of meteorological conditions. Snow-covered roofs preclude successful thermography. In many areas of the country when cold weather otherwise would lead to good thermographic conditions, it will be necessary to limit the thermographic analysis to ground operation. Aerial thermography will deteriorate during high winds when light aircraft may be buffeted giving rise to decreased spatial resolution. High water content in the atmosphere decreases transmission with both 3 to $5.5 \mu \mathrm{m}$ and 8 to $12 \mu \mathrm{m}$ instrumentation and is a function of imaging range. The thermal time lags in roof temperature caused by solar illumination must be accounted for. These factors indicate the need for careful scheduling for any and all flight data. These factors can be assessed best by deliberate flights during adverse conditions to evaluate the effects of each factor above and to determine limitations and scheduling requirements.

Metecrological conditions are important in understanding and interpreting day-today variations in aerial qualitative thermography. There is even greater importance in quantitative analysis. The atmospheric transmission and its day-to-day variation has great importance. It should be possible to spectrally compensate for the atmos- 
phere in either the 3 to $5.5 \mu \mathrm{m}$ or 8 to $12 \mu \mathrm{m}$ instruments. Available codes that are discussed in Section 3.2 may be used and can be validated by flight test thermographic analysis.

It is quite possible that the reflected background problem may be handled more easily in aerial thermography than in ground thermography. Rooftops reflect nearly a uniform cold sky. It will be necessary, however, to ensure an understanding of the emissivity compensation along with the background reflection problem.

The possibility for quantitative aerial thermography may be greater than for ground thermography. Such possibility must be evaluated in carefully controlled flight test validation programs.

The elements for interpretation of aerial thermographic data are about the same as for ground data. Aerial data is almost always taken on magnetic tape. The ground processing of tapes, however, offers greater flexibility than direct hard copies.from small CRT's. There are more options open including larger CRT displays, laser beam recording on film, direct CRT photography, and/or computer analysis. The problems with quantitative interpretation are about the same for aerial as for ground thermography. At the present time, then, the usefulness of aerial thermography is more of a qualitative nature.

The U. S. Energy Research and Development Administration has contracted with the Minnesota Energy Agency for a "Pilot Aerial Infrared Rooftop Study." Included in that study are the following:

(1) A requirement to conduct flyovers, and obtain complete and accurate infrared thermographic and other necessary data. Process and interpret the data using sound scientific principles to obtain the best and clearest conclusions regarding the rate of energy loss from the buildings surveyed; the detectability of the energy loss in relation to all important technical constraints and factors; the reliability of conclusions that can be drawn from the interpreted data and its dependence on important factors; the uses such data and conclusions can be put to in the execution of practical energy conservation programs; and recommendations for future research, 
development and demonstration activities that would increase the accuracy, effectiveness, or usefulness of infrared thermographic techniques and devices for national energy conservation.

(2) Verification of the accuracy of the thermographic imagery and results using such additional measurements and data as may be necessary beyond those made in the flights.

(3) The preparation and delivery of training material and manuals for the dissemination and interpretation of the thermographic data. The final material should be available in July 1977. 


\section{SECTION 4 \\ CURRENT ELECTRO-OPTICAL TECHNOLOGY}

The current status of infrared technology runs the gauntlet of cost from a $\$ 600$ package with an analog meter readout to a $\$ 250,000$ airborne system which provides digitized scan data on magnetic tape or $70 \mathrm{~mm}$ film. In the case of the magnetic tape system, additional equipment is required so reconstruct the image from magnetic tape. Scanned data is displayed on CRT monitors, light emitting diodes (LED'S), oscilloscopes, analog meters, and digital displays. A temperature range of $-50^{\circ} \mathrm{C}$ to $2500^{\circ} \mathrm{C}$ can be detected in whole or in part by each of the instruments at sensitivities varying from $0.05^{\circ} \mathrm{C}$ to $2^{\circ} \mathrm{C}$. In addition, a spectral range of $2 \mu \mathrm{m}$ to $300 \mu \mathrm{m}$ is covered by the collection of instruments surveyed. Some are man-portable, some are vehicleportable, some are designed for stationary laboratory use, and others are designed specifically for airborne applications.

In general, all of the currently available instrumentation can be broken down into four somewhat homogeneous groups based on a combination of their detector technology and their intended application. Figure 4-1 shows the four basic groups (solid state, pyroelectric, radiometer, and airborne) and the subclasses within these general groups. The group categorized as solid state types by far comprises the largest collection of instruments which are most directly applicable to infrared thermography measurements of individual dwellings. Pyroelectric vidicons have been singled out as the second group due to their current prototype production status and the performance/ cost advantages theoretically offered in the future. Group number three represents a sampling of a narrow class of IR instrumentation called radiometers used strictly for specialized, noncontact, narrow field-of-view surface temperature measurement. These instruments not only represent the bottom line of the cost spectrum, but offer the greatest degree of operator simplicity as well. The actual application of radiometers is pointed out in more detail in Section 4.3 .

Airborne systems represent the fourth group of inst rumentation due to their singularly high cost, and the need to scan large geographical areas in order to achieve economics of scale versus single dwelling scanning possibilities by the first three groups already mentioned. 


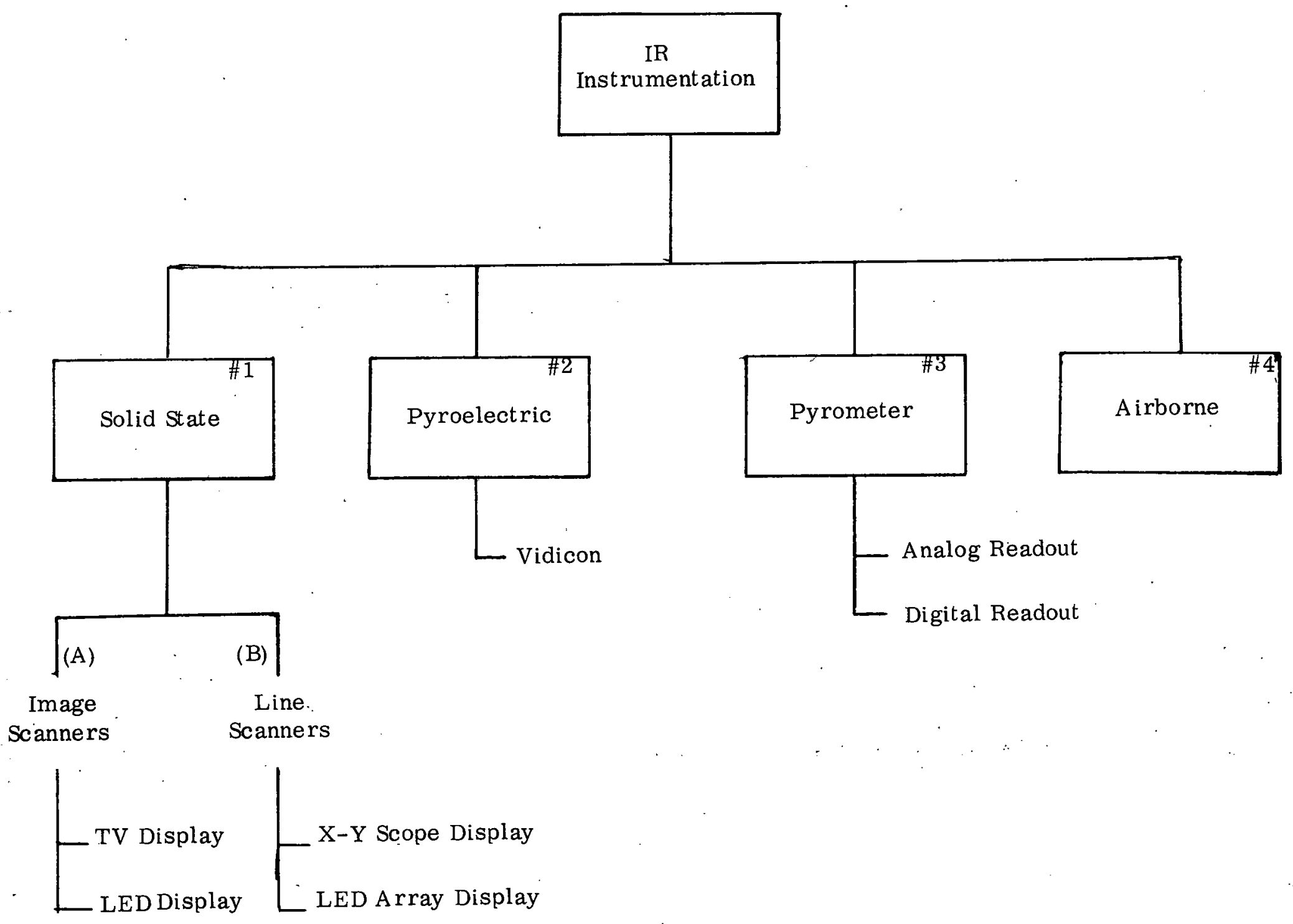

Figure 4-1. IR Instrumentation Breakdown 


\title{
4.1 SOLID STATE SYSTEMS
}

Solid state systems comprise the majority of present-day, off-the-shelf technology which can be applied to infrared thermography measurement of buildings. Although airborne systems technically come under the heading of solid state systems, they will be treated as a separate and distinct group due to their high cost and large scale application requirements. The remaining solid state instruments cover a range of man-portable and laboratory-type scanners which are applicable to single dwelling scanning from the exterior or interior. Table 4-1 lists the manufacturers contacted in this category and the type of information contributed to this study.

\subsubsection{Displays}

Solid state systems are typically divided into two subcategories based on their display or subject field technology (reference Figure 4-1). Instrument category A can be called solid state imaging scanners; e.g. they provide a complete raster image of the object being scanned.

\begin{abstract}
"Conventional thermal imaging system designs differ from each other in two fundamental ways: the means by which the scene is dissected and the means by which preamplified detector signals are processed for video presentation. The particular implementation of the optics, scan mechanism, cooler, and display are not fundamentally significant if they meet at least minimum requirements. $" 1$
\end{abstract}

Figure 4-2 shows an example of a conventional photograph versus a thermal photograph. AGA Corp., Inframetrics, and Spect rotherm provide inst rumentation of this type using cryogenic detectors. CRT display systems of this type retail from $\$ 25,000$ to $\$ 60,000$. Less expensive versions of imaging scanners (at a sacrifice of resolution) are produced by providing a display of scanned LED's. Barnes Engineering, Hughes Aircraft Corporation, and Philips Audio Video Systems Corporation provide image scanners with this type of display in the $\$ 6,000$ to $\$ 15,000$ range (reference Table 4-2).

T. M. Lloyd, "Thermal Imaging Systems, " Plenum Press, New York, N. Y., p. 329 


\begin{tabular}{|c|c|c|}
\hline Manufacturer & Contact Summary & Person Contacted \\
\hline $\begin{array}{l}\text { A GA Corporation } \\
550 \text { County A venue } \\
\text { Secaucus, New Jersey } \\
07094\end{array}$ & $\begin{array}{l}\text { A RI representative visited AGA in New Jersey, } \\
\text { witnessed demonstration of equipment, secured } \\
\text { manufacturer's brochure, etc. }\end{array}$ & $\begin{array}{l}\text { Deitrich Baeu } \\
\text { President } \\
\text { (201) } 866-3344\end{array}$ \\
\hline $\begin{array}{l}\text { Barnes Engineering Co. } \\
30 \text { Commerce Road } \\
\text { Stamford, Connecticut } \\
06904\end{array}$ & $\begin{array}{l}\text { Mr. Leftwich visited ARI facility. Answered } \\
\text { questions and provided manufacturer's } \\
\text { brochures. }\end{array}$ & $\begin{array}{l}\text { Richard F. Leftwich } \\
\text { Manager, Product Appli- } \\
\text { cations and Planning } \\
(203) 348-5381\end{array}$ \\
\hline $\begin{array}{l}\text { Hughes A ircraft Co. } \\
\text { Industrial Products Div. } \\
6855 \text { El Camino Real } \\
\text { Carlsbad, California } \\
92008\end{array}$ & $\begin{array}{l}\text { Mr. Smith visited ARI and demonstrated } \\
\text { PROBEYE, answered questions, and provided } \\
\text { manufacturer's brochures. }\end{array}$ & $\begin{array}{l}\text { Robert D. Smith, II } \\
\text { Member of Technical } \\
\text { Staff } \\
\text { (714) } 729-9191\end{array}$ \\
\hline $\begin{array}{l}\text { Inframetrics, Inc. } \\
225 \text { Crescent St reet } \\
\text { Waltham, Mass. } \\
02154\end{array}$ & $\begin{array}{l}\text { A RI representative vis ited Inframetrics and wit- } \\
\text { nessed demonstration of equipment, secured } \\
\text { manufacturer's brochures, etc. }\end{array}$ & $\begin{array}{l}\text { G. J. Burrer } \\
\text { (617) } 891-6784\end{array}$ \\
\hline $\begin{array}{l}\text { Laser Precision Corp. } \\
5 \text { West Whitesboro St. } \\
\text { Yorkville, New York } \\
13495\end{array}$ & $\begin{array}{l}\text { Phone contact by ARI representative. Manu- } \\
\text { facturer's brochure forwarded through the } \\
\text { mail. }\end{array}$ & $\begin{array}{l}\text { Donald W. Sypek } \\
\text { Marketing Engineer } \\
\text { (315) 797-4449 }\end{array}$ \\
\hline $\begin{array}{l}\text { SpectroTherm } \\
325 \text { North Matilda Ave. } \\
\text { Sunnyvale, California } \\
94086\end{array}$ & $\begin{array}{l}\text { Mr. Wickersheim visited A RI facility. } \\
\text { Answered questions and provided manu- } \\
\text { facturer's brochures. }\end{array}$ & $\begin{array}{l}\text { Ken Wickersheim } \\
\text { President } \\
\text { (408) } 738-3301\end{array}$ \\
\hline $\begin{array}{l}\text { Philips Audio Video } \\
\text { Systems Corp. } \\
91 \text { McKee Drive } \\
\text { Mahwah, New Jersey } \\
07430\end{array}$ & $\begin{array}{l}\text { Phone contact by ARI representative. Manu- } \\
\text { facturer's brochures forwarded through the } \\
\text { mail. }\end{array}$ & $\begin{array}{l}\text { John Duke } \\
\text { (201) 529-3800 }\end{array}$ \\
\hline
\end{tabular}




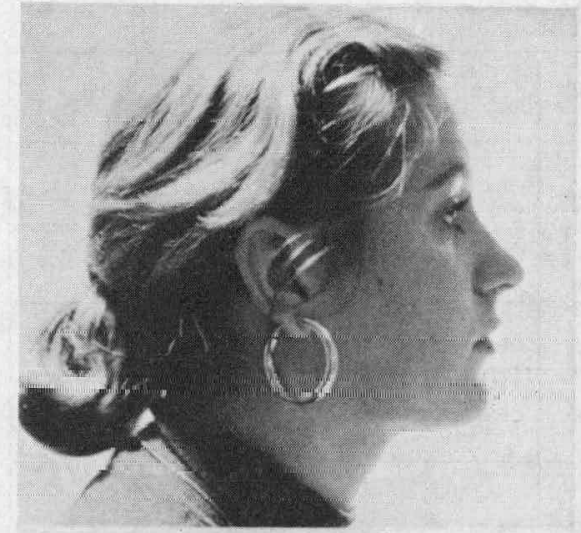

Conventional photograph

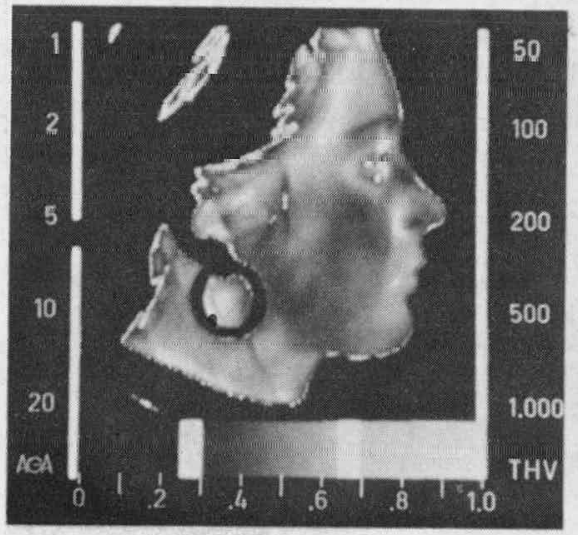

3. Dual isotherms

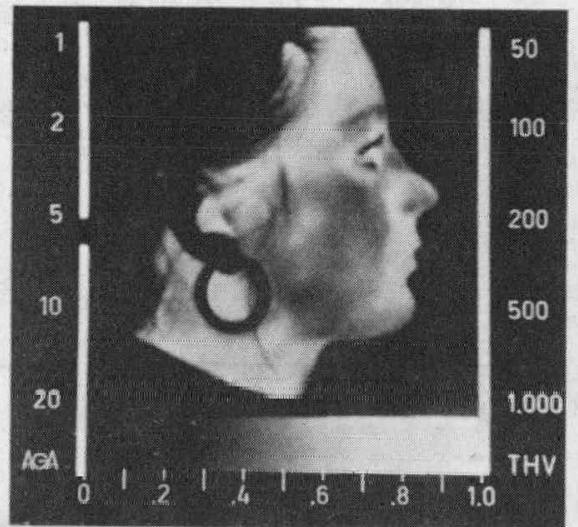

1. Normal thermogram

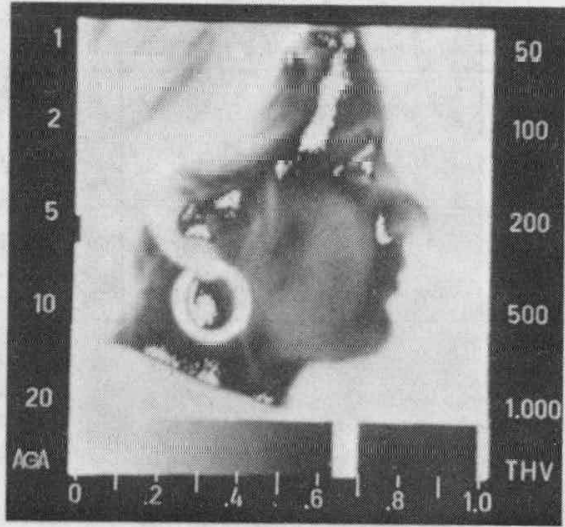

4. Inverted thermogram with isotherm

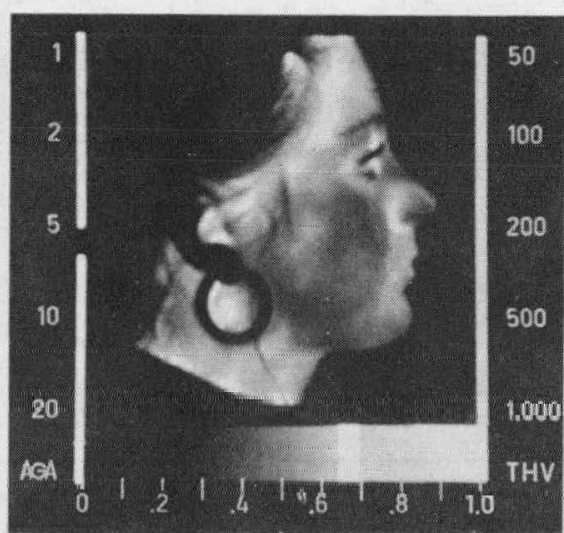

2. Single isotherm

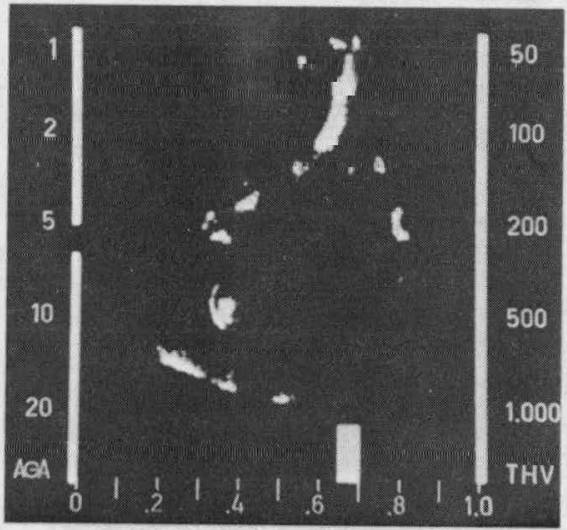

5. Suppressed gray tones

Figure 4-2. Thermal Image versus Conventional Photograph

Instrument category B is also made up of solid state line scanners. A line scanner scans a single line in only one plane of its field-of-view. The resulting display shows an analog trace of the single line scanned. Some line scanners superimpose the analog trace on top of the actual projected scene, and others simply display the analog trace on the screen of an oscilloscope. Barnes Engineering, Inframetrics, and Laser Precision provide instrumentation of this type. Line scanner prices may range from $\$ 3,000$ to $\$ 30,000$ (refer to Table $4-2$ ). 
Table 4-2. IR Thermographic Systems

\begin{tabular}{|c|c|c|c|c|c|c|c|c|}
\hline $\begin{array}{l}\text { System } \\
\text { Type }\end{array}$ & Manufacturer & $\begin{array}{l}\text { Spectral } \\
\text { Range }\end{array}$ & FOV & $\begin{array}{l}\text { Minimum } \\
\text { Resolvable } \\
\text { Temperature }\end{array}$ & $\begin{array}{c}\text { Temperature } \\
\text { Range }\end{array}$ & $\begin{array}{l}\text { Display } \\
\text { Type }\end{array}$ & $\begin{array}{l}\text { Approx. } \\
\text { Cost }\end{array}$ & $\begin{array}{c}\text { Man } \\
\text { Portable }\end{array}$ \\
\hline Solid State Imaging & $\begin{array}{l}\text { AGA } \\
\text { Model } 750 \\
\text { Model } 680\end{array}$ & $\begin{array}{l}2 \text { to } 5.6 \mu \mathrm{m} \\
7 \text { to } 12 \mu \mathrm{m}\end{array}$ & $\begin{array}{r}45^{\circ} \times 45^{\circ} \\
25^{\circ} \times 25^{\circ} \\
15^{\circ} \times 15^{\circ} \\
8^{\circ} \times 8^{\circ} \\
2^{\circ} \times 8^{\circ}\end{array}$ & $0.2^{\circ} \mathrm{C}$ at $30^{\circ} \mathrm{C}$ & & $\begin{array}{l}\text { CRT Monitor } \\
\text { CRT Monitor }\end{array}$ & $\begin{array}{l}\$ 40,000.00 \\
\$ 62,000.00\end{array}$ & $\begin{array}{l}\text { Yes } \\
\text { No }\end{array}$ \\
\hline Solid State Imaging & $\begin{array}{l}\text { Inframet rics } \\
\text { Model } 510\end{array}$ & 8 to $11 \mu \mathrm{m}$ & $30^{\circ} \times 22.5^{\circ}$ & $0.2^{\circ} \mathrm{C}$ & $0^{\circ} \mathrm{C}$ to $100^{\circ} \mathrm{C}$ & CRT Monitor & $\$ 20,000.00$ & Yes \\
\hline Solid State Imaging & $\begin{array}{l}\text { Inframet rics } \\
\text { Model } 810\end{array}$ & 8 to $14 \mu \mathrm{m}$ & $\begin{array}{l}10^{\circ} \times 10^{\circ} \\
25^{\circ} \times 25^{\circ}\end{array}$ & 0.05 at $30^{\circ} \mathrm{C}$ & $-50^{\circ}$ to $500^{\circ} \mathrm{C}$ & CRT Monitor & $\$ 30,000,00$ & No \\
\hline Solid State Imaging & $\begin{array}{l}\text { Hughes Ind. } \\
\text { Products Div. } \\
\text { Probeye }\end{array}$ & 2 to $5.6 \mu \mathrm{m}$ & $18^{\circ} \mathrm{H} \times 7.5^{\circ} \mathrm{V}$ & $0.1^{\circ}$ at $25^{\circ} \mathrm{C}$ & $-25^{\circ}$ to $850^{\circ} \mathrm{C}$ & $\begin{array}{l}6 \text { LED } \\
10: 1 \text { Interlace } \\
\text { Viewing Screen }\end{array}$ & $\$ 6,000.00$ & Yes \\
\hline Solid State Imaging & $\begin{array}{l}\text { Philips Audio } \\
\text { Visual Systems } \\
\text { AN/PAS-7 }\end{array}$ & $\begin{array}{l}\mathrm{Pb}-\mathrm{SE} \\
3 \text { to } 5 \mu \mathrm{m}\end{array}$ & $12^{\circ} \mathrm{H} \times 6^{\circ} \mathrm{V}$ & $0.2^{\circ} \mathrm{K}$ at $25^{\circ} \mathrm{C}$ & & $\begin{array}{l}48 \text { LED View- } \\
\text { ing Screen }\end{array}$ & $\$ 15,000.00$ & Yes \\
\hline Solid State Imaging & $\begin{array}{l}\text { Spectrotherm } \\
\text { Model } 800\end{array}$ & $\begin{array}{l}\text { HqCdTe } \\
8 \text { to } 14 \mu \mathrm{m}\end{array}$ & $30^{\circ} \times 30^{\circ}$ & $0.2^{\circ} \mathrm{C} \mathrm{rms}$ & $\begin{array}{l}2-16^{\circ} \mathrm{C} \text { in } 12 \\
\text { steps } \\
20-160^{\circ} \mathrm{C} \text { in } 12 \\
\text { steps }\end{array}$ & CRT & $\$ 38,225.00$ & No \\
\hline $\begin{array}{l}\text { Solid State Line } \\
\text { Scanner }\end{array}$ & $\begin{array}{c}\text { Inframetrics } \\
\text { Model } 401 \\
\text { Model } 200\end{array}$ & $\begin{array}{l}\text { InSb } \\
2 \text { to } 5.6 \mu \mathrm{m} \\
\text { HqCdTe } \\
8 \text { to } 14 \mu \mathrm{m}\end{array}$ & $\begin{array}{l}10^{\circ} \times 2.5^{\circ} \\
10^{\circ} \mathrm{H}\end{array}$ & $\begin{array}{l}0.2^{\circ} \text { at } 30^{\circ} \mathrm{C} \\
0.5^{\circ} \text { at } 30^{\circ} \mathrm{C}\end{array}$ & $\begin{array}{l}0^{\circ} \text { to } 2000^{\circ} \mathrm{C} \\
-20^{\circ} \text { to }+150^{\circ} \mathrm{C}\end{array}$ & $\begin{array}{l}\text { X-Y Display } \\
\text { Output } \\
\text { X-Y Display } \\
\text { Included }\end{array}$ & $\begin{array}{l}\$ 7,800.00 \\
\$ 30,000.00\end{array}$ & No \\
\hline
\end{tabular}


Table 4-2, IR Thermographlc Systems (Cont'd)

\begin{tabular}{|c|c|c|c|c|c|c|c|c|}
\hline $\begin{array}{l}\text { System } \\
\text { Type }\end{array}$ & Manufacturer & $\begin{array}{l}\text { Spectral } \\
\text { Range }\end{array}$ & FOV & $\begin{array}{c}\text { Minimum } \\
\text { Resolvable } \\
\text { Temperature }\end{array}$ & $\begin{array}{c}\text { Temperature } \\
\text { Range }\end{array}$ & $\begin{array}{l}\text { Display } \\
\text { Type }\end{array}$ & $\begin{array}{l}\text { Approx. } \\
\text { Cost }\end{array}$ & $\begin{array}{c}\text { Man } \\
\text { Portable }\end{array}$ \\
\hline $\begin{array}{l}\text { Solid State Line } \\
\text { Scanner }\end{array}$ & $\begin{array}{l}\text { Barnes Engi- } \\
\text { neering } \\
\text { Therm-A- } \\
\text { Trace }\end{array}$ & $\begin{array}{l}\text { Triglycine } \\
\text { Sulfate (TgS) } \\
2 \mu \mathrm{m} \\
300, \mu \mathrm{m}\end{array}$ & $24^{\circ} \times 24^{\circ}$ & ${ }_{\text {at }}^{0.1^{\circ} \mathrm{rms}}$ & $0^{\circ} \mathrm{C}$ to $1000^{\circ} \mathrm{C}$ & $\begin{array}{l}100 \text { element } \\
\text { LED array } \\
\text { superimpósed } \\
\text { on scene }\end{array}$ & $\begin{array}{l}\text { (Estimated) } \\
\$ 6,000.00\end{array}$ & Yes \\
\hline $\begin{array}{l}\text { Solid State Line } \\
\text { Scanner }\end{array}$ & $\begin{array}{l}\text { Laser Precision } \\
\text { Corp. } \\
\text { Pyroanalyzer } \\
\text { Series }\end{array}$ & 0.3 to $45 \mu \mathrm{m}$ & $6^{\circ}$ & $2.0^{\circ}$ at $25^{\circ} \mathrm{C}$ & $25^{\circ}$ to $2500^{\circ} \mathrm{C}$ & $\begin{array}{l}X / Y \text { signal } \\
\text { output pro- } \\
\text { vided }\end{array}$ & $\$ 3 ; 000.00$ & No \\
\hline Pyroelectric Vidicon & $\begin{array}{l}\text { ITM, Inc. } \\
\text { Sudbury, Ma. } \\
\text { Model } 202 / \mathrm{A}\end{array}$ & 2 to $15 \mu \mathrm{m}$ & Variable & $0.25^{\circ} \mathrm{C}$ & & $\begin{array}{l}\text { Video output } \\
\text { signal pro- } \\
\text { vided }\end{array}$ & $\$ 15,000.00$ & \\
\hline Pyroelectric Vidicon & $\begin{array}{l}\text { RKB } \\
\text { Pyrigral } \\
\text { (System } \\
\text { conceptual) }\end{array}$ & 8 to $14 \mu \mathrm{m}$ & Not given & Not given & Not given & TV Monitor , & $\begin{array}{c}\text { (Estimated) } \\
\$ 30,000.00 \\
.\end{array}$ & No \\
\hline Pyroelectric Vidicon & $\begin{array}{l}\text { ISI Group } \\
\text { Thermal } \\
\text { Imaging } \\
\text { TV System }\end{array}$ & 8 to $14 \mu \mathrm{m}$ & Not given & Not given & Not given & $\begin{array}{l}\text { Video output } \\
\text { signal pro- } \\
\text { vided }\end{array}$ & $\begin{array}{l}\text { (Estimated) } \\
\$ 16,000.00\end{array}$ & No \\
\hline IR Thermometer. & $\begin{array}{l}\text { Barnes Engi- } \\
\text { neerlng } \\
\text { Model PRT-10 }\end{array}$ & 6.5 to $20 \mu \mathrm{m}$ & $28^{\circ}$ (or) $2.8^{\circ}$ & $0.2^{\circ} \mathrm{C}$ & $-10^{\circ}$ to $60^{\circ} \mathrm{C}$ & Analog Meter & $\$ 990.00$ & Yes \\
\hline IR Thermometer & $\begin{array}{l}\text { Williamson } \\
\text { Model HLA } \\
\text { Model } 600 \\
\text { Model } 2000\end{array}$ & $\begin{array}{l}\text { Thermister } \\
\text { Flake }<.3 \mu \mathrm{m} \\
\text { Lead Sulfide } \\
0.6 \text { to } 3.0 \mu \mathrm{m} \\
2.8 \text { to } 3.3 \mu \mathrm{m}\end{array}$ & $22^{\circ}$ & $\begin{array}{l}0.1^{\circ} \mathrm{C} \\
1.0^{\circ} \mathrm{F} \\
.25^{\circ} \mathrm{C} \text { at } \\
25^{\circ} \mathrm{C}\end{array}$ & $\begin{array}{l}-25^{\circ} \text { to } 100^{\circ} \mathrm{C} \\
40^{\circ} \text { to } 1100^{\circ} \mathrm{C} \\
25^{\circ} \text { to } 1640^{\circ} \mathrm{C}\end{array}$ & $\begin{array}{l}\text { Analog Meter } \\
\text { Analog Meter } \\
\text { Digital Dis- } \\
\text { play }\end{array}$ & $\begin{array}{l}\$ 2,000.00 \\
\$ \quad 625.00 \\
\$ 1,690.00\end{array}$ & $\begin{array}{l}\text { Yes } \\
\text { Yes } \\
\text { Yes }\end{array}$ \\
\hline
\end{tabular}


Table 4-2. IR Thermographic Systems (Cont'd)

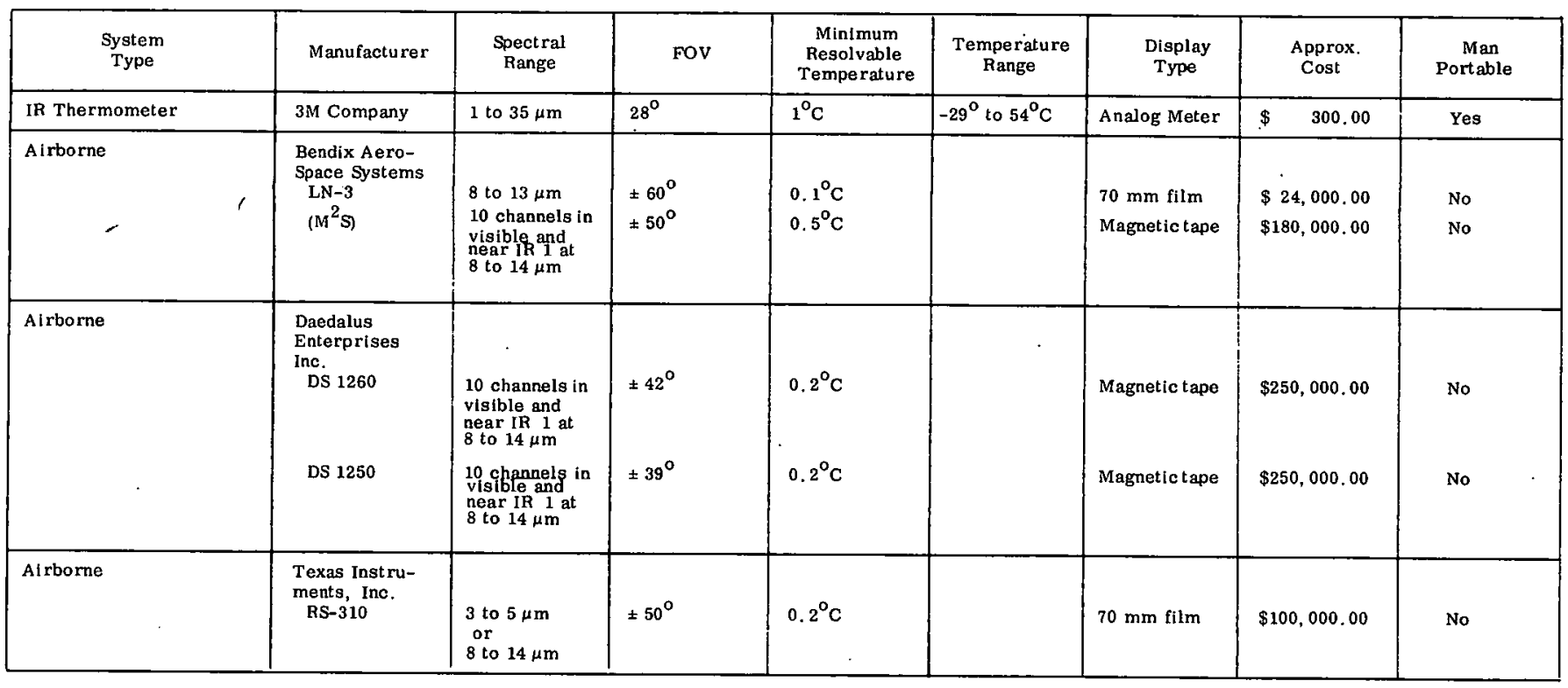




\subsubsection{Solid State Detectors}

An infrared detector can be simply described as a transducer of radiant energy in that it converts radiant energy into some other form (e.g., electrical current). Infrared detectors are classified into three basic groups according to the wavelength region of the infrared spectrum in which they have the best responsivity. Figure 4-3 shows the spectral regions typical of detectors used in visible and infrared systems. All of the instruments surveyed for infrared thermography of buildings use one of three types:

1. Indium Antimonide in the 2 to $6 \mu \mathrm{m}$ range,

2. Mercury cadmium telluride in the 8 to $14 \mu \mathrm{m}$ range, or

3. Monoc rystalline triglycine sulfate which extends from 2 to $300 \mu \mathrm{m}$.

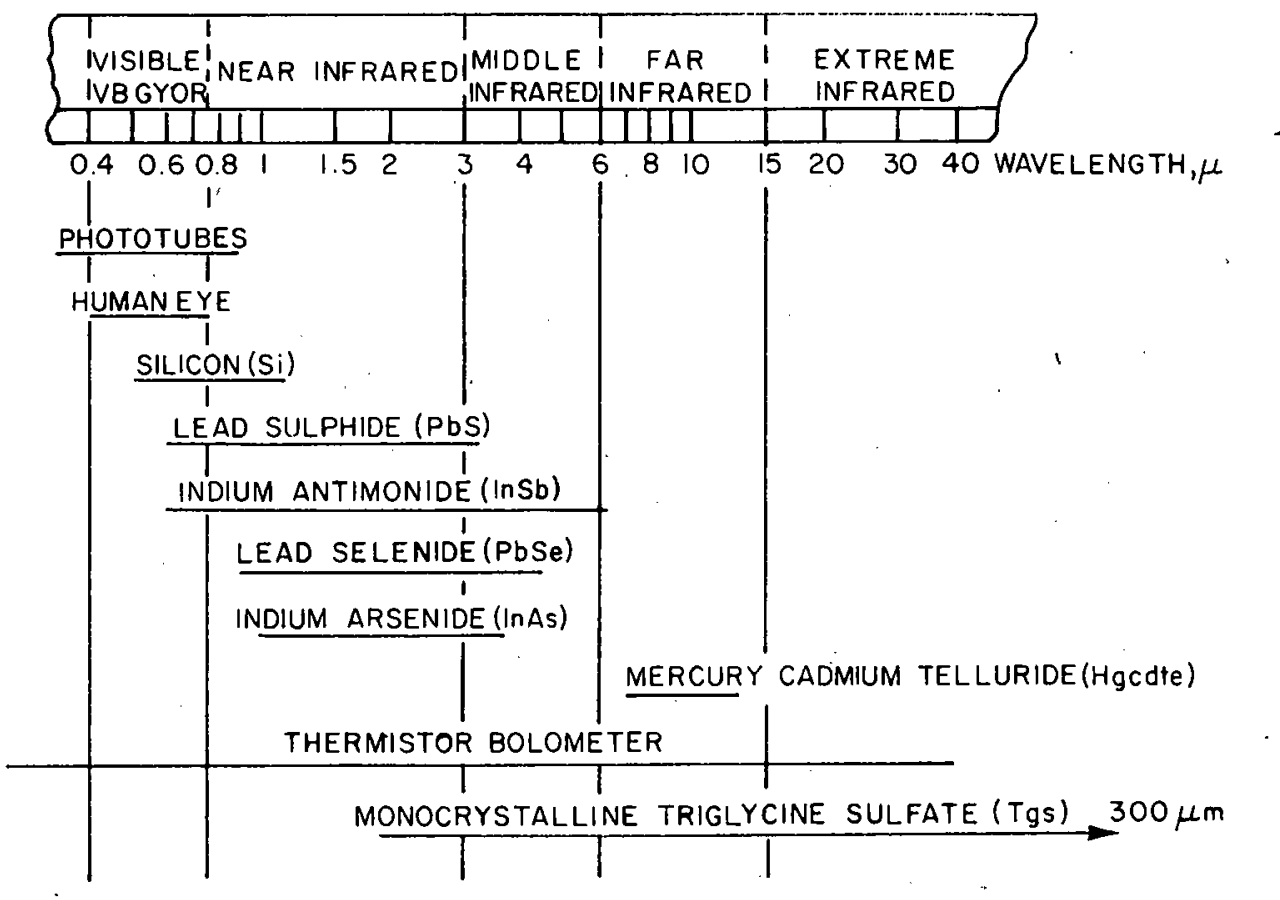

Figure 4-3. Typical Detectors

Table 4-2 lists various detector types used in each manufacturer's individual system. 


\subsubsection{Solid State Specifications}

System specifications can be conveniently divided into four segments: optical data, electrical data, performance data, and physical data. Fundamental system properties such as optical transfer function, field-of-view, image signal-to-noise ratio, frame rate, spectral range, etc., fall under the first two categories.

"Each of these properties describes only a small part of a system's ability to perform practical tasks. They are useful ways to characterize a design, but other measures which combine them in ways appropriate to particular tasks are needed in order to conduct performance trade-offs. The ideal such summary performance measure must include the observer's limitations, must be predictable from fundamental system parameters, must be easily measurable, and must relate to the performance of the system as it is ultimately intended to be used. ${ }^{1}$

The specifications contained in segment four (performance data) are designed to accomplish this task. In real life applications this is not always the case.

It is commonly thought that if one knows a system's resolution in terms of milliradians, and that it will recognize an object at $\mathrm{X}$ meters, then one can confidently predict the resulting recognition capabilities. However, the inclusion of thermal sensitivity changes due to object temperature variations, and atmospheric absorption effects, make this assumption less than accurate.

"Two nominally equivalent systems may have different signal transfer functions, raster effects, frame rates, and magnifications. Performance is sensitive to these variations, and it is commonplace to find in a competition that one system is preferable to another even though both are nominally the same. "

In addition to the technological variables influencing predictable performance data, there seems to be no common standard for descriptive terms used to describe performance data. For example, instantaneous field-of-view, spatial resolution, and precision are used interchangeably. Additionally, instantaneous field-of-view at 50 percent cont rast may be totally different at 10 percent or 90 percent contrast ratios.

$\overline{1}$ J. M. Lloyd, "Thermal Imaging Systems, " Plenum Press, New York, N. Y., p. 166 
Temperature measurement data also have conflicting terms. Minimum detectable temperature (MDT), minimum resolvable temperature (MRT), and thermal sensitivity are all used to describe temperature detection performance. Most manufacturers specify the MRT as some increment of temperature in either degrees Celsius, Kelvin, or Fahrenheit. The problem does not stop here. The MRT or temperature sensitivity changes at different object temperatures. Most manufacturers only specify the MRT as a function of one object temperature. Some just give an MRT with no reference to object temperature. The detailed specifications should be used very carefully before drawing any conclusions concerning quantitative measurements for infrared thermography. Qualitative possibilities can be presumed through manufacturers' published specifications, yet even then actual field trials may be more in order before final purchase is made. It should be noted that all of the specifications contained within this survey have been taken directly from manufacturers' published specification sheets.

\subsection{PYROELECTRIC VIDICON CAMERAS (Reference Table 4-3)}

Unlike solid state IR images which are based on arrays of quantum detectors, operating at cryogenic temperature, pyroelectric vidicons (PEV) operate at room temperature in a modified video camera.

"These devices, which sense directly the differences in the thermal scene, presently have a capability of resolving temperature differences of $0.3^{\circ} \mathrm{C}$ at a resolution of $100 \mathrm{TV}$ lines/picture height with $\mathrm{f} / 1.0$ germanium optics. " 1

Although the PEV is an efficient energy sensor from $2 \mu \mathrm{m}$ to $350 \mu \mathrm{m}$, a germanium window is used in front of the detector to limit the response to the 8 to $14 \mu \mathrm{m}$ spectral region. To view stationary objects, however, one must either pan the scene or modulate the information using a chopper wheel. A change of the scene (e.g., a change in the temperature) on the TGS crystal results in a change in the surface potential of the crystal. The vidicon electron beam is then used to sense the change of potential, and deposits a charge on the crystal surface to reestablish an equipotential at approximately cathode potential. This deposition of charge is the video signal. Figure 4-4 shows the minimum resolvable temperature versus integration time, and Figure 4-5 shows the performance of present and projected PEV's.

${ }^{1}$ Richard Kurczewski, "Pyroelectric Vidicon Camera System, " Philips Laboratories, Briarcliff Manor, New York, 1975, p. 1 


\begin{tabular}{|c|c|c|}
\hline Manufacturer & Contact Summary & Person Contácted \\
\hline $\begin{array}{l}\text { Amperex Electronic Corp. } \\
\text { A North American Philips } \\
\text { Co. } \\
\text { Electro-Optical Devices } \\
\text { Div. } \\
\text { Providence Pike } \\
\text { Slatersville, R. I. } \\
02876\end{array}$ & $\begin{array}{l}\text { Phone contact made by ARI representative. } \\
\text { Manufacturer's brochures forwarded through } \\
\text { the mail. }\end{array}$ & $\begin{array}{l}\text { Dr. Ralph S. Levitt } \\
\text { Product/Market } \\
\text { Manager, New Products } \\
(401) 762-3800 \\
\text {. }\end{array}$ \\
\hline $\begin{array}{l}\text { Thomson - CSF } \\
\text { Electron Tubes } \\
750 \text { Bloomfield A venue } \\
\text { Clifton, New Jersey } \\
07015\end{array}$ & $\begin{array}{l}\text { Phone contact made by ARI representative. } \\
\text { Manufacturer's brochures forwarded through } \\
\text { the mail. }\end{array}$ & $\begin{array}{l}\text { Robert J. KeeHammer } \\
\text { Product Manager for } \\
\text { Imaging Devices } \\
(201) 779-1004\end{array}$ \\
\hline $\begin{array}{l}\text { Barnes Engineering Co. } \\
30 \text { Commerce Road } \\
\text { Stamford, Connecticut } \\
06904\end{array}$ & $\begin{array}{l}\text { Mr. Leftwich visited ARI facility. Answered } \\
\text { questions, provided manufacturer's brochures } \\
\text { and data from contract DAAG } 46-76-C-0013 \\
\text { entitled "Pyroelectric Vidicon Evaluat ion" }\end{array}$ & $\begin{array}{l}\text { Richard F. Leftwich } \\
\text { Manager, Product Appli- } \\
\text { cations and Planning } \\
\text { (203) } 348-5381\end{array}$ \\
\hline $\begin{array}{l}\text { RKB, Inc. } \\
5 \text { Alfred Circle } \\
\text { Bedford, Mass. } \\
01730\end{array}$ & $\begin{array}{l}\text { ARI representative visited RKB, Inc. Manu- } \\
\text { facturer's brochures were provided. No } \\
\text { demonstration system available for viewing. }\end{array}$ & $\begin{array}{l}\text { Dr. Richard K. Brehm } \\
\text { President } \\
\text { (617) } 275-6566\end{array}$ \\
\hline $\begin{array}{l}\text { ISI Group, Inc. } \\
133 \text { Jackson St. , NE } \\
\text { A lbuque rque, N. M. } \\
97108\end{array}$ & $\begin{array}{l}\text { Phone contact by ARI representative. Manu- } \\
\text { facturer's brochures were provided by mail. }\end{array}$ & $\begin{array}{l}\text { Tom Anderson } \\
(505) 265-6771\end{array}$ \\
\hline $\begin{array}{l}\text { ITM Incorporated } \\
\text { Image Technology Methods } \\
\text { P.O. Box } 385 \\
\text { Sudbury, Mass. } 01776\end{array}$ & $\begin{array}{l}\text { Mr. Newitt visited ARI, discussed their } \\
\text { system that includes edge enhancement and } \\
\text { supplied brochure material. }\end{array}$ & John Newitt, President \\
\hline
\end{tabular}




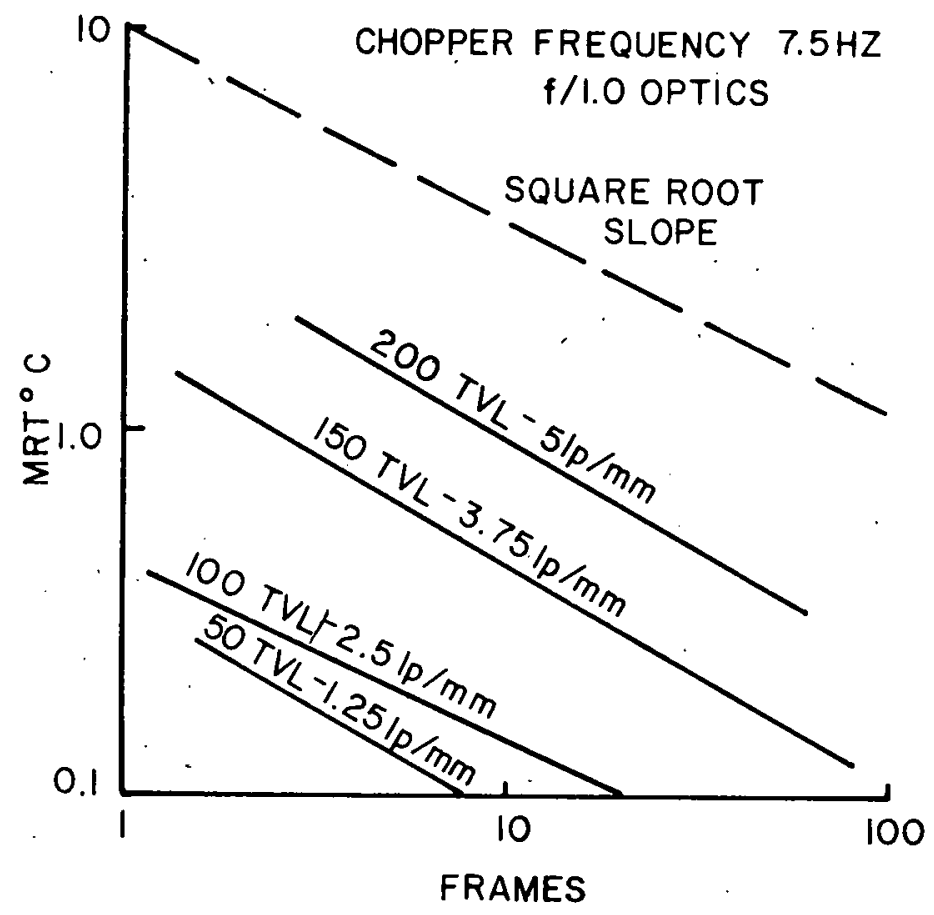

Figure 4-4. Minimum Resolvable Temperature versus Integration Time

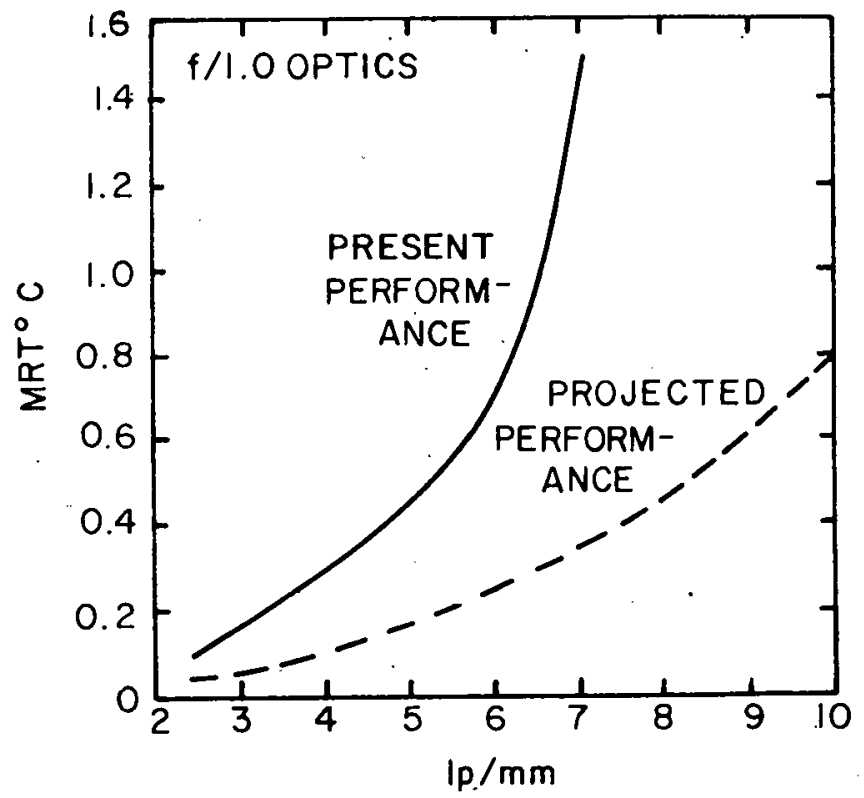

Figure 4-5. Performance of Present and Projected PEV's 
Although PEV tube manufacturers (Thomson CSF and Amperex) indicate that PEV's are mature devices ready for application in the commercial sector, very few companies were discovered during this survey that are actually producing pyroelectric vidicon systems on a quantity basis.

Experimental work has been done by Barnes Engineering Co. for the Army Materials and Mechanics Research Center, Watertown, Massachusetts. Three commercially available PEV systems were discovered during this survey. The first consists of a modified video camera and TV-compatible interface offered by the ISI Group, Inc. (reference Table 4-2) for about $\$ 16,000$. The second system is offered by RKB, Inc. as a complete thermal imaging system. The RKB system uses the ISI Group camera in conjunction with an RKB polyprocessor TV display system for an approximate cost of $\$ 30,000$. It should be noted that the RKB system is not in production at the time of this survey. Manufacturers' performance specifications for both of these systems are quite incomplete. However, pyroelect ric vidicon technology does offer the possibility of low cost (in quantity), uncooled, TV compatible performance in the near future.

\subsubsection{Representative Vidicon Camera System}

ITM, Inc. in Sudbury, Mass, is perhaps representative of what can be expected with a high quality pyroelectric vidicon camera system.

The Models 202/A hard tube and 202/B soft tube pyroelectric vidicon scanners provide standard composite 525 line TV signal for real time imaging of low temperature and sub-zero scenic phenomena. The scanners directly drive stock video monitors, tape recorders, video disk units and scan converter storage devices.

The compact, solid-state, self contained scanner units are provided in a ruggedized die-cast case and require no cryogenic cooling. The units, without lens, weigh $10 \mathrm{lbs}$. and measure only $12^{n} \times 5^{n} \times 3-1 / 2^{n}$. A $24 \mathrm{VDC}$ prime power input is provided fọr hand-held roving surveillance with portable monitors and/or backpack video tape recorders. Line cord power adaptors provide operation from 12VDC and 115VDC. The units are designed for remote mode switching and control from fixed unattended 
locations in hostile or adverse environments. All adjustment and remote-local mode switching facilities including master/slave sync control are provided on the rear panel facility of the scanner unit and short of a major malfunction, it should never be necessary to open the scanner case.

A single BNC coaxial terminal provides all video output signal modes. A strip line connector is used for remote mode switching and internal-external sync control.

Lens, filter and chopper facility options are conveniently interchanged from a universal optical mounting provided on the face of the scanner unit.

Lens Requirement - The inherently low energy levels characteristic of ambient thermal emissions require the use of large aperture lenses for bright, high contrast imaging and small MRT. $\mathrm{T} / 1$ or $\mathrm{f} / 1$ apertures are desirable for passive lowtemperature imaging in the 8 to 12 micron spectral range. Higher energy responses (such as those provided by laser illumination) may utilize a less expensive smaller aperture lens ( $\hat{f} / 2.5$ or higher). When the anticipated emissive energy range is substantial (situations involving large temperature or energy differentials), it is desirable to use a variable aperture control lens (f / 4 or higher) to prevent saturation of a sensitively adjusted detector by the higher energy emissions. With the ITM LOGAMP module, a greatly extended dynamic range is provided and aperture control is not required for the non-saturated imaging of temperature differentials involving many hundreds of degrees. The extended gray-scale linearity and dynamic range provided by the LOGAMP ${ }^{\mathrm{R}}$ module not only simplifies measurement procedures by a linearization of the gray-scale response, but facilitates remote control operation by not requiring f -stop adjustment.

Lens assemblies for 2 to 15 micron far IR imagery vary considerably in weight and size, depending upon the application. With ITM Model 202/A scanner, a common $3-1 / 2$ " $\times 5$ " $\times 1 / 2$ " QUICKMOUNT ${ }^{\mathrm{R}}$ adaptor is provided as a universal coupling means for all lens and chopper elements applied to the scanner. The QUICKMOUNT ${ }^{R}$ adaptor which accepts the lens fastens directly to the face of the scanner by means of four knurled captive screws. Various lens may thus be quickly and interchangeably deployed 
on the face of the scanner. Various configurations of the QUICKMOUNT ${ }^{\mathrm{K}}$ adaptor may be provided to include special purpose devices such as filters, choppers and the rmal reference probes.

Germanium lenses are used for lower-temperature long-wavelength imagery ( 8 to 12 microns) because of their uniform index of refraction. IRTRAN lenses may be used for the shorter wavelength ( 3 to 5 microns) band. Reflective optics are recommended for narrow angle remote imaging service and for microscopic work. Although somewhat heavier than reflective lenses, refractive lenses are smaller in size and provide greater convenience in close up and wide angle service. Narrow angle telescopic optics may be provided to image artifacts beyond 30 feet. To provide useful detail, it is desirable to keep scenic artifasts of interest large with respect to the vidicon imaging surface. Beyond 30 feet, such a procedure may require a lens which is specifically configured to an application requirement.

Performance - The ITM Model 202/A and B pyroelectric scanners utilize basic electrical and mechanical standards and features. One major operational difference between the pyroelectric scanner and the conventional scanner should be noted. Negative charges, not experienced to an objectionable degree in the conventional vidicon, tend to accumulate on the high-impedance matrix (target) of the pyroelectric vidicon and will disorientate the crystal domains of the detecting structure and interfere with the imaging action unless removed. Provision for charge removal must be continuous to maintain a suitable condition for imaging. Pyroelectric vidicons utilize special poling circuitry for target "cleanup" in addition to the circuitry required for normal vidicon operation. Because of the mode of target restoration, the soft and hard tube vidicons employ a distinct poling procedure. ITM Model 202/A and $B$ scanners therefore are not interchangeable devices. Soft tube pyroelectric vidicons use ionizing gas (usually helium) to remove the target charges.

Due to the operational conditions caused by aging of the ionizing gas into the tube elements of the soft tube pyroelectric vidicon, soft tube scanners are sometimes difficult to start up after a quiescent period. Although service reliability of several thousand continuous hours has been experienced with soft tube vidicons, it is difficult to 
assure turn-on reliability and consistently reliable performance from the soft tube devices. For applications involving long unattended service, thermal measurement, remote operation and turn-on reliability, the hard tube scanner is recommended. For constantly-attended viewing-only surveillance applications, the soft tube pyroelectric vidicon can provide the user with substantially equal sensitivity and otherwise completely acceptable performance.

While constant poling is required to maintain a proper imaging condition on the pyroelectric vidicon target, manual poling may be instituted to supplement or speed up the poling process. In situations where the vidicon has been inadvertently subjected to excessive levels of radiation, or where it is simply desirable to expedite turn-on, the manual poling mode may be utilized. In the case of the hard tube vidicon, poling is accomplished by encouraging secondary emission from the target during the blanking cycle by power application. Since charge removal during the retrace duty cycle is a matter of time and the amount of accumulated charge, target clean-up can be expedited by scanning intervention and $100 \%$ duty cycle manual poling under toggle switch control. Poling for the soft tube is produced by continuous ion bombardment of the target during normal operation. Soft tube poling may be accelerated by scanning intervention and manual switch control of the ionizing action.

Once the pyroelectric vidicon is set into proper continuous operation, manual poling of the target should not be required except as an emergency, precautionary or start-up convenience. The need for frequent manual poling would be indicative of improper operating conditions or an erratic tube condition and would serve as forewarning of the need for scanner maintenance or readjustment.

Sensitivity and Resolution - Ambient thermal gradient's with differentials as small as a quarter of a degree may be contrasted easily at an optical resolution of $100 \mathrm{TV}$ lines $(3 \mathrm{lp} / \mathrm{mm})$, using a pyroelectric vidicon scanner operating directly into a standard TV monitor. Thermal differentials on the surface of the human body may be defined accurately and easily in this manner. Considerably higher resolution (to $350 \mathrm{TV}$ lines) with $0.25^{\circ} \mathrm{MRT}$ thermal contrast is achievable at somewhat increased cost by the use of $\mathrm{T} / 1$ (f/0.7) lenses and controllable lag, high resolution vidicons. 
With the linear gray-scale response, provided by the ITM LOGAMP ${ }^{\mathrm{R}}$ module, measuring and enhancing analyzers may be driven by the video output signal of the scanner for increased scenic definition ${ }^{1}$ and/or a quantitive readout of the gradient values.

Special Features - ITM Model 200 Series Scanners provide several operating features designed to take maximum advantage of the imaging capability of the pyroelectric vidicon; these are:

1. Synchronous chopping for high-quality flicker-free pictures With properly controlled vidicon lag characteristics ${ }^{2}$ the IR path to the scanner may be chopped synchronously to provide a high resolution dynamic picture which is virtually flicker-free. Heat spread in the imaged view normally increases with each successive unchopped video frame delivered to the monitor. The result of several successive unchopped video frames (provided at low chopping speeds) therefore serves to progressively deteriorate the monitored image view. A scan converter may be used to "snatch" and freeze an initial high quality TV frame immediately after chopper unblanking but the user is then limited to operation with a frozen picture. For high-quality dynamic-viewing, chopping should be provided at each TV frame to prevent image deterioration. A synchronous chopper device is required to meet such a condition.

\section{Wide dynamic-range low-noise operation}

Extreme emission levels from an imaged objective will normally cause a sensitively adjusted detector to saturate. Sensitively adjusted scanners therefore should be provided with an $\mathrm{f}$-stop adjustment in the lens facility for the reduction of excessive levels of emission. A three-decade logarithmic scaling corrector plus a power provision for extension of the beaming action of the vidicon in Model 202/A and B scanners provides a facility which prevents amplifier saturation over a greatly extended emissive range. Very considerable ranges of operation, characteristic of laserilluminated patterns, may thus be imaged without encountering saturation or requiring the adjustment of scanner f-stop settings.

\footnotetext{
${ }^{1}$ Such as by edge or color encoding enhancement of the gray-scale gradients. ${ }^{2}$ Many pyroelectric vidicons do not have the proper lag characteristics for this action.
} 


\section{Linearity}

The gray scale linearity provided by logarithmic correction is helpful for conducting general purpose wide range thermal measurements. A low noise video amplifier is required in conjunction with the above facility to provide suitable sensitivity to image the more subtle thermal gradients and to provide the "floor" for the extended dynamic range (over 900:1) in the case of ITM Model 202/A scanner. Measuring devices applied to the linearized scanner signal may be used to provide quantitative data from the scenic view.

\section{Edge enhancement}

The normally blurry picture response caused by heat spread (even in a high-resolution chopping mode) can be improved substantially by use of the edgeenhancement option provided in Model 202/A scanner. With Model 202/A and B thermal scanners, an adjustable edge enhancing is provided under toggle switch option (and knob adjustment) from the rear panel of the instrument. Edge enhancement increases the rate of density change in the scanning of a picture to sharpen (enhance) interface responses. External enhancers such as gray scale color encoding quantizers, which operate from a standard video signal may be used to provide interpolation between barely discernible gray scale levels in the black and white imaged view.

\subsection{RADIOMETERS}

"An infrared radiometer converts radiant energy emitted by a target into electrical energy for focusing energy from the target onto the infrared detector. " 1

The electrical signal from the detector is converted directly into a temperature reading similar to a photographic light meter. The basic block diagram of an infrared radiometer is shown in Figure 4-6. Typically, an infrared radiometer is used to monitor narrow band, industrial processes in such industries as steel, plastics, paper, and petroleum, Table 4-4 lists four manufacturers of this type of instrumentation.

\footnotetext{
$\overline{1_{\text {"Elements }}}$ of Infrared Radiation, " Williamson Corp. Catalog, 1976.
} 


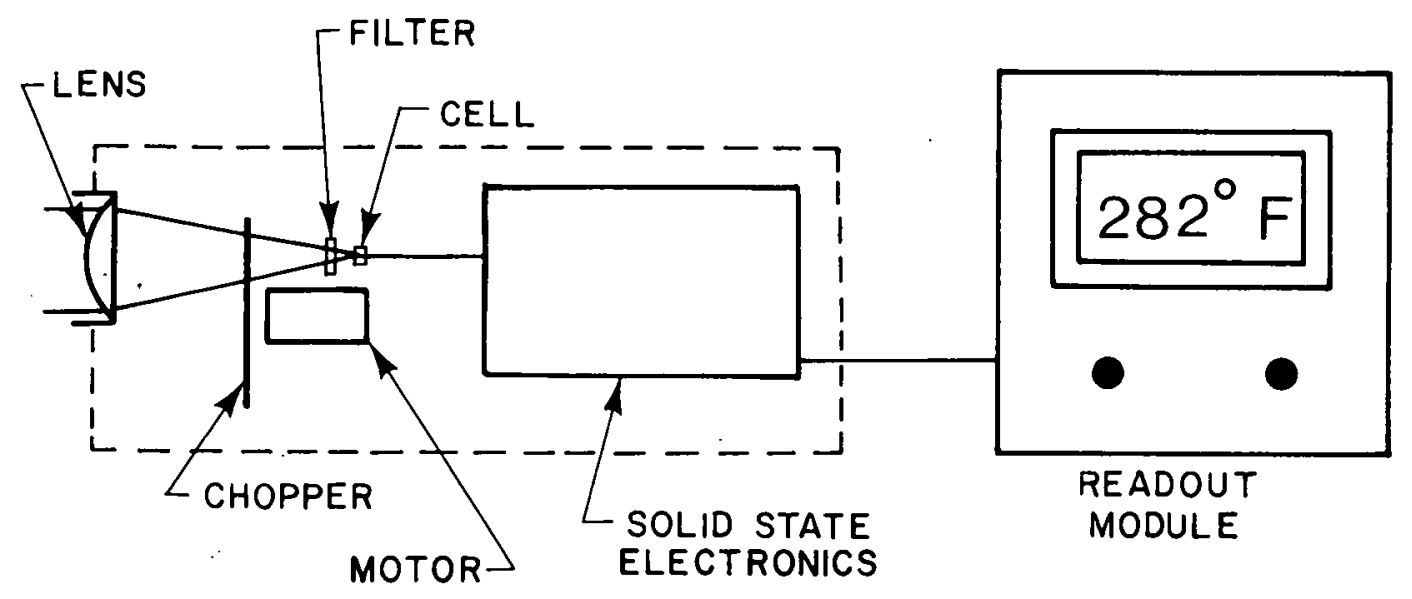

Figure 4-6. Basic Block Diagram of Infrared Radiometer

Radiometers have been included in this survey for several reasons; primarily, however, because they represent the low end of the cost scale for infrared measuring equipment ( $\$ 300$ to $\$ 1200$ ). They also represent the greatest simplicity in terms of operator skills required for successful operation. Some units with automatic calibration only require that they be aimed at the target and the temperature read from digital display. The temperature measurement error, however, occurs for nonunity emissivity of the radiating surface to the extent described in Section 3.

The Bay State Gas Co. of Boston, Massachusetts offers a free infrared house survey with one of these instruments. The actual scenario of use involves a zeroing of the instrument on the interior surface of an outside wall; the operator then quickly moves to the outside of the dwelling and measures the corresponding exterior surface of the same wall. Theoretically the difference between interior and exterior surface temperatures is an indication of the $R$ value of the wall.

The temperature error measurement includes instrument errors and the fact that inside and outside surface emissivities are different. The implicit thermal resistance measurement is in error by uncertainties in both inside and outside surface 
Table 4-4. List of Radiometer Manufacturers and Services Contacted

\begin{tabular}{|c|c|c|}
\hline $\begin{array}{l}\text { Manufacturers } \\
\text { or Services } \\
\text { Contacted }\end{array}$ & Contact Summary & Person Contacted \\
\hline $\begin{array}{l}\text { Barnes Engineering Co. } \\
30 \text { Commerce Road } \\
\text { Stamford, Connecticut } \\
06904\end{array}$ & $\begin{array}{l}\text { Mr. Leftwich visited ARI facility. Answered } \\
\text { questions, provided manufacturer's brochures } \\
\text { and data. }\end{array}$ & $\begin{array}{l}\text { Richa rd } F \text {. Leftwich } \\
\text { Manager, Product Appli- } \\
\text { cations and Planning } \\
\text { (203) } 348-5381\end{array}$ \\
\hline $\begin{array}{l}\text { Williamson Corporation } \\
1152 \text { Main Street } \\
\text { Concord, Mass. } \\
01742\end{array}$ & $\begin{array}{l}\text { A RI representative visited Williamson Corp. } \\
\text { Witnessed demonstration of equipment, and } \\
\text { secured manufacturer's brochures }\end{array}$ & $\begin{array}{l}\text { Charles } F . \text { Lanqenhagen, } \\
\text { Jr., President } \\
(617) 369-9607\end{array}$ \\
\hline $\begin{array}{l}\text { 3M Company } \\
\text { New Business Ventures } \\
\text { Divis ion } \\
\text { 3M Center, Building } 219 \\
\text { St. Paul, Minn. } \\
55101\end{array}$ & $\begin{array}{l}\text { Phone contact by ARI representative. } \\
\text { Brochures forwarded by mail. }\end{array}$ & $\begin{array}{l}\text { J. Sullivan } \\
\text { Manager of Firm's } \\
\text { Insulation Services } \\
(612) 733-1110\end{array}$ \\
\hline $\begin{array}{l}\text { Bay State Gas Co. } \\
995 \text { Belmont Street } \\
\text { Brockton, Mass. } \\
02401\end{array}$ & $\begin{array}{l}\text { Phone contact. Small hand-held close range } \\
\text { spot imager used to sense temperature dif- } \\
\text { ferentials when scanning. }\end{array}$ & $\begin{array}{l}\text { Dr. Taylor } \\
\text { Director of Engineering } \\
\text { (617) } 588-5990\end{array}$ \\
\hline
\end{tabular}


film resistance, and by uncertainties in knowledge of actual inside and outside temperature. The dynamic range of the instrument and its thermal resolution also limits its usefulness for this application. In principle, it is possible to tell the difference between an insulated and uninsulated wall. The conditions under which this determination can be made are highly fortuitous, however, even in the hands of knowledgeable engineers to the extent that these radiometers are not practicable for this application. (It should be noted that Bay State Gas is interested in selling insulation programs.) It is conceivable, however, that further refinement of this technique could produce an inexpensive, qualitative instrument for spot-checking by small economic units such as single builders, real estate brokers, etc.

\subsection{AIRBORNE SYSTEMS (Reference Table 4-5)}

Airborne systems have been segregated into the fourth and final group of infrared devices to be considered under this survey for two very obvious reasons-cost, and economics of scale.

"The scanning process is expensive. One of the leaders in infrared scanning, Daedalus Enterprises, Inc. of Ann A rbor, Michigan, charges colleges and universities from $\$ 7,000$ to $\$ 12,000$ depending on campus size. " 1

Outright purchase of a system approaches $\$ 250,000$.

Normally a Mercury-Cadmium Telluride (HqCdTe) roll-compensated scanner is used to pick up infrared energy as an aircraft flys over the target area. Digital scan data is stored on magnetic tape or $70 \mathrm{~mm}$ film which must be processed off-line for production of hard copy data. Figures 4-7 and 4-8 show examples of aerial hard copy data generated by Daedalus Enterprises, Inc. and Texas Instruments, Inc. Figure 4-7 shows leaky steam pipes on the Cornell University Campus (Daedalus) and Figure 4-8 shows a residential dwelling survey by the Texas Instruments group.

It is intuitively obvious that an airborne system can only achieve economies of scale when large geographic areas are to be scanned, such as multiplant facilities,

${ }^{1}$ Robert A. Hess, "Aerial Heat Sensing Detects Hidden Energy Waste," Airconditioning and Refrigeration Business, October, 1975. 
Table 4-5. List of Airborne Manufacturers Contacted

\begin{tabular}{|c|c|c|}
\hline Manufacturer & Contact Summary & Person Contacted \\
\hline $\begin{array}{l}\text { Bendix } \\
\text { Aerospace Systems Div. } \\
3621 \text { South State Road } \\
\text { Ann A rbor, Michigan } \\
48107\end{array}$ & $\begin{array}{l}\text { Phone contact by ARI representative. Manu- } \\
\text { facturers brochures and data forwarded by } \\
\text { mail. }\end{array}$ & $\begin{array}{l}\text { Eugene M. Zaitaeff } \\
\text { Program Development } \\
\text { Manager, Earth } \\
\text { Earth Resources } \\
\text { (313) 665-7766 }\end{array}$ \\
\hline $\begin{array}{l}\text { Daedalus Enterprises, } \\
\text { Inc. } \\
\text { P. O. Box } 1869 \\
\text { Ann A rbor, Michigan } \\
48106\end{array}$ & $\begin{array}{l}\text { Phone contact by ARI representative. } \\
\text { Manufacturer's brochures and data forwarded } \\
\text { by mail. }\end{array}$ & $\begin{array}{l}\text { Thomas R. Ory } \\
\text { Director } \\
\text { Applications Division } \\
\text { (313) } 769-5649\end{array}$ \\
\hline $\begin{array}{l}\text { Texas Instruments, Inc. } \\
\text { Services Group } \\
\text { P. O. Box } 5621 \\
\text { Dallas, Texas } \\
75222\end{array}$ & $\begin{array}{l}\text { Phone contact by ARI representative. Manu- } \\
\text { facturer's brochures and data forwarded by } \\
\text { mail. }\end{array}$ & $\begin{array}{l}\text { G. Suhren } \\
\text { (214) } 238-2011\end{array}$ \\
\hline
\end{tabular}




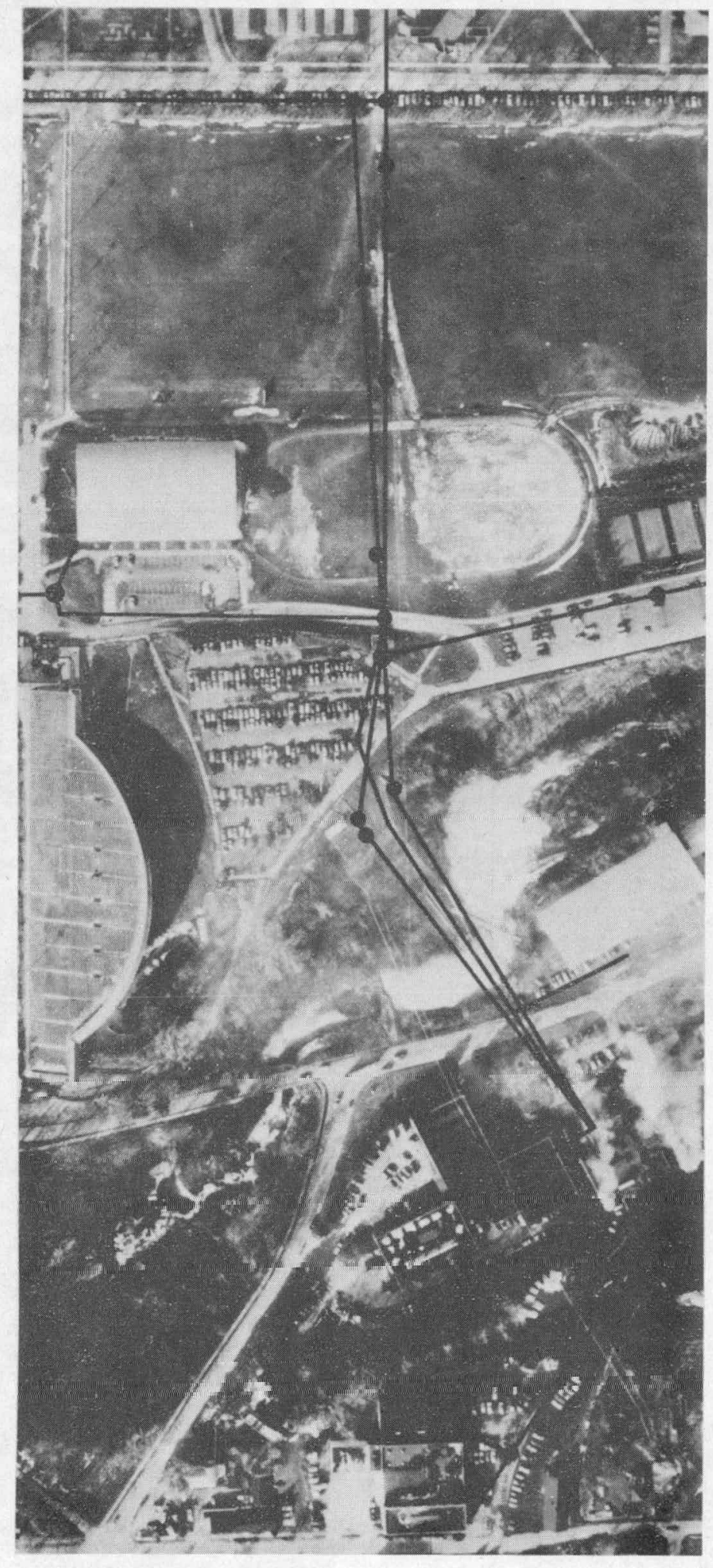

A - Photograph with pipe route overlay

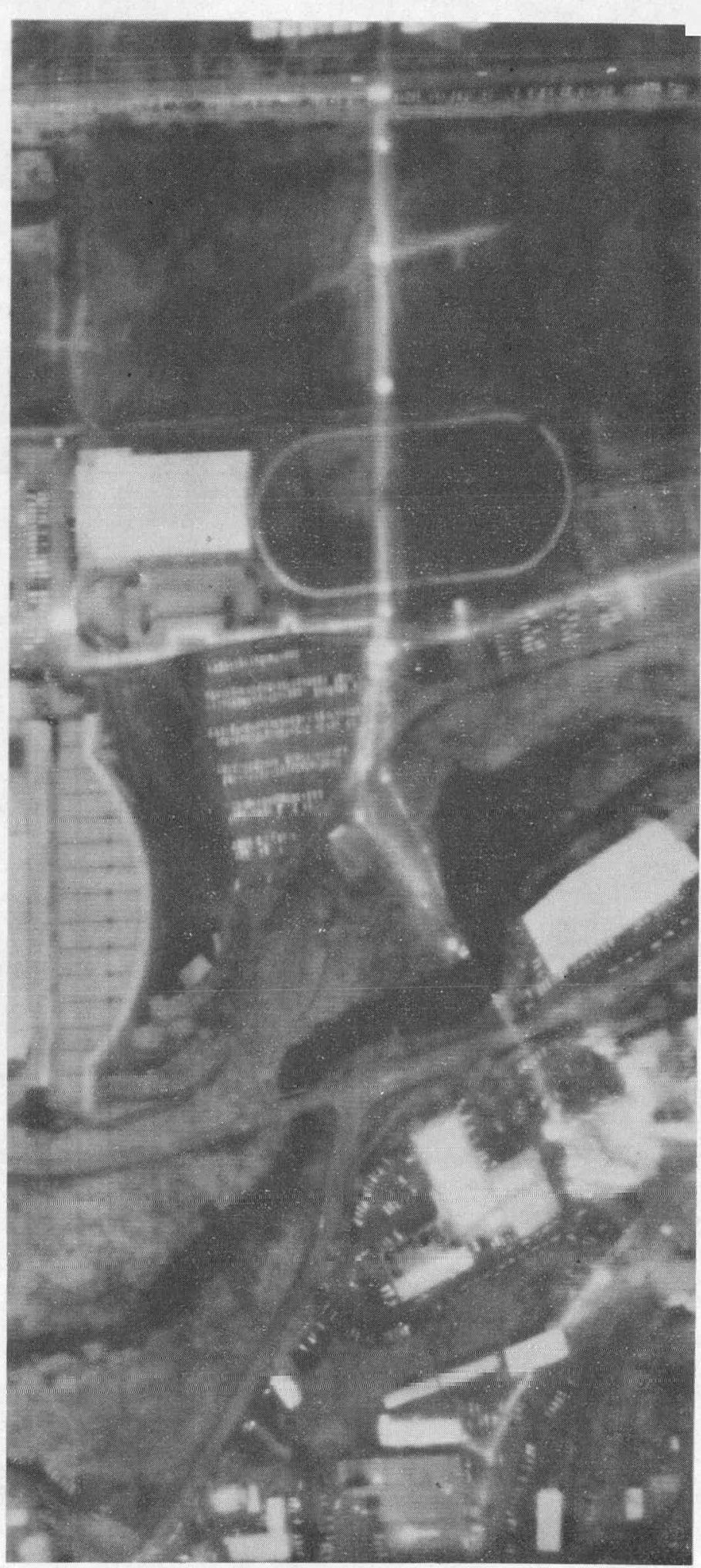

B - Continuous tone analog (IR)

(Daedalus) 


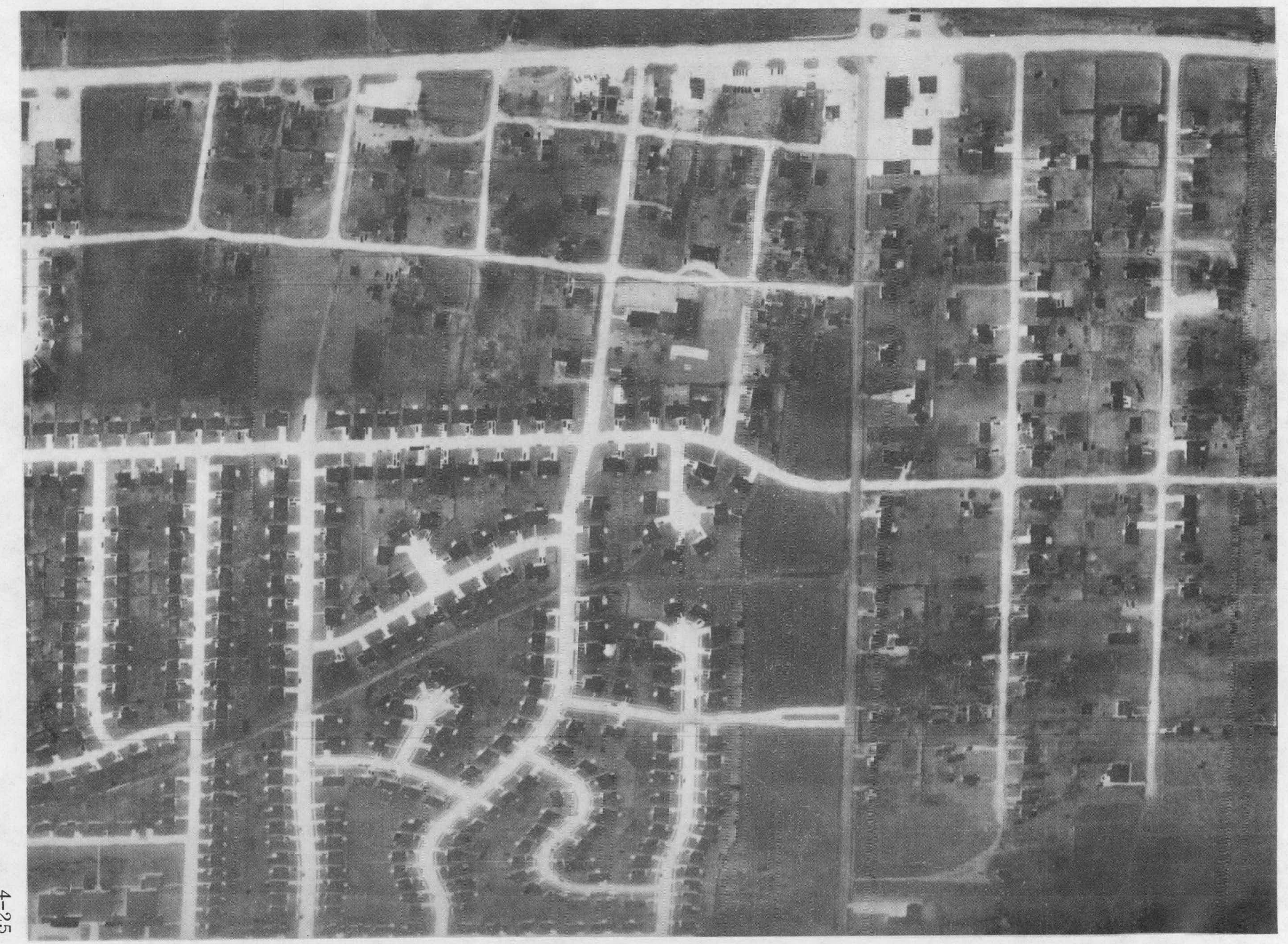

(Texas Insi rumerts)

Figure 4-8. Dwelling Survey 
large groups of residential dwellings, or government facilities. Furthermore, another practical limitation of this type of system is that it can only scan thermal data in the Z-axis. Actual analysis of side walls, windows, doors, etc., would still have to be scanned with ground-based scanning systems. Qualitative location of gross heat losses, steam leaks, underground fires, etc., are handled effectively by airborne systems. Quantitative measurements are not easily ascertained. Airborne radiometers must account for atmospheric transmissions even in the 8 to $14 \mu \mathrm{m}$ band. It is not anticipated that this will be very successful. The anticipation is that air measurements will continue to be useful for qualitative identification of major heat leaks. First order quantitative evaluation may be possible by placing a heat reference source in the measurement area.

Aerodyne has not labored the air instrument field extensively because of the survey that has been sponsored by NASA ${ }^{1}$. A summary of instruments that was publisted by the NASA study is enclosed here in Table 4-6 for reference.

Attempts to better the airborne instrument cost by flying ground-based instruments have not proved too successful. Aircraft vibration and even small angular velocities, together with ground velocity, contribute to degrade spatial resolution; the correction gives rise to the expense that is shown in Table 4-6.

\footnotetext{
${ }^{1}$ P. A. Adler, M. H. Loew, "Thermal Infrared Scanning Capabilities, A Survey," Analytic Services, Inc., Falls Church, Virginia, 1975.
} 
Table 4-6. Airborne Infrared Scanners Available

\begin{tabular}{|c|c|c|c|c|c|c|c|}
\hline Manufacturer & Model & Channels & $\begin{array}{c}\text { Spatial } \\
\text { Resolution }\end{array}$ & FOV & $\begin{array}{c}\text { Temp. } \\
\text { Resolution }\end{array}$ & Cost & Display \\
\hline \multirow{2}{*}{$\begin{array}{l}\text { Bendix } \\
\text { Aérospace } \\
\text { Systems }\end{array}$} & $\mathrm{LN}-3$ & $8-13 \mu \mathrm{m}$ & $\begin{array}{c}2.5 \mathrm{mr} \\
2.5 \mathrm{ft} / 1000 \mathrm{ft}\end{array}$ & $\pm 60^{\circ}$ & $0.1^{\circ} \mathrm{C}$ & Lease only & $70 \mathrm{~mm}$ Film \\
\hline & $\left(M^{2} S\right)$ & $\begin{array}{l}10 \text { in visible } \\
\text { and near IR } \\
1 \text { at } 8-14 \mu \mathrm{m}\end{array}$ & $2.5 \mathrm{ft} / 1000 \mathrm{ft}$ & $\pm 50^{\circ}$ & $0.5^{\circ} \mathrm{C}$ & $\$ 180,000$ & Magnetic Tape \\
\hline \multirow{2}{*}{$\begin{array}{l}\text { Daedalus } \\
\text { Enterprises, } \\
\text { Inc. }\end{array}$} & DS 1260 & $\begin{array}{l}10 \text { in visible } \\
\text { and near IR } \\
1 \text { at } 8-14 \mu \mathrm{m}\end{array}$ & $2.5 \mathrm{ft} / 1000 \mathrm{ft}$ & $\pm 42^{\circ}$ & $0.2^{\circ} \mathrm{C}$ & $\begin{array}{l}\text { Channels: } \\
1-\$ 200 \mathrm{~K} \\
11-\$ 250 \mathrm{~K}\end{array}$ & $\begin{array}{l}\text { Digital on Mag- } \\
\text { netic Tape }\end{array}$ \\
\hline & DS 1250 & $\begin{array}{l}10 \text { in visible } \\
\text { and near IR } \\
1 \text { at } 8-14 \mu \mathrm{m}\end{array}$ & $2.5 \mathrm{ft} / 1000 \mathrm{ft}$ & $\pm 39^{\circ}$ & $0.2^{\circ} \mathrm{C}$ & $\begin{array}{l}\text { Earlier } \\
\text { Version } \\
\text { Special } \\
\text { OrderOnly }\end{array}$ & $\begin{array}{l}\text { Analog on Mag- } \\
\text { netic Tape }\end{array}$ \\
\hline \multirow{2}{*}{ A GA } & 750 & $2-5.6 \mu \mathrm{m}$ & $3.4 \mathrm{ft} / 1000 \mathrm{ft}$ & $\begin{array}{c}20^{\circ} \\
\mathrm{x} \\
20^{\circ}\end{array}$ & $0.2^{\circ} \mathrm{C}$ & $\$ 40,000$ & Direct Video \\
\hline & $680 \mathrm{LW}$ & $7-12 \mu \mathrm{m}$ & $2.5 \mathrm{ft} / 1000 \mathrm{ft}$ & $\begin{array}{l}25^{\circ} \\
\times \\
25^{\circ}\end{array}$ & $0.2^{\circ} \mathrm{C}$ & $\$ 62,000$ & Direct Video \\
\hline $\begin{array}{l}\text { Texas } \\
\text { Inst ruments, } \\
\text { Inc. }\end{array}$ & RS-310 & $\begin{array}{l}3-5 \mu \mathrm{m} \\
\quad \text { or } \\
8-14 \mu \mathrm{m}\end{array}$ & $1 \mathrm{ft} / 1000 \mathrm{ft}$ & $\pm 50^{\circ}$ & $0.2^{\circ} \mathrm{C}$ & $\begin{array}{l}\text { About } \\
\$ 100,000\end{array}$ & $\begin{array}{l}70 \mathrm{~mm} \text { Film } \\
\quad \text { or } \\
\text { Magnetic Tape } \\
\text { (analog or digital) }\end{array}$ \\
\hline
\end{tabular}




\section{SECTION 5 PHOTOCHEMICAL SENSORS}

On surveying various photochemical methods that have been used for detection of infrared radiation to determine whether they might be adapted for use in the IR thermography of buildings, we found that for the most part the energy inputs required were excessive; only high energy infrared sources, such as lasers, would satisfy them. However, two systems responding to lower levels of infrared energy may be suitable for application in the building energy conservation area if the necessary development work is completed. Cholesteric liquid crystals, which change color with temperature, form the basis of one system; the other is based on a combination of a semiconductor and a second substance whose reactivity is influenced by the free carriers produced when the semiconductor is exposed to infrared energy. This report examines the known parameters of both systems and summarizes the problems that rnust be solved before devices based on either can be fabricated.

Before proceeding to the discussion of the two systems under consideration there is need for clarification of some of the terminology that will be used. For the most part, infrared detectors fall into two classes. Thermal detectors sense changes in temperature brought about by changes of the incident radiant energy while photodetectors sense changes in the number of incident photons. Liquid crystal systems can be classed as thermal detectors while the semiconductor systems are in the class of photodetectors. Therefore, in a sense, the two types should not be compared to each other, but should be discussed on their own individual merits.

For imaging applications the factors of interest include sensitivity, spectral range, response time, resolution and noise level of the detector, as well as operating parameters of the system such as cost, weight, and power requirements. In discussing these factors confusion often arises because they may have different meanings under different circumstances. For instance, the term "resolution" must be further classified for the problem at hand since two types of resolution are involved. Spatial resolution, the ability to distinguish between two objects that are in close proximity to 
each other will be expressed, as usual, in units of line pairs per millimeter $(\ell \mathrm{p} / \mathrm{mm})$ while thermal resolution, the ability to detect differences in temperature, will of course be expressed in ${ }^{\circ} \mathrm{C}$. "Sensitivity is inversely proportional to the energy needed to produce a detectable result. However, the sensitivity can have an intensity dependence. Thus, if the processes that dissipate the energy occur at a faster rate than the rate of delivery of energy to the detector, there will be no measurable response. In other words, under picture-taking conditions exposure is the product of intensity and time (It) but the intensity must be above a certain threshold value before an image will be obtained. Spectral range in the case of a thermal detector can encompass much of the infrared region while in the case of a photodetector may be limited to a relatively narrow infrared band characteristic of the particular semiconductor used. Response time has essentially the same meaning in either type of system. It is the interval between the time that the energy strikes the detector and the appearance of the detectable result. The noise level is a measure of the background energy and any spurious factors other than infrared energy that influence the detector.

Another factor that should be considered is the dynamic range of the system, which is the span of temperatures the system is able to record. This parameter is tied in with the thermal resolution. For instance, if the maximum temperature variation under measurement conditions is expected to be $15^{\circ} \mathrm{C}$ and the detector can produce 21 discrete density levels over this range, the thermal resolution will be $0.7^{\circ} \mathrm{C}$. A system with a thermal resolution of $0.07^{\circ} \mathrm{C}$ capable of producing the same number of discrete density levels will only be able to cover a dynamic range of $1.5^{\circ} \mathrm{C}$.

\section{1 LIQUID CRYSTAL SYSTEMS}

Certain types of organic solids when heated do not melt directly, but pass through a stage where their properties are intermediate between the liquid and crystalline states. In that stage, referred to as the liquid crystal stage, they have a host of unusual properties that have been adapted for commercial applications. They have been used widely for detection of thermal effects over the past few years. As early as 1964 a liquid crystal viewer was built to detect the $3.3 \mu \mathrm{m}$ output of a HeNe laser. A liquid crystal camera was built by Westinghouse for the Night Vision Laboratory at 
Fort Belvoir. ${ }^{1,2}$ The camera consisted of reflective optics, a thermoelectric thermostat, a thermostated chamber containing an illuminator, a radiation heater, and an evacuated cell unit for the liquid crystal film. The cell unit was closed on the imaging side with a germanium window, but the opposite side was glass (to allow observation). The detector was a 10 to $15 \mu \mathrm{m}$ liquid crystal film coated over an infrared absorbing layer (carbon granules in a binder) on a $6 \mu \mathrm{m}$ Mylar substrate. The optics transmitted only 15 percent of the incident infrared. The camera could image a man sitting in a room and had a thermal resolution of $0.2^{\circ} \mathrm{C}$. From these data the authors estimated that, with collimated, linear polarized viewing light and optics of 30 percent transmission the thermal resolution could be improved to $0.02{ }^{\circ} \mathrm{C}$. The spatial resolution was limited to the order of $1 \mathrm{lp} / \mathrm{mm}$ because of the thickness of the recording liquid crystal film. The ultimate response time of the system was estimated to be of the order of 10 milliseconds.

The recording film was kept in an evacuated chamber to minimize heat loss and to prevent degradation of the liquid crystals in the presence of oxygen. This problem should not be insurmountable since microencapsulated liquid crystals available from commercial sources are much more stable. ${ }^{3,4}$ Films prepared from capsules have been used as detectors for infrared interferometry. 5 . A black foil coated with the capsules responded to less than $5 \mathrm{~mW} / \mathrm{cm}^{2}$. The time lag that could be attributed to heat conduction through the foil was approximately $45 \mathrm{msec}$. During this interval lateral flow in the film caused loss in spatial resolution.

\footnotetext{
$\overline{1}$ R. E. Ennulat and J. L. Fergason, Mol Cryst Liq Cryst, 13, 149 (1971).

2 J. L. Fergason, T.P.Vogl, and M. Garbuny (to Westinghouse), U.S. 3, 114, 836 (1963).

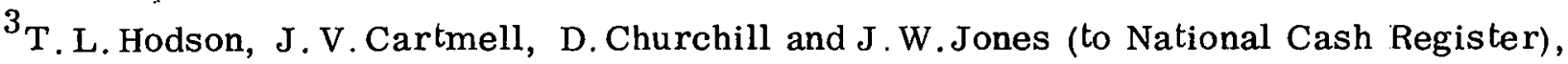
U.S. $3,585,381$ (1971) .

${ }^{4}$ D. Churchill, J. V. Cartmell and R. E. Miller (to National Cash Register), U. S. 3, 697, 297 (1972).

5 F. Keilmann, Appl. Opt. 9 , 1319 (1970).
} 
There are several potential readout mechanisms for the cholesteric liquid crystal films. Since they change color with temperature over a limited range, photography on color film will reveal the temperature distribution. Circular dichroism of these compounds is also a temperature dependent effect that can be measured. ${ }^{1}$ In addition, the optical rotatory power has been used as a means of temperature sensing. ${ }^{2}$ It offers the advantage of a wider dynamic range $\left(\sim 10^{\circ} \mathrm{C}\right)$ and high sensitivity $\left(0.02^{\circ} \mathrm{C}\right)$. However, the use of a monochromatic light source, polarizers and a photodetector are required and readout must be accomplished in a scanning mode.

Currently available data indicate that at least two companies other than Westinghouse have patented infrared cameras for use with liquid crystal detectors. ${ }^{3,4}$ Several companies offer either microencapsulated liquid crystals or plastic films with liquid crystal coatings. However, it is difficult to quantitate such parameters as sensitivity and spatial resolution. Since the liquid crystal infrared came ra was capable of imaging a man sitting in a room it would seem that the sensitivity of the system would be adequate for the application being considered. Data recorded for a type of liquid crystal receptor that contained the radiation absorber within the liquid crystal matrix ${ }^{5}$ indicated that an exposure of 11 millijoules $/ \mathrm{cm}^{2}$ was required to produce an image. Visualization of the image in the particular system described depended on heating the liquid crystal past its isotropic transition temperature (point where it melts to a clear liquid) which would require much more energy than, for instance, a readout system based on optical rotatory power capable of detecting an $0.02{ }^{\circ} \mathrm{C}$ temperature change.

Spatial resolution is limited mainly by the thickness of the liquid crystal layer. The ability of cholesteric liquid crystals to change color over a narrow temperature range is dependent on achieving a helical film structure by building up many oriented layers of active material. Thus, a certain minimum film thickness is required for good color contrast. This thickness is in the range of 10 to $15 \mu \mathrm{m}$. The spatial reso-

\footnotetext{
$\overline{1}$ J.L.Fergason, T.P.Vogl, and M. Garbuny (to Westinghouse), U.S. 3, 114, 836 (1963).

${ }^{2}$ C.W. Smith, D. G. Gisser, M. Young and S. R. Powers, J r., Appl. Phys. Lett. $\underline{2} 4$, 453 (1974).

${ }^{3}$ G. Jankowitz (to Barnes Engineering), U.S. 3, 527, 945 (1970).

${ }^{4}$ M. R. Wank (to Optical Coating Laboratories, Inc.) U. S. 3, 569, 709 (1971).

${ }^{5}$ W.E.L.Haas, J.E. Adams, J.B.Flannery, Jr., B. Mechlowitz (to Xerox), U.S. 3, 666, 947 (1972). 
lution varies inversely with thickness and we might expect a limiting resolution of the order of 30 to $50 \mathrm{lp} / \mathrm{mm}$. The liquid crystal matrix containing the heat absorber (referred to previously) ${ }^{1}$, when exposed at a level of 27 millijoules $/ \mathrm{cm}^{2}$, gave imagery with a resolution of $28 \mathrm{lp} / \mathrm{mm}$. The spatial resolution of imagery produced by the Westinghouse liquid crystal camera was closer to $1 \mathrm{lp} / \mathrm{mm}$. Since existing cryogenic systems have spatial resolutions approximately. $2.5 \ell \mathrm{p} / \mathrm{mm}$ the liquid crystal receptors should be adequate in this respect.

The complexity of the camera required for use with the liquid crystal film will determine the ultimate cost of the thermography system. A camera such as the Westinghouse camera would probably cost in the vicinity of $\$ 10,000$. If the need for vacuum can be eliminated (as in the OCLI design) ${ }^{2}$ and photography of the color changes can be used for permanent recording, the cost of the system can probably be reduced to the $\$ 5,000$ to $\$ 7,500$ range. If the more sensitive and more sophisticated measurement of optical rotatory power is used for readout, the expense of the camera again rises above the $\$ 10,000$ level.

To apply liquid crystal technology to the building thermography field work is required in two areas. The problem of preparing a large area liquid crystal film with a high degree of uniformity must be solved. Simplification of the camera hardware is needed to bring the price of the system down to a reasonable level. Readout is also a problem. Color photography provides the simplest readout, but may not provide the ultimate in thermal resolution or dynamic range.

\subsection{SEMICONDUCTOR SYSTEMS}

For the past ten years a group of Russian workers have been engaged in the investigation of the use of semiconductors for infrared photography. They have put forth several mechanisms whereby imagery can ultimately be recorded as a result of the movement of free carriers produced by the interaction of infrared energy with a semiconductor. The systems studied have all required more than one reactant to be

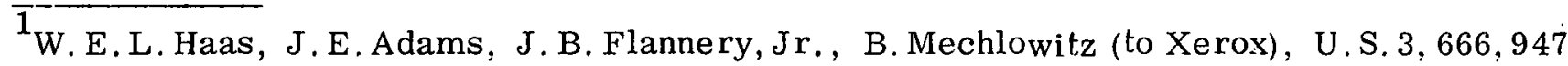
(1972).

${ }^{2}$ M. R. Wank (to Optical Coating Laboratories, Inc.), U. S. 3, 569, 709 (1971).
} 
present at the time of exposure for a photographic result to occur. The individual reactants by themselves are not permanently changed by infrared exposure. The initial papers on this work ${ }^{1,2}$ describe chemically and electrically controlled systems. In the chemical systems a semiconductor is contacted with a solution of electrolyte d'uring the exposure cycle. Redox reactions at the interface dependent on the concentration of electrons and/or holes produced in the semiconductor either cause deposition of metal atoms, etching of the semiconductor surface, or formation of oxide to produce a permanent image. In the electrically controlled systems the semiconductor is part of an electrolytic cell and electrons generated by exposure catalyze deposition of metal from the electrolyte solution onto the semiconductor surface. Alternatively an electronsensitive film prepared by impregnating a polymeric film with a solution of electrolyte can be held in contact with the semiconductor while the current is passed and the carriers generated by the exposure cause metal deposition on the film. Subsequent work ${ }^{3-11}$ extended these principles to a host of semiconductor-electrolyte combinations.

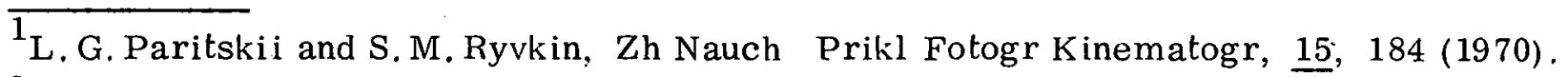

${ }^{2}$ L. G. Paritskii and S. M. Ryvkin, Fiz Tekh Poluprov 4 , 764 (1970).

${ }^{3}$ L. G. Paritskii, S. M. Ryvkin, et al, Fiz Tekh Poluprov 4, 1580, 1602, 1819 (1970).

${ }^{4}$ N. I. Bochkareva, L. G. Paritskii, and S. M. Ryvkin, Fiz Tekh Poluprov $\underline{5}, 963$ (1971).

5 L. G. Paritskii, S. M. Ryvkin, et al, Fiz Tekh Poluprov $\underline{6}, 427,588,1148,1158,1166$, 1400, 1831 (1972).

${ }^{6}$ V. Zhelev, L. G. Paritskii, and J. Malinovski. Phys Stat Sol A $10-$ - K-5 (1972).

${ }^{7}$ N. S. Vol'berg, E. I. Ivanova, V.V. Kolin, B. V. Novgrudskii and L. G. Paritskii, Zh Nauch Prikl Fotogr Kinematogr 17, 197 (1972).

${ }^{8}$ L. G. Paritskii et al, Fiz Tekh Poluprov $\underline{7}, 192,433,435,558,1436,1449,1667$ (1973).

${ }^{9}$ L.V. Belyakov, D. N. Goryachev, Yu. I. Ostrovskii, L. G. Paritskii, Zh Nauch Prikl Fotogr Kinematogr 19, 54 (1974).

${ }^{10}$ E. I. Ivanov, V.V.Kolin, B. V. Novogrudskii, and L. G. Paritskii, Fiz Tekh Poluprov 8, 635 (1974).

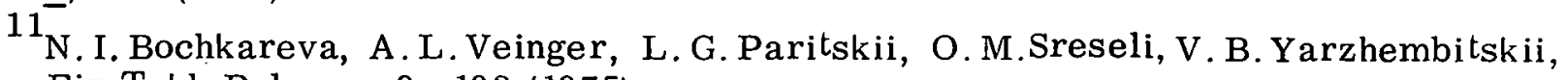
Fiz Tekh Poluprov $\underline{9}, 193$ (1975). 
Data generated by the Russian work were insufficient to allow the assignment of approximate values to all the parameters of interest for building thermography. Those that were measured varied over a wide range depending on the semiconductorelectrolyte combination. The wavelength region in which the majority of the work was carried out was from $1.8 \mu \mathrm{m}$ to $3.4 \mu \mathrm{m}$. The most sensitive systems responded to as little as $2 \times 10^{-8} \mathrm{~W} / \mathrm{cm}^{2}$ although the average threshold power required for many of them was closer to $10^{-4} \mathrm{~W} / \mathrm{cm}^{2}$. Measured spatial resolutions ranged from 6 to $35 \mathrm{\ell} \mathrm{\rho}^{\prime} \mathrm{\prime}: \mathrm{n}$. Since the systems were sensitive to infrared photons, as opposed to . thermal energy, and operated in a range where the room temperature black body curve shows minimal radiated energy there is no means for estimating their the rmal resolution or dynamic range under the desired conditions of use.

The camera used for the Russian work was of fairly simple construction and probably could be fabricated for a cost of the order of $\$ 1,000$. The technology of preparing the semiconductor might make this component of the photographic sys tem quite expensive but it should not raise the overall cost significantly. The semiconductor systems should offer advantages over the liquid crystal systems in hardware costs, sensitivity and spatial resolution. They may also offer a mechanism to compensate for background radiation. By using opposing balanced $p-n$ junctions the system can be made to give no response to a uniform background while recording in areas where there is a photon imbalance. 1

Despite these advantages the potential of semiconductor photography for building thermography is largely unknown. The Russian work would have to be extended to the 8 to $12 \mu \mathrm{m}$ region. The re are semiconductors capable of functioning at these wavelengths, but since photon energy decreases with increased wavelength, it is difficult to predict whether the sensitivity would fall off to the point where the systems would be inadequate. Since the work already completed indicates that resolution is an inverse function of the thickness of the semiconductor, a research and development effort on fabrication of this portion of the detector system would undoubtedly be required. From the standpoint of simplicity and versatility, this approach would appear to warrant the attempt to extend its sensitivity to the wavelength region of interest.

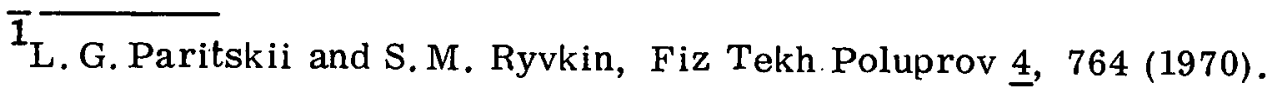




\subsection{OTHER PHOTOCHEMICAL TECHNOLOGY}

Several other techniques were evaluated, as described below, but do not offer any significant applications.

\subsubsection{Silver Halide Films}

If the properties of photographic silver halide films in the visible region of the spectrum could be maintained in the infrared, film would be the preferred detector from the standpoint of ease of usage, relative inexpensiveness of equipment, speed and resolution. However, the instability of infrared sensitizing dyes prevents the extension of photographic emulsion technology to regions beyond $1.35 \mu \mathrm{m}$ and calculations show that fundamental limitations for such films exist at $2.1 \mu \mathrm{m}^{1}$. Examination of the blackbody emission curves indicates that, in the temperature range of interest for IR thermography of buildings, the radiated energy in the region of film sensitivity is negligible. Kodak data ${ }^{2}$ confirm that no photographic record can be obtained for objects at temperatures below $250^{\circ} \mathrm{C}$. Objects at temperatures between 250 and $500^{\circ} \mathrm{C}$ can be photographed, but the exposure time is of the order of hours, the temperature variation within this span is limited $\left(60\right.$ to $\left.120^{\circ} \mathrm{C}\right)$, and, for the $60^{\circ} \mathrm{C}$ variation, the temperature differential that can be easily distinguished is $15^{\circ} \mathrm{C}$. Thus, film when used conventionally in the region where its sensitivity is falling off sharply leaves much to be desired as an infrared detector.

Within the past five years use of photographic film in a nonconventional manner has extended its recording capability well into the infrared region of interest for the current study. A Kodak patent ${ }^{3}$ appearing in 1972 describes a photoemulsion sensitive to the 2 to $3.5 \mu \mathrm{m}$ band when exposed at liquid nitrogen temperatures to visible or near ultraviolet light in the wavelength range of 370 to $460 \mathrm{~nm}$, then subsequently exposed to $120 \mathrm{~mW} / \mathrm{cm}^{2}$ of the infrared radiation. The initial exposure creates a latent image in the film which is desensitized by the infrared exposure, thus negating the

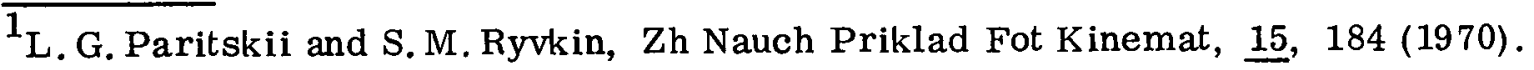
2 Kodak Tech Bits, 1976, Volume 1, p. 3.

${ }^{3}$ L. M. Kellogg and N. B. Liebert, U.S. Patent 3, 685, 997 (1972).
} 
effect of the first exposure. Development of the film to reveal the thermal image is done in the conventional manner after removal of the film from its low temperature surroundings. This process received further study ${ }^{1,2}$ that led to some procedural variations and extension of the sensitivity range to the $10 \mu \mathrm{m}$ region: Lasers providing film irradiance in the range of 0.1 to $1 \mathrm{~W} / \mathrm{cm}^{2}$ at wavelengths near $5 \mu \mathrm{m}$ and $10 \mu \mathrm{m}$ were used to provide the infrared exposure. This was followed immediately by a flooding exposure with visible light. On development the areas exposed to infrared were found to be desensitized. There was no mention of a requirement for cryogenic cooling. The authors report a linear resolution in the region of 6 to 8 line pairs $/ \mathrm{mm}$ for most conditions.

At present little is known about the mechanism of this effect, but because of the high energy levels required for infrared recording it is unlikely that it can be utilized under operating conditions required for thermography of buildings.

\subsubsection{Vesicular Films}

Vesicular films contain diazonium compounds in a thermoplastic matrix. Exposure of these films with active light (in the ultraviolet or near blue region of the spectrum) causes the diazonium compounds to decompose and release microscopic bubbles of nitrogen gas. Rapid heating of the thermoplastic matrix at this point allows the bubbles to expand and create permanent voids in the plastic. If, however, the film is not heated after exposure, the microbubbles slowly diffuse through the matrix and are lost to the surrounding air.

Vesicular films have been used to detect $10.6 \mu \mathrm{m}$ laser radiation ${ }^{3}$ by preexposure to ultraviolet light. The subsequent localized heating provided by the laser beam selectively expanded the bubbles to provide a continuous tone image. The effect is purely thermal and high energies are again necessary to provide a result. Since visualization of the image of a vesicular film is accomplished primarily by light scattering from the bubbles the bases on which this material are available all are poor heat absorbers. The system is thus inefficient and is not likely to be drastically improved by foreseeable technology.

${ }_{2}^{1}$ G. F. Frazier, -T. D. Wilkerson, and J. M. Lindsay, Appl. Opt. 15, 1350 (1976).

3 G. F. Frazier, J.Appl. Phot. Eng. 3, 31 (1977).

3 H. Inaba, T.Kobayashi, K. Yamawaki and A. Sugiyama, Infrared Phys. 7 , 145(1967). 
A recent general analysis of thin film detectors ${ }^{1,2}$ concludes that in any system of this type heat conduction within the matrix restricts the spatial resolution.

\subsubsection{Thermochromic Films}

Certain chemical compounds undergo phase transitions in a definite temperature range and change color in a readily detectable manner. Compounds of this type have been investigated as potential photographic systems, but none have been successfully applied for this purpose. They have more recently been studied from the standpoint of infrared recording 3,4 . Cuprous mercuric iodide $\left(\mathrm{Cu}_{2} \mathrm{Hg} \mathrm{I}_{4}\right)$ has a transition point just about $66^{\circ} \mathrm{C}$. A suspension of this material painted on a copper plate held at $66^{\circ} \mathrm{C}$ will respond to a threshold power density of $100 \mathrm{~mW} / \mathrm{cm}^{2}$. The spatial resolution is of the order of $125 \ell \mathrm{p} / \mathrm{mm}$. The compound is a good absorber in the regions of interest. Between 4 and $6 \mu \mathrm{m}$ it absorbs 70 percent, and in the 6 to $14 \mu \mathrm{m}$ region it absorbs 85 percent of the incident radiation. The phase transition curve shows hysteresis so that the change in reflectance produced by infrared exposure remains visible after the heat source is removed.

As with the previously mentioned systems, this system also is orders of magnitude from the required sensitivity level for building thermography. Since little can be done to improve the heat absorbing characteristics of the compound it is unlikely that the ultimate threshold sensitivity of the system will be much better than the current value.

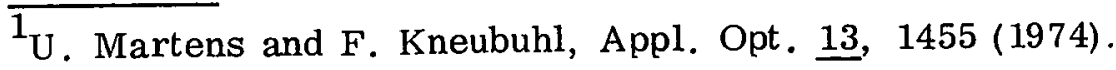

${ }^{2}$ U. Martens, P. Jeannet and F. Kneubuhl, Appl: Opt. 14, 1177 (1975).

$3^{3}$. S. Chivian, R. N. Claytor, D. D. Eden, Appl. Phys. Lett. 15, 123 (1969).

${ }^{4}$ J. S. Chivian, R. N. Claytor, D. D. Eden, and R. B. Hemphill, Appl. Opt. 11, 2649 (1972). 


\subsection{THERMOGRAPHIC PHOSPHOR SCREEN}

Infrared photography utilizing the principle of persistent internal polarization in a phosphor screen was investigated by Kallman, et al ${ }^{1}$ and several schemes were suggested for making permanent images. The operating principles of the system involve excitation of a phosphor screen with ultraviolet or visible light and subsequent alteration of selected areas of the screen by infrared radiaton. The excitation causes dissociation and trapping of electrons and holes. The infrared exposure releases the trapped species and increases the recombination rate. Depending on the nature of the photoconductor its conductivity may either be quenched or enhanced in the process. The lifetime of the resultant state may be prolonged for months by applying a DC field which causes separation and inhomogeneous trapping of the negative and positive charges.

The various schemes by which this effect can be visualized are not pertinent to the discussions and will not be detailed. However, they all required exposure times of the order of hours.' Much of the polarization is released after five minutes, but the rate slows thereafter. Data more pertinent to the evaluation of this type of system have been reported ${ }^{2}$ but nothing more recent has been found. The phosphor screen was prepared by suspending Zn Cd S: Ag Ni phosphor in a lacquer and coating on Mylar. It was operable over the region from 0.97 to $28 \mu \mathrm{m}$ although its peak sensitivity, to $1 \mathrm{~mW} / \mathrm{cm}^{2}$, occurred near $1 \mu \mathrm{m}$. In the region of interest for this study power levels from 20 to $60 \mathrm{~mW} / \mathrm{cm}^{2}$ would probably be required. This system, while more sensitive than those described previously, is still well outside the range of practical utility.

\subsection{UPCONVERSION}

Two methods for converting infrared wavelengths to visible wavelengths have been investigated in depth. One of these involves the mixing of long wavelength radiation with radiation from a coherent pump in a nonlinear crystal to provide a sum fre-

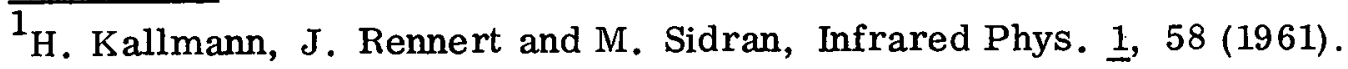

2 J. D. McGee and J. L. Helios, IEEE J. Quant. Elect. QE-3, 31 (1967)。 
quency output. The other involves pumping a suitably doped crystal with a frequency not absorbed by the ground state and relying on an infrared signal to cause a transition to a low-lying excited state which can absorb the pump light. This causes a transition to a state from which visible light is emitted on decay. The first process is generally referred to as "parametric upconversion" while the second is an optical double resonance process described by identifying the crystal used as an "infrared quantum counter".

\subsubsection{Parametric Upconversion}

This particular process offers the advantages that it does not require scanning for readout and it does not require cooling of the detector. Three rather detailed analyses of the capabilities and limitations of parametric upconversion ${ }^{1,2,3}$ have reached somewhat different conclusions as to its potential utility for ambient temperature measurements.

In practice the system generally operates with a high power laser as the pump and a narrow band infrared signal. The input power to the laser is larger than the power required to refrigerate a conventional detector. The system suffers severe material problems because of the many constraints placed on the properties of the mixing crystal. Pump powers are high enough to damage the crystal. The sum frequency image is of low contrast $\left(-1.4\right.$ percent $\left.\rho_{C}\right)$ so a device such as a low light level TV camera is needed as the viewing system.

The analyses of the capability of the system indicate that although it can be used in either the 3 to $5 \mu \mathrm{m}$ band or the 8 to $12 \mu \mathrm{m}$ band, the latter band is to be preferred. Signal-to-noise considerations limit the detectable temperature difference in the former band to about $10^{\circ} \mathrm{C}$. Theoretically in the 8 to $12 \mu \mathrm{m}$ band $1^{\circ} \mathrm{C}$ could be differentiated if the pump is uniform to less than 0.2 percent and if the recording system is similarly uniform. Resolution values for various crystals have been calculated to be near 100 line pairs $/ \mathrm{mm}$.

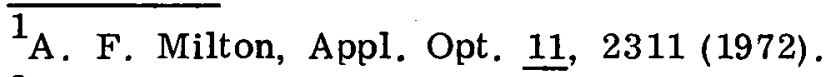

${ }_{3}$ K. F. Hulme and J. Warner, Appl. Opt. 11, 2956 (1972).

${ }^{3}$ J. Falk and W. B. Tiffany, J. Appl. Phys. $\underline{43}, 3762$ (1972). 
Because of the material problems and high pump powers required it does not seem likely that this system will ever progress to a point where it will be useful for thermography of buildings. It has, however, been used successfully to monitor 3.2 to $5.0 \mu \mathrm{m}$ radiation from the moon and Venus. ${ }^{1}$

\subsubsection{Infrared Quantum Counters}

Crystals useful for infrared quantum counting are generally rare earth halides doped with other rare earth ions. Since the process that produces visible light involves low-lying excited states populated as a result of the infrared exposure, the system requires cryogenic cooling to keep the ions in the ground state. Europium ions $\left(\mathrm{Eu}^{3+}\right)$ supposedly are best for detecting $10 \mu \mathrm{m}$ photons. ${ }^{2}$ Laser fluxes of the order of $1 \mathrm{~W} / \mathrm{cm}^{2}$ are required. The visible light outputs can be monitored with a photomultiplier. Published work on this type of system does not contain enough data to allow an evaluation of its properties for the desired usage. However, the requirements for cryogenic cooling and a laser pump do not offer any advantages over present systems.

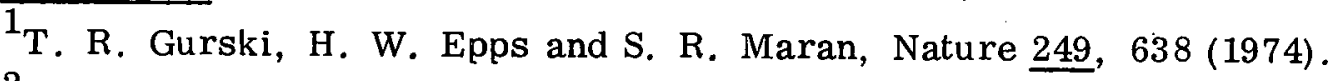

${ }^{2}$ F. K. Fong, L. A, Vredevoe and R. E. DeWames, Phys. Rev. 170, 412 (1968).
} 


\section{SECTION 6 \\ RECOMMENDED RESEARCH AND DEVELOPMENT}

\subsection{DEMONSTRATION OPPORTUNITIES}

Section 2.4 contains an extensive list of potential users and uses of IR thermography. That section should be reviewed as needed rather than to repeat it here. The list includes those who are now somewhat aware of the existence of IR thermography. For the most part, however, the potential user community does not know of IR thermoography or its capabilities and limitations. Accordingly, an extensive educational program is required. The requirements are listed in Section 2.5 and include:

1. Public relations and educational presentations to all age levels, civic and social groups.

2. Development of guidelines, training and licensing for interpretation and application of thermography.

The most extensive need for thermography appears to be for qualitative heat loss/gain purpose. Instruments with $1^{\circ} \mathrm{C}$ thermal resolution for outdoor use and $3.5^{\circ} \mathrm{C}$ for indoor use should be adequate to identify and locate building thermal faults.

Figure 6-1 shows instrument and service cost curves requirements. Lower services cost is associated with amortization of lower instrument cost. The need is for low cost instruments with a sharp break at $\$ 9,000$.

The other functional requirement is for quantitative measurements as indicated in Section 2.4. This more sophisticated need is typified by the requirement to show compliance with evolving building codes such as ASHRAE 90-75. Accuracy and thermal resolution requirements are $0.1^{\circ} \mathrm{C}$ for outdoor measurements and $0.35^{\circ} \mathrm{C}$ for indoor measurements.

The cryogenic inst ruments that dominate the user community today have thermal resolution that approach $0.1^{\circ} \mathrm{C}$. They are used, however, for qualitative purposes. For quantitative purposes their accuracy is limited to about $1^{\circ} \mathrm{C}$ in outdoor use and may achieve $0.35^{\circ} \mathrm{C}$ for indoor use. The required accuracies may be realizable but will require an extensive measurement program to provide a data base that will allow for compensation of those parameters discussed in Section 3 . 

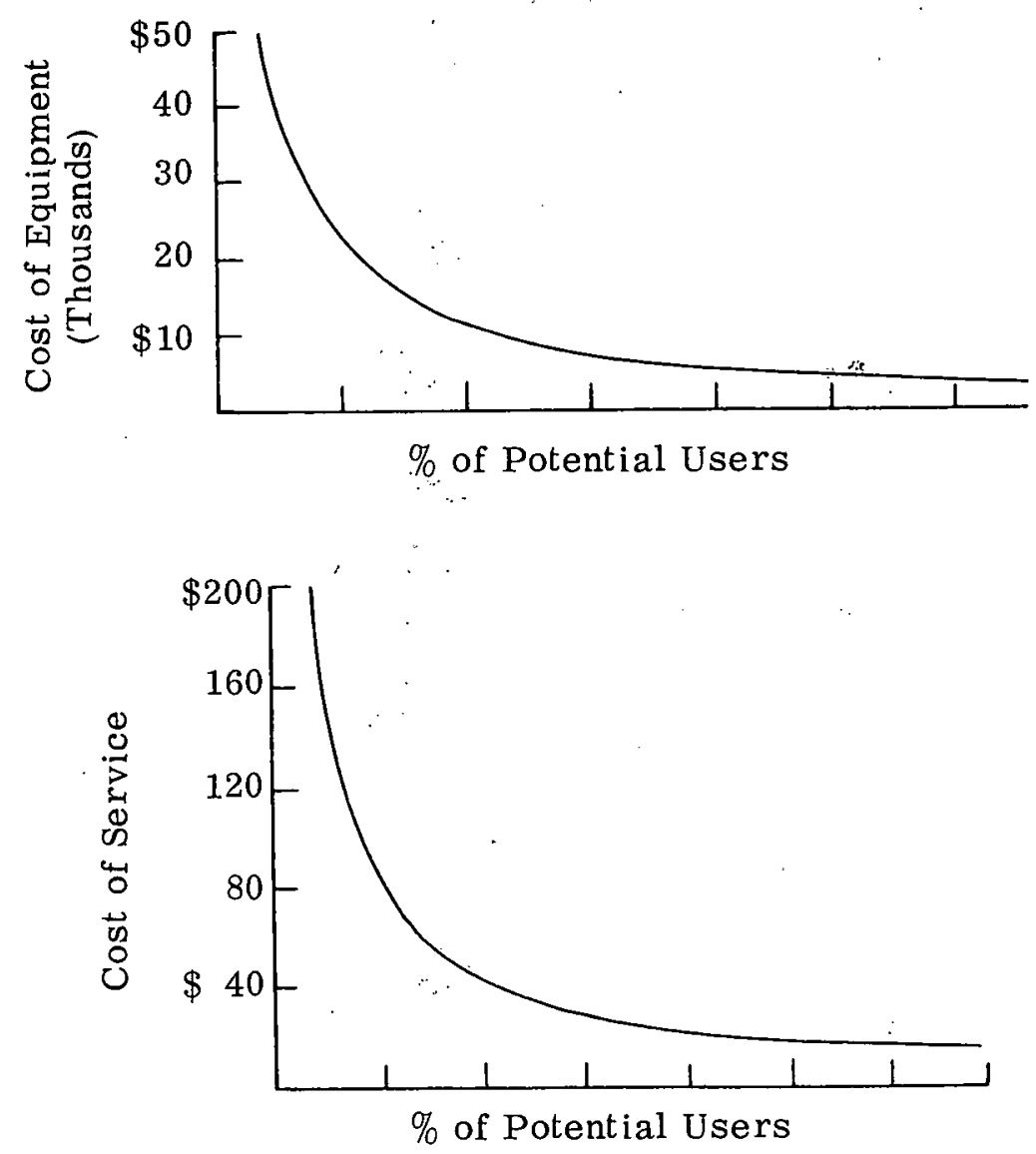

Figure 6-1. Cost Requirements

\subsubsection{Summary-Demonstration Opportunities}

The use of thermography for either qualitative heat loss evaluation or for precise quantitative measurements will depend on proper understanding, interpretation, and application. The U. S. Energy Research and Development Administration can play a dominant role in coordination and implementation of thermographic programs. In parallel, and perhaps even preceding hardware development described in Sections 6.1 and 6.2 below, is the need for ERDA's direct involvement in the following:

1. Collect thermographic data, correlate the data with known building faults, and develop understanding of thermographs. 
2. Study the environmental effects on thermographic data including requirements for thermal equilibrium following solar heating, infiltration effects from high winds, and background reflected energy effects.

3. Generate user manuals for both ground and aerial thermography describing requirements for successful the rmography, its limitations and advantages, methods of data collection for particular conditions and interpretation. . .

4. Provide learning and training opportunities through seminars and course studies:

5. Conduct public relations campaigns through use of film strips on a regional basis through articles in trade journals, through news releases and by news media advertising such as spot TV oppor tunities.

\subsection{QUALITATIVE THERMOGRAंPHY}

Fundamentally, qualitative the rmography can, and does, ignore surface emissivity. Quantitative thermography must account for surface emissivity and reflective properties. As shown in Section 3, these two forms are approximated as follows:

Qualitative

$$
\mathrm{W}=\sigma \mathrm{T}_{\mathrm{M}}^{4}
$$

Quantitative

$$
\mathrm{W}=\sigma\left[\epsilon_{\mathrm{s}} \mathrm{T}_{\mathrm{S}}^{4}+\left(1-\epsilon_{\mathrm{S}}\right) \epsilon_{\mathrm{A}} \mathrm{T}_{\mathrm{A}}^{4}\right] \text {. }
$$

IR instruments, unless expressly implemented to allow for the surface temperature $\mathrm{T}_{\mathrm{S}}$ as an output from Equation (2), will ordinarily give an "effective" equivalent temperature $T_{M}$ as expressed in Equation (1) where surface emissivity is implied to be unity. The fact that building materials do not have such emissivities means that the measured temperature $\mathrm{T}_{\mathrm{M}}$ from IR instruments is only an approximation to the 
actual surface temperature $\mathrm{T}_{\mathrm{S}}$. The measurement errors as shown in Table 3-2 depend upon the spectral response of the instrument. At best, the errors are no better than $1^{\circ} \mathrm{C}$ if the temperature measurement is made from the outside and no better than $0.3^{\circ} \mathrm{C}$ if made from the inside. Any errors within the instrument itself will add to these values

The building section requirements evaluation conducted by the NAHB Research Foundation, Inc. (Section 2) shows the need for qualitative heat loss/gain measurements that are good to $1-3.5^{\circ} \mathrm{C}$. This requirement is consistent with the measurement approximation errors associated with Equation (1). There is no need to implement Equation (2) for qualitative heat loss evaluation. The cost factor for qualitative evaluation, however, is significant.

The NAHB Research Foundation, Inc. shows a large user need for qualitative instruments with a price break at $\$ 9,000$ and approaching $\$ 1,000$ or less. Noncontact spot temperature thermometers fall in the $\$ 300-\$ 1,000$ price range. The need, however, is for thermal imaging instruments that are in the $\$ 1,000$ price region. At the present time such instruments do not exist. Lower price may be achieved by a designto-cost approach. The instruments that have been used for qualitative heat loss thermography have been nearly an order of magnitude better in performance than that which is required but have cost in the vicinity of $\$ 50,000$. Competitive performance and price now exists at about $\$ 25,000$ for cryogenic thermographic systems. A dequate thermal resolution but with somewhat poorer spatial resolution cryogenic systems exist down to $\$ 5,000$. The latter should be useful to a large segment of the user community with an adequate educational and training program as suggested by the NAHB Research Foundation, Inc. in Section 2. 


\section{Pyroelectric Vidicon Cameras}

Higher quality pyroelectric vidicon cameras with displays cost about $\$ 20,000$ from several sources. They appear to be competitive in performance and cost with cryogenic systems but have not been used for building thermography to date except in a very limited way. At least two companies appear to be in the final development stages for cameras that should sell at about $\$ 5,000$.

Cost limitations are associated with pyroelectric vidicon tubes and lens elements. Tubes cost in the vicinity of $\$ 2,000$ to $\$ 3,000$. Production engineering and tooling will lower these costs significantly. Tube manufacturers will not do this, however, until they understand that a large proven market exists.

Pyroelectric vidicon cameras require approximately $\mathrm{f} / 1$ refractive optical lens. Material is limited to IRTRAN or, principally, Germanium. The wide field of view requirements $\left(>20^{\circ}\right.$ ) require a refractive lens subsystem for good spatial resolution. These requirements result in lens subsystem costs that may run as high as $\$ 7,000$ in limited quantities. Large quantity buys should lower the cost significantly.

Reflective optics would be the most inexpensive route to pursue if it can be shown that poor spatial resolution imaging is adequate for building thermography. Reflective optics are used in the low cost spot temperature thermometers. For imaging purposes, however, reflective $\mathrm{f} / 1$ optics become very expensive at fields-of-view approaching $6^{\circ}$. It may well be that the large field-of-view requirements will make it difficult to reach an instrument price below $\$ 5,000$. Lower price inst ruments may have limited fields-of-view and could be used for limited wall area thermography. Instrument manufacturers will have to make a trade-off between field-of-view and spatial resolution versus cost. Minimum acceptable spatial resolution vs cost from a user's standpoint will have to be determined. From a user's standpoint, spatial resolution requirements are subjective phenomena which could be evaluated by a measurement program to establish acceptable levels.

Some of these pyroelectric vidicon camera items may be funded by ERDA. It should not be expected that ERDA would fund specific camera hardware development 
unless the technology was to be made available for general industry use. The progress of pyroelectric vidicon cameras quite likely will be supported by industry if the demand for cameras, in sufficient numbers, follows from demonstration opportunities that ERDA should fund.

\section{Cryogenic Cameras}

The present cryogenic thermographic cameras are very expensive. The liquid nitrogen dewars for ground operated systems possess a logistics inconvenience. It would seem that lesser performance requirements for qualitative thermography at $1^{\circ} \mathrm{C}$ thermal resolution may allow for thermoelectrically (TE) cooled detectors. TE coolers are available but may require some funding by ERDA for thermographic poriability in this applicable field environment.

With no changes in cooling, however, the cost of instruments will decrease as demand increases and as pyroelectric vidicon cameras compete. At the present time the limited market size will keep the price of cryogenic cameras high. A larger market with some product improvement from a production standpoint may reduce the cost by a factor of two or more over present day prices. It is not clear that ERDA would have a funding role here except to expedite some timetable that ERDA may develop to be compatible with a user program.

\section{Photochemical Cameras}

The photochemical possibilities have been suggested in Section 5 above. The expectations here are riskier than with electro-optical devices. The payoff, however, could be quite favorable in the interest of low cost systems with the possibilities of hard copy photograph type thermographs under $\$ 1.00$. There is no real time display as with electro-optical CRT's but this may be only a small disadvantage in the interest of cost. Development effort in these areas will have to be supported by ERDA funds.

Two possibilities exist for photochemical cameras: namely, liquid crystal and semiconductor photographic cameras.

Section 5 identifies three companies that have experimented with liquid crystal cameras. Spatial resolution approaches that of cryogenic systems and may be adequate; they have been used for imaging small scenes. Building thermography will re- 
quire large area liquid crystal film development with a high degree of uniformity. It would appear that liquid crystal cameras initially will cost in the $\$ 5,000$ to $\$ 10,000$ range. Simplification of the camera hardware is needed to bring the price of the system down to a reasonable level.

Sensitivities of liquid crystal films approach $0.02{ }^{\circ} \mathrm{C}$ over $10^{\circ} \mathrm{C}$ dynamic range. They have the potential for rather precise temperature mensuration. Cameras should - be proven on a qualitative basis first.

The Russian work with semiconductor materials described in Section 5.2 has shown high spatial resolution between 1.8 and $3.4 \mu \mathrm{m}$. Thermal imaging will require matèrial research and development to obtain material responsive out to about $10 \mu \mathrm{m}$. Semiconductors will have to be developed with high enough sensitivity to compensate for the decreased photon energy at the longer wavelengths. The possible success level of this effort is not known at the present time. It offers an attractive possibility, however, for camera costs of the order of $\$ 1,000$ with low cost hard copies.

\subsubsection{Summary-Qualitative The rmography}

A summary recommendation for qualitative thermography research and development with decreasing priority is listed below and slanted towards the development of very low cost inst rumentation:

1. Pyroelectric vidicon cameras.

2. Some forms of cryogenic (possibly thermoelectric temperature) sensors with improved spatial resolution.

3. Liquid crystal cameras.

4. Semiconductor materials research.

5. Semiconductor photographic cameras.

In the above list, the requirements for low cost sensors may be satisfied by. either pyroalectric vidicon cameras or cryogenic thermographic systems. The need to generate a list should not suggest that cryogenic thermographic systems cannot be shown to be cost competitive with pyroelectric systems. Low cost thermographic cameras are near term (within $1 \mathrm{yr}$ ). Liquid crystal cameras are perhaps 1- to 2-yr programs. Semiconductor photographic cameras are parhaps $3-$ to $5-y r$ programs with high risk. 
The above list prioritizes hardware requirements. The need for a parallel software program with immediate initiation is of great importance. Thermographic usage is in its infancy. The need for education, training, and promotion has been identified in Section 2.5. This may require educational, advertising, and marketing expertise for successful exploitation. New thermographic interpretation material will be needed. The problems associated with interpretation are discussed in Section 3.4. Material should be generated, in part, by the need to promote, teach, certify and practice. This requires more skilled technician work to identify the potential and limitations of thermography working with other disciplines (educators, etc.) to express the material in mutually acceptable terms for each particular user community_(insulation salesmen, etc.).

\subsection{QUANTITATIVE THERMOGRAPHY}

The need for precise measurement of surface temperature is exemplified by building inspactors for building code validation. Research laboratories have a need for quantitative measurement for evaluation of building materials including insulation. In these cases, the measurement of surface temperature is a means to the computation of a wall's $R$ value or $U$ value from the equation

$$
\mathrm{R}=\frac{1}{\mathrm{U}}=\frac{\mathrm{R}}{\mathrm{T}_{1}-\mathrm{T}_{\mathrm{S}}}\left(\mathrm{T}_{1}-\mathrm{T}_{\mathrm{o}}\right)
$$

Inside temperature $T_{1}$ and outside temperature $T_{0}$ can be measured with standard thermometers. Tolerance requirements on temperature measu rements are of the order of $0.1^{\circ} \mathrm{C}$. In the case of surface temperature measurement the $0.1^{\circ} \mathrm{C}$ tolerance includes instrument errors and environmental compensation errors for conversion from measured (effective) temperature to actual temperature $\left(T_{S}\right)$. The conversion is ' implemented from Equation (2) in Section 6.2.

The computation requirements for direct $R$ value thermographic readout can be implemented rather easily with electronic analog circuits and needs no development. 
Values for surface film resistance $\left(R_{S}\right)$, surface emissivity $\left(\epsilon_{S}\right)$, background emissivity $\left(\epsilon_{A}\right)$, background temperature $\left(T_{A}\right)$, inside air temperature $\left(T_{1}\right)$, outside air temperature $\left(\mathrm{T}_{\mathrm{o}}\right)$, can all be inserted into the control panel of a thermographic inst rument by setting potentiometers. The thermographic instrument, then, would display either temperature profiles of a wall or $R$ values. If display of temperature is possible, then display of $\mathrm{R}$ value is possible to the same degree of uncertainty. Unfortunately, this is idealistic at the present time, however. 'There is uncertainty in knowledge of $\epsilon_{S}, \epsilon_{A}$ (particularly including spectral effects), $T_{A}$ and $R_{S}$ (although to a lesser degree). This uncertainty could easily lead to $R$ value errors that are in excess of $100 \%$ for R10 insulated walls. The errors are even larger for higher $\mathrm{R}$ value ceilings.

The possibility for satisfying building code needs by direct $R$ value measurement does exist, however. The limitations will have to be determined by a measurement program. The spectral wavelength characteristics of building materials including long term aging will have to be evaluated. The effects of nonuniform background reflectance from the building being measured will have to be evaluated.

Equation (2) in Section 6.2 represents the nonuniform background by an average emissivity $\epsilon_{A}$ and temperature $\mathrm{T}_{\mathrm{A}}$. A measurement program will be required to evaluate this possibility. These measurements would have to be undertaken to evaluate the possibilities of measuring either actual surface temperature or $R$ value.

The building industry and, in particular, the insulation industry have a particular interest in determining the $R$ value of walls to describe its thermal characteristic. Building codes, in fact, may place design specifications on the average $R$ value of a wall. Most of the work described above, then, including the use of thermographs is to lead to $\mathrm{R}$ value evaluation. Heating engineers, on the other hand, generally are interested in heat loss measurement expressed in $\mathrm{BTU} / \mathrm{hr} / \mathrm{ft}^{2}$. If the above equation on Page 6-8 is used to compute and display $R$ value, then in a similar matter heat transfer can be computed and displayed using the equation

$$
Q=\frac{T_{1}-T_{S}}{R_{S}} .
$$


If the indoor temperatre $T_{1}$ and inside surface temperature $T_{S}$ are measured, then the heat transfer $\mathrm{Q}$ expressed in $\mathrm{BTU} / \mathrm{hr} / \mathrm{ft}^{2}$ is scaled by the surface film resistance $\mathrm{R}_{\mathrm{S}}$ in the absence of lateral heat flow.

Either R or Q may be computed and displayed with about the same accuracy limitations.

The instruments required for precise temperature or $R$ value measurements exist today at least in their basic form. Either cryogenic solid state detectors or pyroelectric vidicon cameras have the potential for $0.1^{\circ} \mathrm{C}$ measurements. No further development (for quantitative measurement purposes) would seem warranged at this time. Instrument costs should decrease sharply simply as larger quantity orders are received.

Two alternate approaches to.calibrating IR instruments for actual surface temperature measurements have been examined. A separate calibrated reference source placed near or on the building would allow for a reference signal. Alternatively, a spot area thermocouple temperature reference on the wall could be established. If either of these should work, then there would be no need to inst rument Equation (2) in Section 6.2. The uncertainties in either of these approaches, however, probably are no better than that, which is described in Section 3. Neither of these two approaches allows for the situation of changes in emissivity with respect to masonry, walls, wallpapar, ceilings, paint, etc.

After spactral wavelength data described above are collected, there may be a need to optimize the spectral passband of instruments. Cryogenic systems operate in either the 3 to $5.5 \mu \mathrm{m}$ or 8 to $12 \mu \mathrm{m}$ passband. Very narrow filtering is possible before concerns with detector $D^{*}$ become significant. At the present time, $S / N$ is adequate. If narrow filtering becomes desirable, then low noise amplifiers may have to be used in cryogenic systems. At this point, pyroelectric vidicons probably canno: be used. Pyroalectric vidicon $\mathrm{D}^{*}$ is one to two orders of magnitude lower than cryogenic detectors.

Spectral optimization of instruments will have to be concerned with atmospheric transmission. For short range imaging, 8 to $12 \mu \mathrm{m}$ operation eliminates this problem. For longer ranges, such as in airborne use, a simple relative humidity cor- 
rection as a function of range should be adequate. A more rigorous analysis of atmospheric transmission will be necessary to completely assess this possibility. If spectral optimization of InSb detector imaging systems is made below the $4.2 \mu \mathrm{m}$ $\mathrm{CO}_{2}$ absorption band (see Figure 3-8), then atmospheric transmission problems at short ranges are minimized. The radiation signal into the aperture will drop significantly, however, and there may be $\mathrm{S} / \mathrm{N}$ problems that could require good $\mathrm{D}^{*}$ selection and amplifier redesign.

Signal procassing requirements may include better display of the video signal , for precise temperature determination. CRT displays may not be adequate as they exist today. Instrument dynamic range for building thermography should be between $-15^{\circ} \mathrm{C}$ to $+25^{\circ} \mathrm{C}$ (typically). $0.1^{\circ} \mathrm{C}$ represents one part in 400 which is not discernible on small CRT displays and is difficult in any analog circuit without significant cost impact. Inst rument manufacturers will have to address themselves to this problem.

Video signal processing may be extended to provide a direct digital readout of the $U$ value over any segment of a wall including a total side of a building. This could be used against direct requirements of building codes. ASHRAE 90-75, for example, proposes average $U$ values of walls as a function of degree heating days. If a CRT display is used simply to place fiduciary lines around any section of a wall, as illustrated in Figures 6-2 and 6-3, then video gate integration within the gate will allow for direct $U$ value averaging with a digital readout. Direct video prosessing can be accomplished to an equivalent $0.1^{\circ} \mathrm{C}$. Cost may be high, however.

A irborne thermography using ground based designed instruments has not been too satisfactory when compared with the more expensive avionic systems. Spatial resolution deteriorates with line-of-sight angular noise and V/h ground smear. Angle noise induced by aircraft vibrations may be minimized by good vibration isolation and gyro platform stabilization. This tends to inc rease the cost of flight systems. V/h ground smear is minimum for high frame rate systems. Those cryogenic systems that have been flown and operate at TV frame rates appear to have better parformance than the slower frame rate systems. Any system that is flown should oparate at near $\mathrm{TV}$ frame rates as a minimum. 


\subsubsection{Summary-Quantitative Thermography}

Precise quantitative temperature and/or $R$ and $U$ values will require research and development which may be summarized as follows in decreasing priority:

1. Spectral emissivity measurement of building materials, evaluation aging effects and identification of uncertainty values.

2. System evaluation of the environment through a measurement program to establish fundamental limitations on temperature measurement accounting for such unknown factors as the effect of nonuniform background reflection.

3. Spectral optimization of the rmographic instruments with respect to the data base generated by Items 1 and 2 .

4. Improvement in inst rument readout. CRT displays over the dynamic temparature range for building thermography are limited to $0.25^{\circ} \mathrm{C}$ and quite often may be as bad as $1{ }^{\circ} \mathrm{C}$. The requirement is for $0.1^{\circ} \mathrm{C}$ readout resolution.

5. Data processing spectral compensation to change from apparent temparature to absolute temparature. 


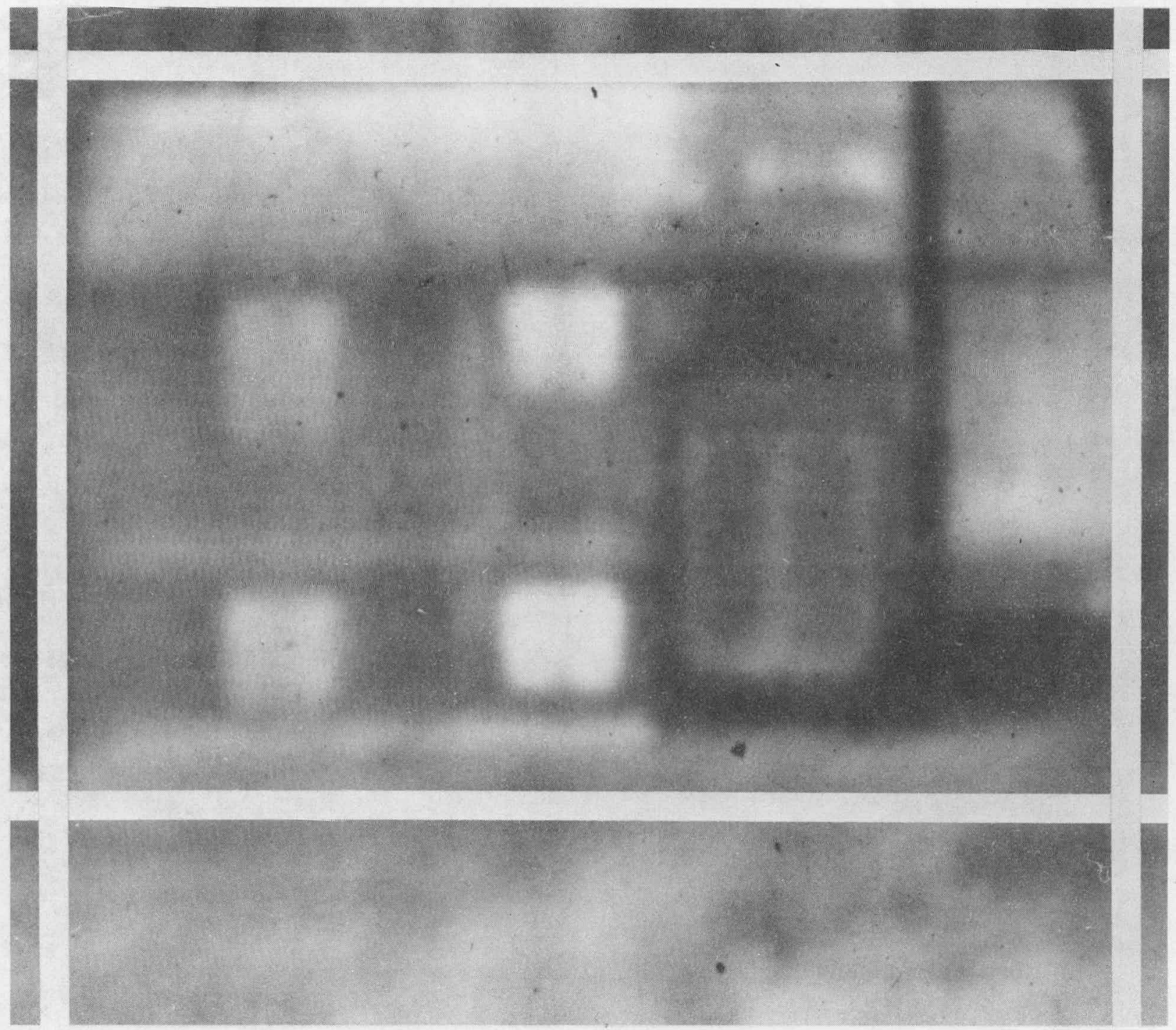

Figure 6-2. An IR Thermography Showing U-Value Averaging 

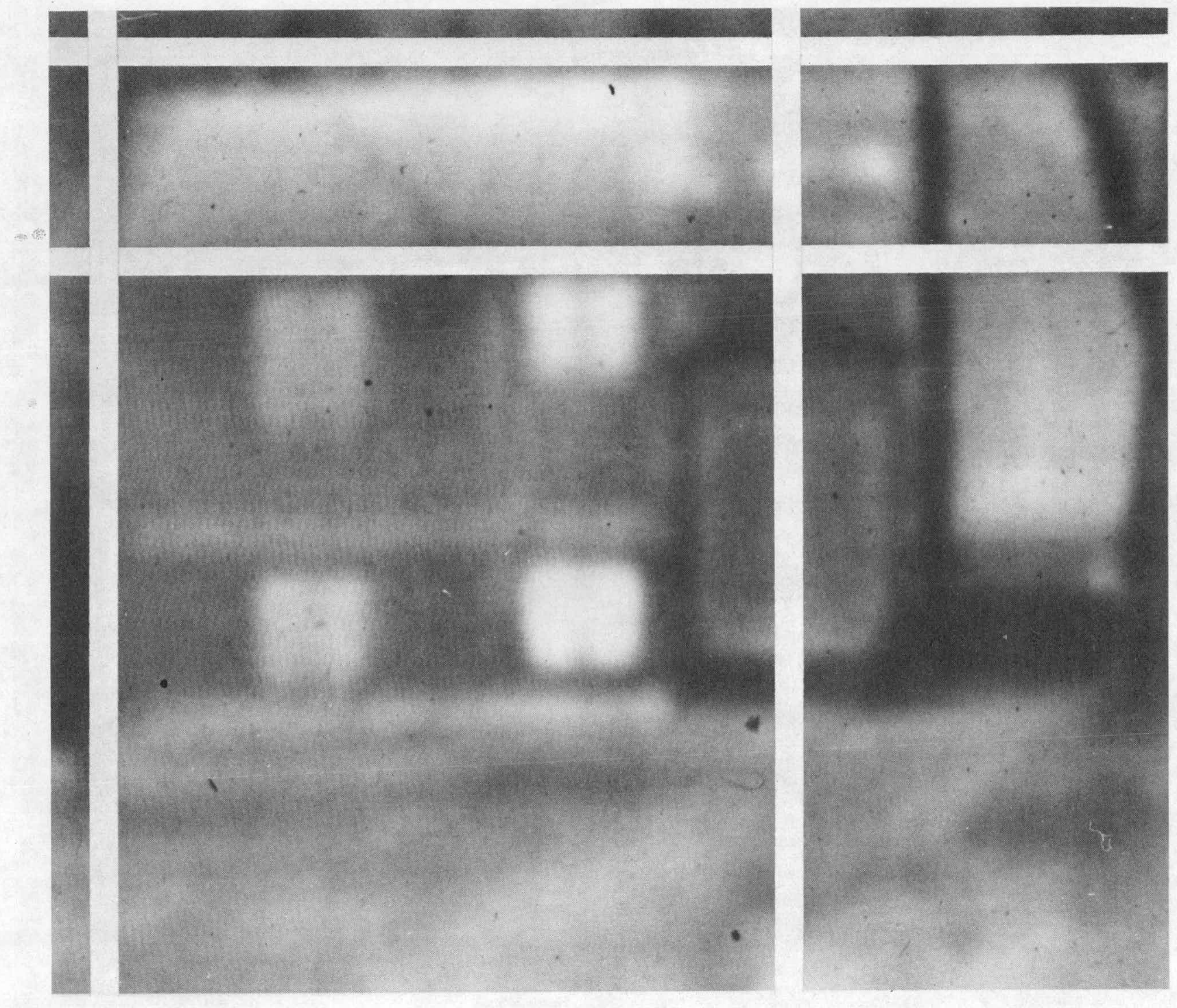

Figure 6-3. U-Value Averaging Through A Cathedral Ceiling 


\section{APPENDIX A STATEMENT OF WORK}

The contractor shall provide the personnel, services, material, facilities and equipment required to accomplish the following tasks:

Task 1. Submit a detailed program plan which indicates more completely than the proposal does final allocation of financial and personnel resources, timing of principal events that are to occur during the execution of the project, decision points and major milestones, program management plan, technical approach, and other items of direct relevance to timely and successful accomplishment of the program objectives. The contractor shall not proceed with Task 2 or beyond until this plan is approved by the ERDA Program Manager. No changes to the plan shall be made without approval of the Program Manager.

Task 2. Identify the major potential users of infrared technology and techniques of analysis, for application to energy conservation programs in the buildings sector. Such users may include, but are not necessarily limited to, homeowners, homebuilders, real estate brokers, insulation contractors, local code authorities, states and the federal government.

Task 3. Identify the major potential uses of and needs for infrared technology and techniques of analysis, for application to energy conservation programs in the buildings sector. Such uses may include, thermal insulation characteristics in existing buildings; quantitative analysis of building components with respect to energy gains/losses; quantitative analysis of net energy performance of buildings as measured against performance design standards such as ASHRAE 90-75; auxiliary instrumentation necessary for evaluating the in-place performance of a system of components (e.g., as in a complete wall panel assembly) during the research phase of energy performance standards development. In all cases, the uses identified should be responsive to actual or foreseen needs of the users identified in Task 2. 
Task 4. List and evaluate the status of currently available infrared technology, commercial systems, and techniques for data processing and analysis. Determine the relevance of these existing devices and techniques to the needs and users identified in the tasks preceding. Such determination shall include consideration of technical performance, compatibility with identified needs, costs, ease of operation, optimal effective wavelength range, suitability for the particular use in terms of ease of operation, or other important factors.

Task 5. Define opportunities for further research and development that would lead to instrumentation and techniques for infrared thermography measurement of buildings, meeting needs not presently served by existing technology. Rank these opportunities according to importance with respect to the primary objective of realizing energy savings in buildings. 